\title{
Aluminum Removal from Hanford Waste by Lithium Hydrotalcite Precipitation - Laboratory Scale Validation on Waste Simulants - Test Report
}

\author{
Kevin Hagerty (AREVA Federal Services LLC) \\ Washington River Protection Solutions LLC \\ Richland, WA 99352 \\ U.S. Department of Energy Contract DE-AC27-08RV14800
}

$\begin{array}{llll}\text { EDT/ECN: } & \text { DRF } & \text { UC: } & \\ \text { Cost Center: } & \text { 2GB00 } & \text { Charge Code: } & 200700 \\ \text { B\&R Code: } & & \text { Total Pages: } & 71\end{array}$

Key Words: Lithium Hydrotalcite (LiHT), Aluminum, Precipitation, Lithium Hydroxide, Technology Maturation Plan

Abstract: To reduce the additional sodium hydroxide and ease processing of aluminum bearing sludge, the lithium hydrotalcite (LiHT) process has been invented by AREVA and demonstrated on a laboratory scale to remove alumina and regenerate/recycle sodium hydroxide prior to processing in the WTP. The method uses lithium hydroxide $(\mathrm{LiOH})$ to precipitate sodium aluminate $\left(\mathrm{NaAl}(\mathrm{OH})_{4}\right)$ as lithium hydrotalcite $\left(\mathrm{Li}_{2} \mathrm{CO}_{3} .4 \mathrm{Al}(\mathrm{OH})_{3} .3 \mathrm{H}_{2} \mathrm{O}\right)$ while generating sodium hydroxide $(\mathrm{NaOH})$. In addition, phosphate substitutes in the reaction to a high degree, also as a filterable solid. The sodium hydroxide enriched leachate is depleted in aluminum and phosphate, and is recycled to double-shell tanks (DSTs) to leach aluminum bearing sludges. This method eliminates importing sodium hydroxide to leach alumina sludge and eliminates a large fraction of the total sludge mass to be treated by the WTP. Plugging of process equipment is reduced by removal of both aluminum and phosphate in the tank wastes. Laboratory tests were conducted to verify the efficacy of the process and confirm the results of previous tests. These tests used both single-shell tank (SST) and DST simulants.

TRADEMARK DISCLAIMER. Reference herein to any specific commercial product, process, or service by trade name, trademark, manufacturer, or otherwise, does not necessarily constitute or imply its endorsement, recommendation, or favoring by the United States Government or any agency thereof or its contractors or subcontractors.

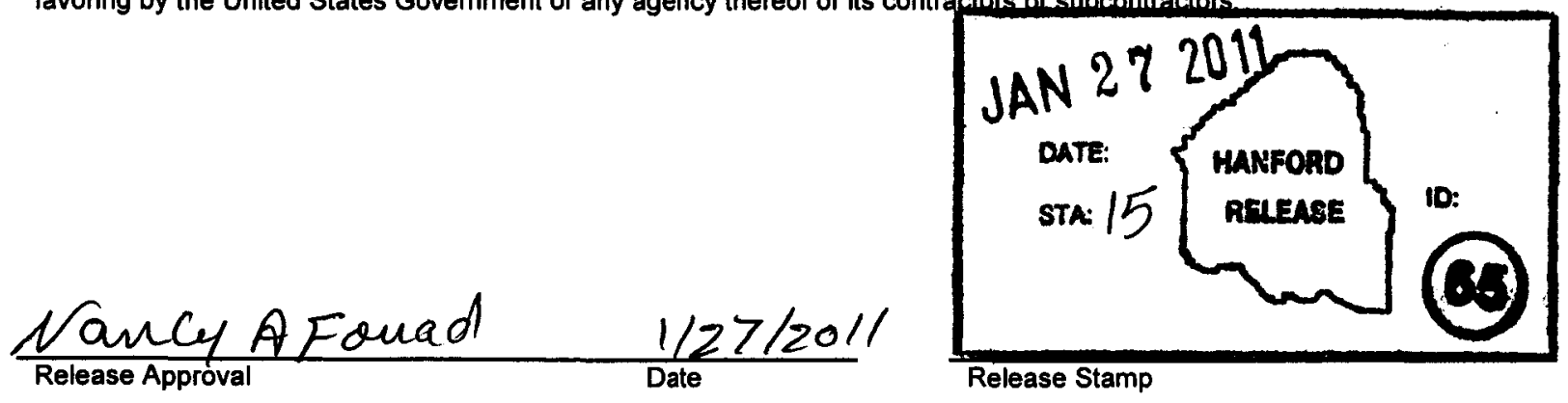

Approved For Public Release 


\section{ALUMINUM REMOVAL FROM HANFORD WASTE BY LITHIUM HYDROTALCITE PRECIPITATION - LABORATORY SCALE VALIDATION ON WASTE SIMULANTS - TEST REPORT}

Kevin Hagerty

AREVA Federal Services LLC

Date Published

December 2010

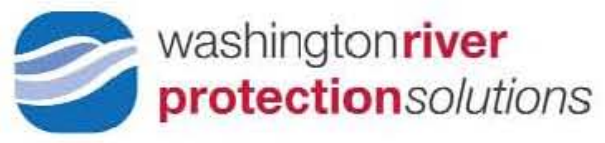

P.O. Box 850

Richland, Washington 99352

Prepared for the U.S. Department of Energy

Assistant Secretary for Environmental Management

Contractor for the U.S. Department of Energy

Office of River Protection und er Contract DE-AC27-08RV 14800 


\begin{abstract}
To reduce the additional sodium hydroxide and ease processing of aluminum bearing sludge, the lithium hydrotalcite (LiHT) process has been invented ${ }^{1}$ by AREVA and demonstrated on a laboratory scale to remove alumina and regenerate/recycle sodium hydroxide prior to processing in the WTP. The method uses lithium hydroxide $(\mathrm{LiOH})$ to precipitate sodium aluminate $\left(\mathrm{NaAl}(\mathrm{OH})_{4}\right)$ as lithium hydrotalcite $\left(\mathrm{Li}_{2} \mathrm{CO}_{3} \cdot 4 \mathrm{Al}(\mathrm{OH})_{3} .3 \mathrm{H}_{2} \mathrm{O}\right)$ while generating sodium hydroxide $(\mathrm{NaOH})$. In addition, phosphate substitutes in the reaction to a high degree, also as a filterable solid. The sodium hydroxide enriched leachate is depleted in aluminum and phosphate, and is recycled to double-shell tanks (DSTs) to leach aluminum bearing sludges. This method eliminates importing sodium hydroxide to leach alumina sludge and eliminates a large fraction of the total sludge mass to be treated by the WTP. Plugging of process equipment is reduced by removal of both aluminum and phosphate in the tank wastes. Laboratory tests were conducted to verify the efficacy of the process and confirm the results of previous tests. These tests used both single-shell tank (SST) and DST simulants.
\end{abstract}

\title{
KEY WORDS
}

Lithium Hydrotalcite (LiHT), Aluminum, Precipitation, Lithium Hydroxide, Cesium, Decontamination, Phosphate

${ }^{1}$ PCT International Application PCT/US2008/076589 


\section{EXECUTIVE SUMMARY}

Approximately 8,710 MT of aluminum bearing compounds ${ }^{2}$ exist in Hanford waste, and comprises $\sim 66 \mathrm{wt} \%$ of waste sludge. Although a fraction $(\sim 30 \%)$ of the alumina compounds are currently soluble in waste supernatants, dilution to $5 \mathrm{M}$ Na must be performed to keep phosphate compounds in solution and to maintain corrosion control as required for Waste Treatment and Immobilization Plant (WTP) processing. Additional sodium hydroxide is required to dissolve and maintain the solubility of aluminum for WTP operations.

To reduce the additional sodium hydroxide and ease processing of aluminum bearing sludge, the lithium hydrotalcite (LiHT) process has been invented ${ }^{3}$ by AREVA and demonstrated on a laboratory scale to remove alumina and regenerate/recycle sodium hydroxide prior to processing in the WTP. The method uses lithium hydroxide $(\mathrm{LiOH})$ to precipitate sodium aluminate $\left(\mathrm{NaAl}(\mathrm{OH})_{4}\right)$ as lithium hydrotalcite $\left(\mathrm{Li}_{2} \mathrm{CO}_{3} \cdot 4 \mathrm{Al}(\mathrm{OH})_{3} \cdot 3 \mathrm{H}_{2} \mathrm{O}\right)$ while generating sodium hydroxide $(\mathrm{NaOH})$. The carbonate form of LiHT is generated according to the equation:

\section{$2 \mathrm{LiOH}_{(A Q)}+\mathrm{Na}_{2} \mathrm{CO}_{3(A Q)}+4 \mathrm{NaAl}(\mathrm{OH})_{4(A Q)}+3 \mathrm{H}_{2} \mathrm{O} \rightarrow \mathrm{Li}_{2} \mathrm{CO}_{3} .4 \mathrm{Al}(\mathrm{OH})_{3} .3 \mathrm{H}_{2} \mathrm{O}_{(S)}+6 \mathrm{NaOH}_{(A Q)}$}

By this reaction, soluble sodium aluminate is precipitated as a filterable solid and sodium hydroxide liquor is recovered in the filtrate. In addition, phosphate substitutes in the reaction to a high degree, also as a filterable solid. The sodium hydroxide enriched leachate is depleted in aluminum and phosphate, and is recycled to double-shell tanks (DSTs) to leach aluminum bearing sludges. This method eliminates importing sodium hydroxide to leach alumina sludge and eliminates a large fraction of the total sludge mass to be treated by the WTP. Plugging of process equipment is reduced by removal of both aluminum and phosphate in the tank wastes.

Laboratory tests were conducted to verify the efficacy of the process and confirm the results of previous tests. These tests used both single-shell tank (SST) and DST simulants and proved the following:

- The solids produced from both the DST and SST simulant tests were primarily LiHT.

- The solids were readily filtered using small pore size filter media in a Büchner funnel

- Aluminum removal efficiency ranged from $83 \%$ to $96 \%$ as a fraction of aluminum in the reaction slurry.

- The filter cakes were readily decontaminated, indicating the filter cakes could be disposed of as Class A waste (most restrictive) according to the Code of Federal Regulations (10CFR61.55, Table 2).

- Phosphate removal by the precipitation process was very effective and ranged from $75 \%$ to $99 \%$ as a fraction of the phosphate in the reaction slurry.

- The generation of hydroxide was inferred by the verification of the production of LiHT by XRD in the filter cake.

\footnotetext{
${ }^{2}$ Alumina and sodium inventories in Hanford waste is from HTWOS model run SP4 Planning Case-3.0-8.4r0-200903-30-at-20-02-39

${ }^{3}$ PCT International Application PCT/US2008/076589
} 
In general, the LiHT process performed as predicted by thermodynamic models and verified previous laboratory testing. Additional testing to further optimize the process should be conducted to advance the understanding of this very promising technology. 


\section{TABLE OF CONTENTS}

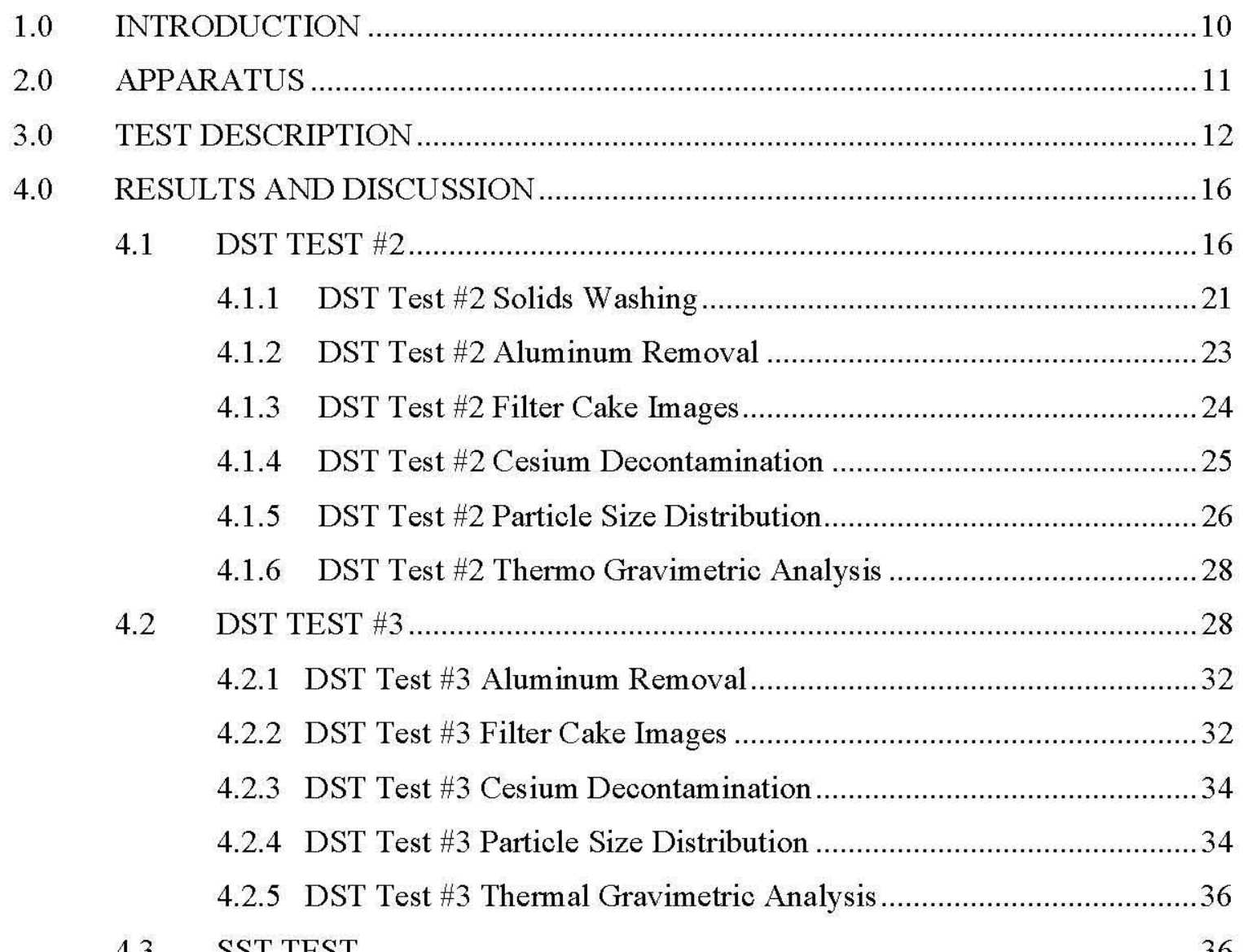

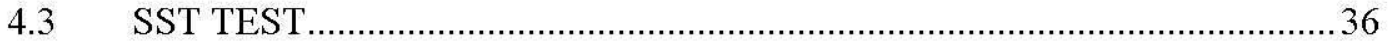

4.3.1 SST Test Solids Washing ............................................................ 40

4.3.2 SST Test Aluminum Removal ........................................................ 41

4.3.3 SST Test Filter Cake Images ......................................................... 42

4.3.4 SST Test Cesium Decontamination ................................................... 44

4.3.5 SST Particle Size Distribution ......................................................... 44

4.3.6 SST Test Filter Cake Speciation ………………………………...... 46

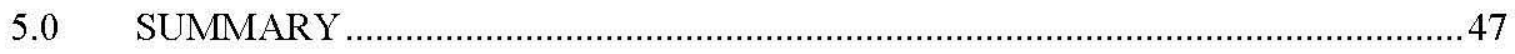

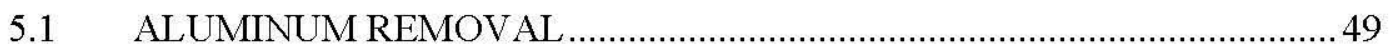

5.2 LiHT FILTRATION..............................................................................

5.2.1 CESIUM DECONTAMINATION ………………………………....51

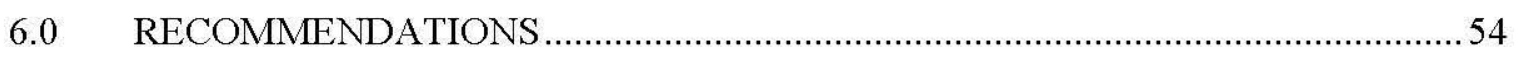

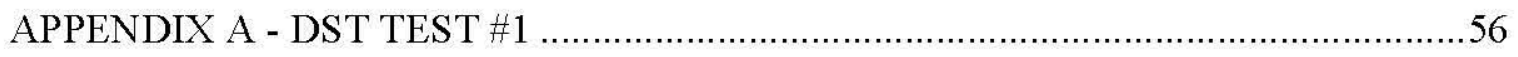

APPENDIX B - ANALYTICAL RESULTS SUMMARY FOR DST \#2.......................68 


\section{TABLE OF FIGURES}

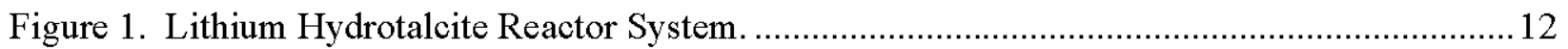

Figure 2. General Flow Chart for Preparation of Lithium Hydrotalcite ...................................... 13

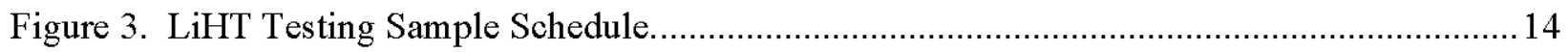

Figure 4. Experiment Flow Chart for DST Test \#2 .................................................................... 18

Figure 5. DST \#2 Reaction Progressions and Elapsed Time from Start of Lithium Hydroxide Addition.

Figure 6. X-Ray Diffraction Pattern of Sample "DST \#2 Initial Filter Cake" in red, and the reference pattern 00-042-0729 in blue with Degrees $2 \theta$ Along the X-Axis and Intensity (Counts) Along the Y-Axis.

Figure 7. Filtrate and Cake Samples from DST \#2 Test. 21

Figure 8. X-Ray Diffraction Pattern of Sample "DST \#2 Initial Filter Cake" 10130236, with Degrees $2 \theta$ Along with $\mathrm{X}$-Axis and Intensity (Counts) Along the $\mathrm{Y}$-Axis. .22

Figure 9. X-Ray Diffraction Pattern of Sample "DST \#2 $4^{\text {th }}$ Wash Filter Cake" 10130237, with Degrees $2 \theta$ Along with X-Axis and Intensity (Counts) Along the Y-Axis. ....................................23

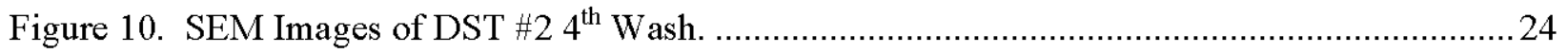

Figure 11. Characteristic EDS Spectrum of Sample "DST \#2 $4^{\text {th }}$ Wash Filter..............................25

Figure 12. Sample "DST \#2 $4^{\text {th }}$ Wash Filter" 10130237 Represented as a Number-Based Distribution.

Figure 13. Sample "DST \#2 $4^{\text {th }}$ Wash Filter" 10130237 Represented as a Volume-Based Distribution. 27

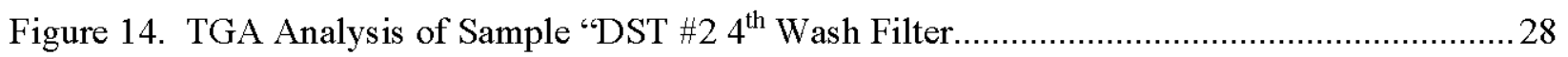

Figure 15. Experiment Flow Chart for DST Test \#3 .............................................................. 30

Figure 16. X-Ray Diffraction Pattern of Sample "DST \#3 4 ${ }^{\text {th }}$ Wash Cake . .................................... 31

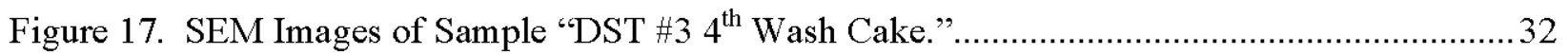

Figure 18. Characteristic EDS Spectrum of Sample "DST \#3 4 th $^{\text {th }}$ ash Cake." .............................33

Figure 19. Sample "DST \#3 $4^{\text {th }}$ Wash Cake" Represented as a Number-Based Distribution. ...........35

Figure 20. Sample "DST \#3 $4^{\text {th }}$ Wash Cake" Represented as a Volume-Based Distribution..............35

Figure 21. TGA Analys is of Sample "DST \#3 4 th Wash Cake." ................................................. 36

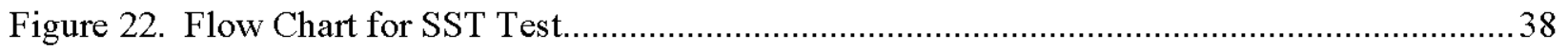

Figure 23. SST Reaction Progression and Elapsed Time from Start of Lithium Hydroxide Addition.

Figure 24. Filtrate and Cake Samples from SST Test 
Figure 25. X-Ray Diffraction Pattern of Sample "SST $4^{\text {th }}$ Wash Filter Cake" with Degrees $2 \theta$ Along the X-Axis and Intensity (Counts) Along the Y-Axis...... 41

Figure 26. SEM Images of Sample "SST $4^{\text {th }}$ Wash Filter Cake." .................................................. 42

Figure 27. Characteristic EDS Spectrum of Sample "SST $4^{\text {th }}$ Wash Filter Cake." '........................43

Figure 28. Sample "SST $4^{\text {th }}$ Wash Filter Cake" 10130239 Represented as a Volume-Based

Distribution.

Figure 29. Sample "SST $4^{\text {th }}$ Wash Filter Cake" 10130239 Represented as a Number-Based

Distribution. 45

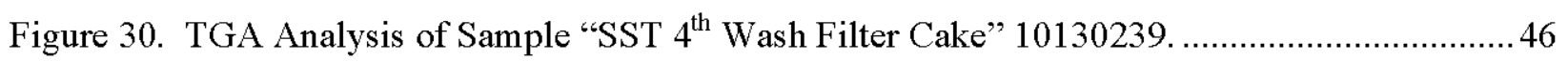

Figure 31. Overlay of X-Ray Diffraction Patterns of Samples......................................................... 48

Figure 32. Aluminum Concentration in Filter Cakes During Wash Progression. ............................ 49

Figure 33. Aluminum Concentration in Filtrates During Wash Progression.................................. 49

Figure 34. DST Test \#3 Filtration Times During Wash Progression.................................................50

Figure 35. Unwashed Cake Particle Size Distribution from Georgia Tech Experiments..................51

Figure 36. Final Washed Cake from SST Test Particle Size Distribution (Volume Based).............51

Figure 37. Filter Cake Cesium Decontamination During Wash Progression. .................................52

Figure 38. Alkali Metals from ICP in DST \#2 Filter Cakes. ......................................................53

\section{TABLE OF TABLES}

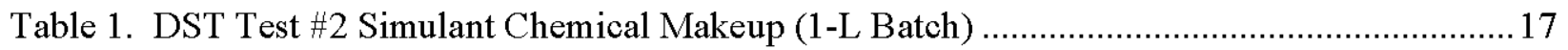

Table 2. DST \#2 Incremental and Cumulative Filter Cake Cesium DF. ......................................26

Table 3. DST Test \#3 Simulant Chemical Makeup (1-L Batch). .................................................29

Table 4. DST Test \#2 Filter Cake Cesium Decontamination ......................................................... 34

Table 5. SST Test Simulant Chemical Makeup (2 Liter Batch). ................................................ 37

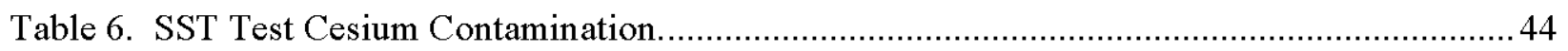

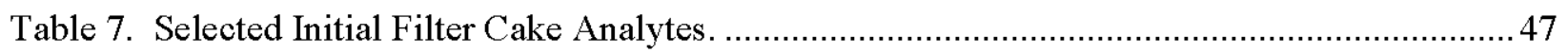

Table 8. Analogous ${ }^{137}$ Cs Concentrations in Final Washed Cakes..............................................53 


\section{LIST OF TERMS}

\section{Abbreviations and Acronyms}

AFS

ANN

$\mathrm{ARF}$

DI

DST

DOE

HLW

IC

ICP-AES

ICP-MS

LAW

LiHT

MT

PSD

PVDF

SEM/EDS

SST

TIC

TGA

TRA

TRL

WRPS

WTP

XRD
AREVA Federal Services LLC

Aluminum Nitrate Nonohydrate

Aluminum Removal Facility

De-ionized water

Double-Shell Tank

U.S. Department of Energy

High-Level Waste

Ion Chromatography

Inductively Coupled Plasma Atomic Emission Spectroscopy

Inductively Coupled Plasma Mass Spectroscopy

Low-Activity Waste

Lithium Hydrotalcite

Metric Ton

Particle Size Distribution

Poly Vinylidene Fluoride

Scanning Electron Microscopy/Energy Dispersive X-Ray Spectroscopy

Single Shell Tank

Total Inorganic Carbon

Thermo Gravimetric Analysis

Technology Readiness Assessment

Technology Readiness Level

Washington River Protection Solutions, LLC

Waste Treatment and Immobilization Plant

X-Ray Diffraction 


\subsection{INTRODUCTION}

The U.S. Department of Energy (DOE) plans to vitrify both high-level waste (HLW) and lowactivity waste (LAW) at the Hanford Site. Removal of aluminum from the waste is of importance to minimize the amount of HLW glass and allow processing flexibility to avoid precipitation and blockage issues, reduce total waste mass, and reduce costs associated with Waste Treatment and Immobilization Plant (WTP) processing.

By Lithium Hydrotalcite (LiHT) precipitation, sodium hydroxide is regenerated thus, eliminating a large mass of imported sodium hydroxide from the LAW waste mass. By reducing the masses of high- and low-activity wastes, processing times for mixing, filtering, separating, and vitrifying the wastes and the costs for long-term storage of the immobilized forms is minimized. The process has been demonstrated in one and two-liter laboratory scale experiments using Hanford waste simulants to remove alumina and regenerate sodium hydroxide. The method uses lithium hydroxide $(\mathrm{LiOH})$ and waste sodium carbonate $\left(\mathrm{Na}_{2} \mathrm{CO}_{3}\right)$ to precipitate sodium aluminate $\left(\mathrm{NaAl}(\mathrm{OH})_{4}\right)$ as lithium hydrotalcite $\left(\mathrm{Li}_{2} \mathrm{CO}_{3} \cdot 4 \mathrm{Al}(\mathrm{OH})_{3} \cdot 3 \mathrm{H}_{2} \mathrm{O}\right)$ and regenerate sodium hydroxide $(\mathrm{NaOH})$. In lieu of carbonate incorporation (intercalation) into the LiHT structure, more thermodynamically stable anionic forms of LiHT may form in the reaction (e.g. phosphate).

As indicated in the general reaction, lithium combines with the aluminate ion to form the Li-Aldihydroxide complex with intercalated anions and water molecules. The excess sodium hydroxide generated by the reaction could be recycled for caustic leaching of aluminum-bearing solids from tank farm sludge to increase the amount of sodium aluminate $\left[\mathrm{NaAl}(\mathrm{OH})_{4}\right]$ in the supernate.

$$
2 \mathrm{NaAl}(\mathrm{OH})_{4}+\mathrm{LiOH}+\mathrm{NaX}^{-}+\mathrm{nH}_{2} \mathrm{O} \rightarrow\left[\mathrm{LiAl}_{2}(\mathrm{OH})_{6}\right] \mathrm{X}^{-} \cdot \mathrm{nH}_{2} \mathrm{O}+3 \mathrm{NaOH}
$$

Washington River Protection Solutions LLC (WRPS) River Protection System Plan Revision 5 includes an Aluminum Removal Facility (ARF) using the LiHT process to reduce mission duration, minimize waste generation, and reduce costs. Recent direction from the DOE, based on the immature technology status of the LiHT process, caused work on the ARF to be discontinued. Instead, alternative implementation scenarios are to be investigated.

Although the LiHT process was integral to the ARF, LiHT does not rely on the ARF. The ability to precipitate aluminum from Hanford waste and generate sodium hydroxide is an important chemical process that has the potential to be incorporated in alternative flow sheets being considered by WRPS. Therefore, AREVA was contracted by WRPS under the "Lithium Hydrotalcite Technology Readiness Confirmation and Closure Project," to assemble the documentation package for advancing the LiHT demonstration documentation and testing to the point where a Technology Readiness Assessment (TRA) can be conducted. 
The proposed laboratory-scale validation program included the following main activities:

- SST and DST (non-radioactive) simulants were prepared from SST and DST formulations developed during the Fractional Crystallization project. The simulant chemistry was based on analyses of actual tank waste samples. During Fractional Crystallization laboratory experiments, the simulants were determined to have the same chemical and physical properties as actual waste samples. Simulant chemistries of some tests were modified somewhat to ameliorate gibbsite dissolution issues.

- One- and two-liter laboratory tests of LiHT precipitation was performed to validate previous experiments using similar methodologies to previous testing.

- Solids washing was accomplished with a stir bar and Teflon beaker; filtration utilized a Büchner funnel and small pore filter media.

- Analysis of the filter cakes and filtrates was performed with:

- ICP-AES and ICP-MS for metals.

- IC, colorimetric analysis, and titrations for anions (including free hydroxide).

- Particle Size Distribution (PSD) and TGA of final washed solids.

- X-Ray Diffraction (XRD) of initial and final washed cakes.

- Total Inorganic Carbon (TIC) for carbonate determination.

- SEM/EDS of final washed solids.

\subsection{APPARATUS}

The reactor utilized in the experiments was a Chemglass (Vineland, NJ) two-liter jacketed vessel, model number CG-1950, with variable speed agitator, digital temperature indicator, condenser, and stand. Ancillary equipment included a chiller for the condenser, silicon oil heater/controller for the reactor jacket, and micro-peristaltic pump with micro bore tubing for $\mathrm{LiOH}$ additions. The system is shown in Figure 1. 


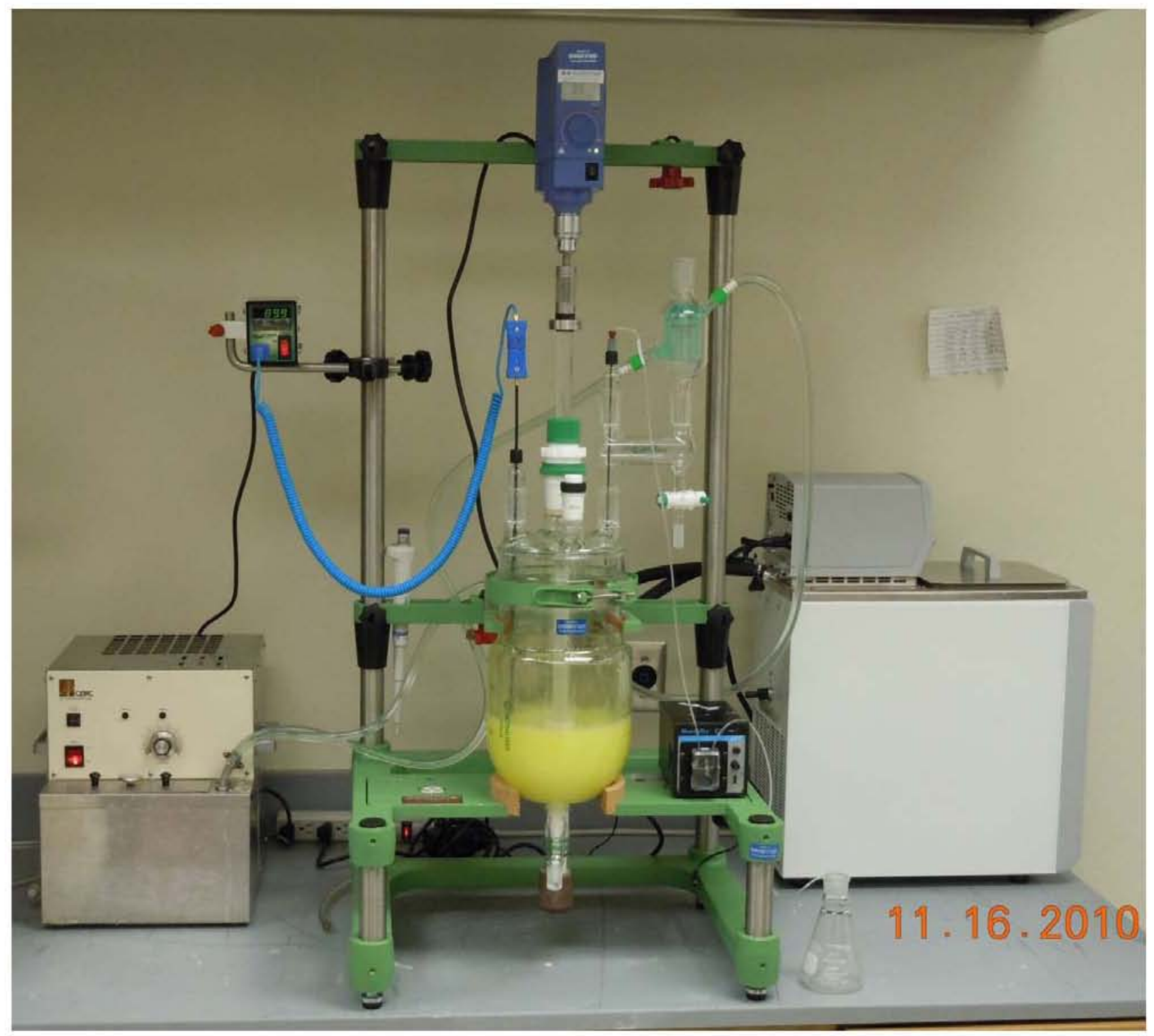

Figure 1. Lithium Hydrotalcite Reactor System.

\subsection{TEST DESCRIPTION}

The tests were performed as described in the Lithium Hydrotalcite Precipitation Development Planning - Single-Shell Tank Supernatant Tests (RPP-PLAN-48090), and Lithium Hydrotalcite Precipitation Development Planning - Double-Shell Tank Supernatant Tests (RPP-PLAN48091).

The general flow chart of the process is shown in Figure 2. It contains all steps including gibbsite leaching, crystal ripening at $90^{\circ} \mathrm{C}$ (for 4 hours), filtration, and final wash steps. This general test sequence was followed for all test runs with modifications described in the individual sections. 
RPP-RPT-48380, Rev. 0

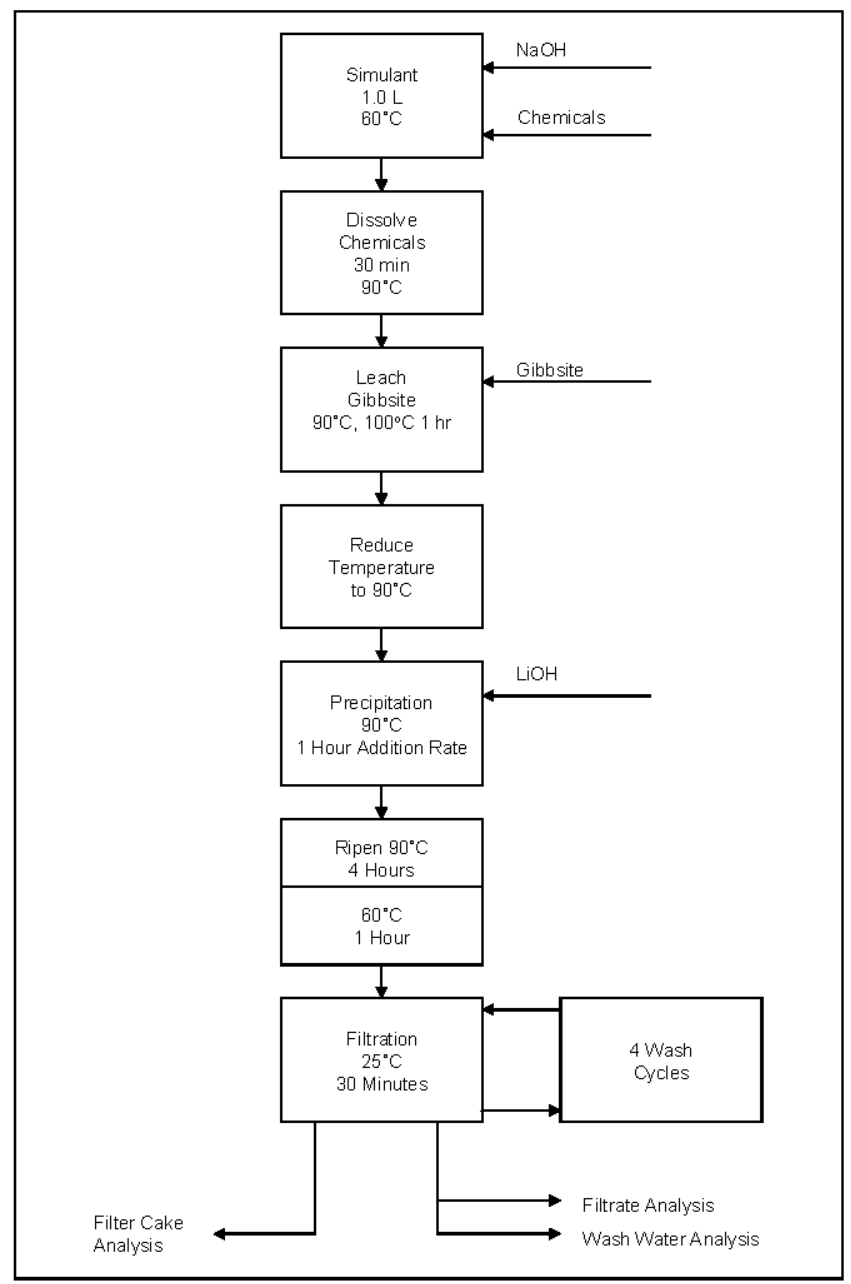

Figure 2. General Flow Chart for Preparation of Lithium Hydrotalcite

The SST and DST simulants were prepared according to the recipes in the test plan, with slight modifications also as noted in the individual sections. The original compositions were based on the formulations of the SST early feed simulant and the DST simulant in CH2M-0403873, Preparation of Simulated Waste Samples for EM-21 Project. These one-liter recipes are normalized to a sodium concentration of $5 \mathrm{M} \mathrm{Na}$. The test procedure specified the leaching of aluminum from gibbsite $(\mathrm{Al}(\mathrm{OH}) 3)$ rather than aluminum being added to the simulant as $\mathrm{NaA1O} 2.2 \mathrm{H} 2 \mathrm{O}$, due to unknown impurity and quantification issues with the Technical Grade Sodium Aluminate. At this time, there is no commercially-available reagent grade Sodium Aluminate.

For the first DST test, the specified gibbsite leaching protocol was followed; however, some gibbsite remained in the reactor, as a suspended solid, after the specified leaching time had elapsed. Extended leaching time did not alleviate the remaining turbidity of the solution, and the test continued in spite of this. This likely affected the product yield in the first DST test. Due to the leaching issue, a decision was made to adjust the simulant recipes and utilize Aluminum 
Nitrate nonahydrate, $(\mathrm{ANN}, \mathrm{Al}(\mathrm{NO} 3) 3 \cdot 9 \mathrm{H} 2 \mathrm{O})$, as an aluminum source as much as practicable, with stoichiometrically correct ratios for hydroxide and nitrate maintained.

For the SST simulant, the entire mass of aluminum to be added was in the form of ANN, while the DST simulant still needed a relatively small amount of leached gibbsite to obtain correct mole ratios due to the lower sodium nitrate quantity added to the DST simulant. The gibbsite leaching was facilitated by a $[\mathrm{OH}-]$ to $[\mathrm{Al}]$ ratio of $6: 1$ using the ANN recipe, vs. a 3:1 ratio with the original chemical constituents.

For each test, simulant chemicals were weighed on a four place balance and transferred to the 2-liter reactor through a port in the lid. Agitation was initiated, and dissolution steps commenced. After simulant make up and heating to $90^{\circ} \mathrm{C}, 10 \% \mathrm{LiOH}$ solution was introduced to the reactor and precipitation of LiHT followed. After the four-hour ripening period, the product was transferred out to the filtration system. Samples for chemical analyses were taken from the initial filtrate (Mother Liquor), wash water of each of the four washing steps, as well as from an aliquot of each of the filter cakes after each sequential wash. All samples were submitted to RJ Lee Group of Pasco, WA. Figure 3 provides details of the Sample Schedule followed for each of the four individual tests.

1. Liquid Samples

1. Mother liquor after first filtration

a. ICP- AES for: Li, Al, Na, P, S, K

b. ICP/MS for $\mathrm{Cs}, \mathrm{Cr}$

c. Alkalinity for free hydroxide by titration

d. Anions by IC for NO3, NO2, SO4, F, PO4

2. Each wash

$\mathrm{CO} 3$ by TIC

f. ICP-AES for: Li, Al, Na, P, S, K

g. ICP/MS for $\mathrm{Cs}, \mathrm{Cr}$

h. Alkalinity for free hydroxide by titration

i. Anions by IC for NO3, NO2, SO4, F, PO4, CO3

2. Filter cake samples

1. Initial filter cake from $\mathrm{LiOH}$ reaction

a. ICP-AES for: Li, Al, Na, P, S, F, K

b. ICP/MS for $\mathrm{Cs}, \mathrm{Cr}$

2. First three filter cakes after washes

a. ICP-AES for: Li, Al, Na, P, S, F, K

b. ICP/MS for $\mathrm{Cs}, \mathrm{Cr}$

3. Dried filter cake ONE SAMPLE PER TEST

a. ICP- AES for: Li, Al, Na, P, S, F, K

b. ICP/MS for $\mathrm{Cs}, \mathrm{Cr}$

c. $\mathrm{CO} 3$ (TIC)

d. XRD

e. SEM/EDS

f. TGA

g. Re-suspension of cake for liquid (slurry) phase PSD

Figure 3. LiHT Testing Sample Schedule. 
The solids washing steps entailed washing the filtered solids with four consecutive 1-liter DI water washes (ambient temperature) in a beaker with magnetic stir bar. Washing in the beaker was performed with a high agitation rate to provide continuous contact between the wash water and solids. After 30 minutes of washing, the slurry was again filtered through a $0.45 \mu \mathrm{m}$ pore filter with vacuum filtration through a Büchner funnel.

Analysis methodologies and equipment for the individual methods:

- Particle Size Analysis

Particle size distribution analysis (volume based and number based) was conducted using a Horiba LA-910 Light Scattering Particle Size Distribution Analyzer. Laser diffraction particle size distribution analyzers report results in volume distribution but the number distribution can be calculated by the data acquisition software. Number distribution should only be used to compare to microscopy data. A small portion of the samples was dispersed in approximately $125 \mathrm{ml}$ of DIUF water. Approximately $100 \mathrm{ml}$ of the dispersed sample was added to the sample reservoir (which contained between 150-315 $\mathrm{ml}$ DIUF water) and was analyzed.

\section{- TGA Analysis}

The instrument used for the analysis of the sample was a simultaneous TGA/DSC (Q600 SDT). The specific experimental conditions used are as follows:

Sample size: see plots

Heating rate: $20^{\circ} \mathrm{C} / \mathrm{min}$

Data sampling interval: $0.5 \mathrm{sec} /$ point

Temperature range: $\sim \mathrm{RT}-1000^{\circ} \mathrm{C}$

Nitrogen: $100 \mathrm{ml} / \mathrm{min}$

The Universal Analysis 2000 Software (Version 4.1D, TA Instruments) was used for the processing of the data. The samples showed a weight loss of in the range of $\sim 65$ to $80 \%$. Samples were in duplicate.

\section{- X-ray diffraction (XRD) for crystalline phases}

A portion of the samples was ground and mounted into a standard XRD holder for analysis. The samples were run on a PANalytical X'Pert Pro diffractometer using copper radiation. The resulting diffraction pattern was then analyzed using the X'Pert HighScore program utilizing the ICDD database

\section{- SEM/EDS Analysis}

A representative portion of each sample was dry deposited on a carbon adhesive tab for SEM analysis. The samples were coated with a thin layer of platinum via sputter deposition. The samples were analyzed in a Hitachi S-5500 ultra-high resolution fieldemission SEM (FESEM) using a $2 \mathrm{kV}$ accelerating voltage. Furthermore to verify the presence of $\mathrm{P}$ (phosphorous) a representative portion of the sample was dry deposited on a carbon adhesive tab for SEM analysis. The sample was analyzed in an RJ Lee Instruments Personal SEM (PSEM) Model 75 using a $20 \mathrm{kV}$ accelerative voltage. Analysis was performed in low vacuum mode in order to prevent charge buildup on the surface without the use of a conductive coating layer. 


\subsection{RESULTS AND DISCUSSION}

In general, the testing proceeded as planned. The major exception was the use of ANN for simulant make up due to issues associated with gibbsite leaching. In addition, for two of the tests, in order to capture additional LiHT, an overnight ripening period at ambient temperatures was utilized in DST \#2 and the SST test.

The results are presented in the order of the second DST test (DST \#2), the third DST test (DST $\# 3$ ), followed by the SST test. The first DST test (DST \#1) results are presented in Appendix A as some of the results were inconclusive, likely due to incomplete leaching of the gibbsite. Appendix B contains the compilation of final analytical results.

In order to verify the amounts of $\mathrm{PO}_{4}$ from the IC and ICP-AES analysis, colorimetric total phosphate was also determined; however, the IC and total phosphate results both proved to be less reliable than the ICP-AES and were not used in calculations. They are, however, presented in the summary tables of Appendix B.

Free hydroxide is generated in the LiHT reaction by stripping carbonate and/or phosphate anions from its respective sodium salt. The reaction generates two moles of sodium hydroxide for every mole of LiHT product. Total alkalinity analysis by titration was performed for determination of carbonate and hydroxide concentrations, and TIC was used for determination of carbonate. The difference between the two yields the free hydroxide concentration. Unfortunately, the expected results for hydroxide generation were not able to be verified by the analysis methods that were selected. Qualitatively, the generation of hydroxide can be inferred from the fact that LiHT was actually generated in the reaction (as verified by XRD) and by the reaction stoichiometry.

\subsection{DST TEST \#2}

Several modifications to the testing protocol were made to facilitate this test:

- Partial use of ANN for simulant make up instead of all gibbsite. To accomplish this, the nitrate source was changed from sodium nitrate to ANN. To balance the hydroxide, the total sodium hydroxide was increased stoichiometrically. For the purpose of improving the leaching process for the balance of the aluminum (from gibbsite), the entire quantity of $\mathrm{NaOH}$ was used, resulting in a caustic to gibbsite ratio of 3 to 1 , rather than 6 to 1 as in the original recipe. When the leachate was combined with the remainder of the chemicals in the simulant, the integrity of the original recipe was maintained. The DST \#2 recipe is shown in Table 1.

- Overnight ripening at ambient conditions to capture excess slow forming precipitates as noted in DST Test \#1

- Previous testing indicated that lithium phosphate (Li3PO4) preferentially precipitates over LiHT. In order to ensure that adequate lithium ion was present for complete conversion of aluminum to LiHT, the total lithium added was determined by first 
satisfying the stoichiometric aluminum demand, then the stoichiometric phosphate demand, and adding $10 \%$ excess.

Table 1. DST Test \#2 Simulant Chemical Makeup (1-L Batch)

\begin{tabular}{|c|c|c|c|c|}
\hline Reagent & MW & Target Molarity & $\begin{array}{c}\text { Target Weight or } \\
\text { Volume }\end{array}$ & $\begin{array}{c}\text { Actual Weight } \\
\text { or Volume }\end{array}$ \\
\hline $\mathrm{NaOH}$ & 40 & 3.51 & $140.26 \mathrm{~g}$ & $140.250 \mathrm{~g}$ \\
\hline $\mathrm{Na}_{2} \mathrm{CO}_{3}$ & 106 & 0.06 & $6.86 \mathrm{~g}$ & $6.862 \mathrm{~g}$ \\
\hline $\mathrm{Na}_{2} \mathrm{C}_{2} \mathrm{O}_{4}$ & 134 & 0.003 & $0.38 \mathrm{~g}$ & $0.384 \mathrm{~g}$ \\
\hline $\mathrm{KNO}_{3}$ & 101 & 0.19 & $19.68 \mathrm{~g}$ & $19.688 \mathrm{~g}$ \\
\hline $\mathrm{NaNO}_{3}$ & 85 & N/A & N/A & N/A \\
\hline $\mathrm{NaNO}_{2}$ & 69 & 1.15 & $79.44 \mathrm{~g}$ & $79.443 \mathrm{~g}$ \\
\hline $\mathrm{Na}_{2} \mathrm{SO}_{4}$ & 142 & 0.007 & $1.02 \mathrm{~g}$ & $1.019 \mathrm{~g}$ \\
\hline $\mathrm{Na}_{3} \mathrm{PO}_{4} \cdot 12 \mathrm{H}_{2} \mathrm{O}$ & 380.1 & 0.007 & $2.74 \mathrm{~g}$ & $2.740 \mathrm{~g}$ \\
\hline $\mathrm{NaCl}^{\mathrm{NaF}}$ & 58.4 & 0.12 & $6.73 \mathrm{~g}$ & $6.732 \mathrm{~g}$ \\
\hline $\mathrm{NaF}$ & 42 & 0.011 & $0.46 \mathrm{~g}$ & $0.461 \mathrm{~g}$ \\
\hline $\mathrm{Na}_{2} \mathrm{Cr}_{2} \mathrm{O}_{7} \cdot 2 \mathrm{H}_{2} \mathrm{O}$ & 298 & 0.001 & $0.43 \mathrm{~g}$ & $0.432 \mathrm{~g}$ \\
\hline $\mathrm{NaC}_{2} \mathrm{H}_{3} \mathrm{O}_{2} \cdot 3 \mathrm{H}_{2} \mathrm{O}$ & 136.1 & 0.04 & $5.48 \mathrm{~g}$ & $5.483 \mathrm{~g}$ \\
\hline $\mathrm{CsNO}_{3} \mathrm{solution}$ & $\mathrm{NA}$ & $1.05 \mathrm{E}-05$ & $2.43 \mathrm{~mL}$ & $2.43 \mathrm{~mL}$ \\
\hline & & & & \\
\hline $\left.\mathrm{Al}_{(\mathrm{OH}}\right)_{3}$ & 78 & 0.577 & $45.01 \mathrm{~g}$ & $45.02 \mathrm{~g}$ \\
\hline $\mathrm{Al}\left(\mathrm{NO}_{3}\right)_{3} \cdot 9 \mathrm{H}_{2} \mathrm{O}$ & 375.1 & 0.305 & $114.41 \mathrm{~g}$ & $114.38 \mathrm{~g}$ \\
\hline $\mathrm{LiOH}_{2} \mathrm{H}_{2} \mathrm{O}$ & 42 & 0.509 & $21.37 \mathrm{~g}$ & $21.37 \mathrm{~g}$ \\
\hline
\end{tabular}

Note: CsNO3 solution is prepared by dissolving $210 \mathrm{mg}$ reagent CsNO3 salt in $250 \mathrm{~mL}$ water.

For the second DST test, the leaching protocol employed for the reduced quantity of gibbsite was to add water, caustic, and gibbsite for extended, agitated leaching at $100^{\circ} \mathrm{C}$ in a Teflon beaker. Use of the Teflon beaker eliminated the silica that was produced from the caustic etching of the glass reactor during the leach process. This, in combination with the higher caustic-to-aluminum ratio, produced a clear leachate in about 45 minutes.

$10 \mathrm{wt} \% \mathrm{LiOH}$ was added to the reactor at a predetermined rate that would ensure a one-hour addition period. Approximately 15 minutes after the start of the $\mathrm{LiOH}$ addition, a sudden formation of precipitate occurred, likely due to a slow increase to super saturated conditions. The white precipitate continued to gradually form through the remainder of the $\mathrm{LiOH}$ addition, as well as the 4-hour ripening period. Reactor contents were cooled to $50^{\circ} \mathrm{C}$ after the ripening period and the product slurry $(935 \mathrm{ml})$ was transferred to a polypropylene container for overnight ripening at ambient conditions. The test sequence for DST \#2 is indicated in the flowchart as shown in Figure 4. 


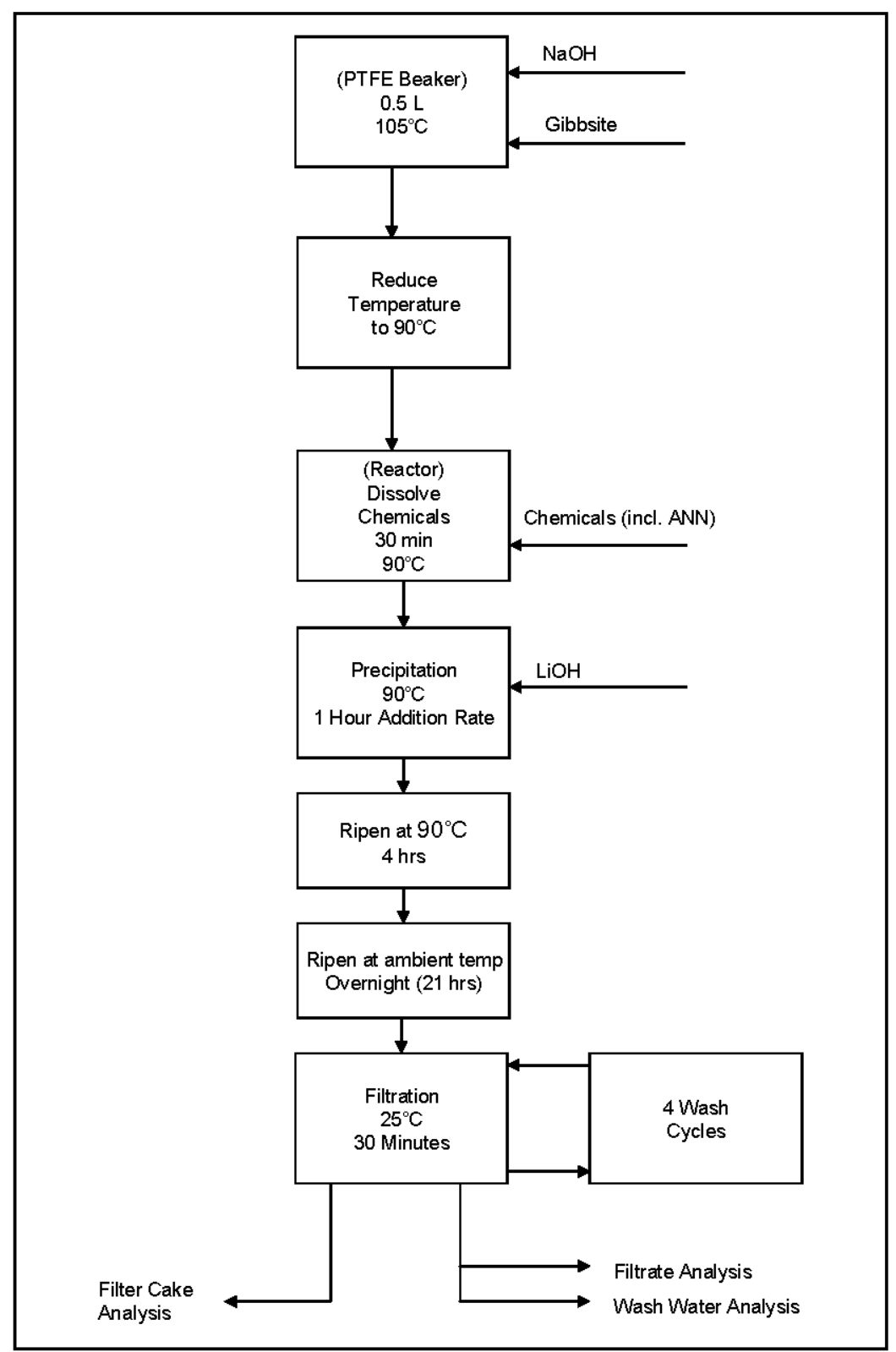

Figure 4. Experiment Flow Chart for DST Test \#2.

Time lapse photographs of the DST Test \#2 reaction progression are presented in Figure 5 . As indicated, the LiHT reaction is characterized by the rapid onset of precipitation at about 25 minutes after the start of $\mathrm{LiOH}$ addition. Using the black thermocouple as a reference, the accumulation of solids as the reaction progresses can be seen (Figure 5). Scaling on the reactor walls is responsible for some of the indicated lack of clarity, but reaction precipitates are the primary cause. 


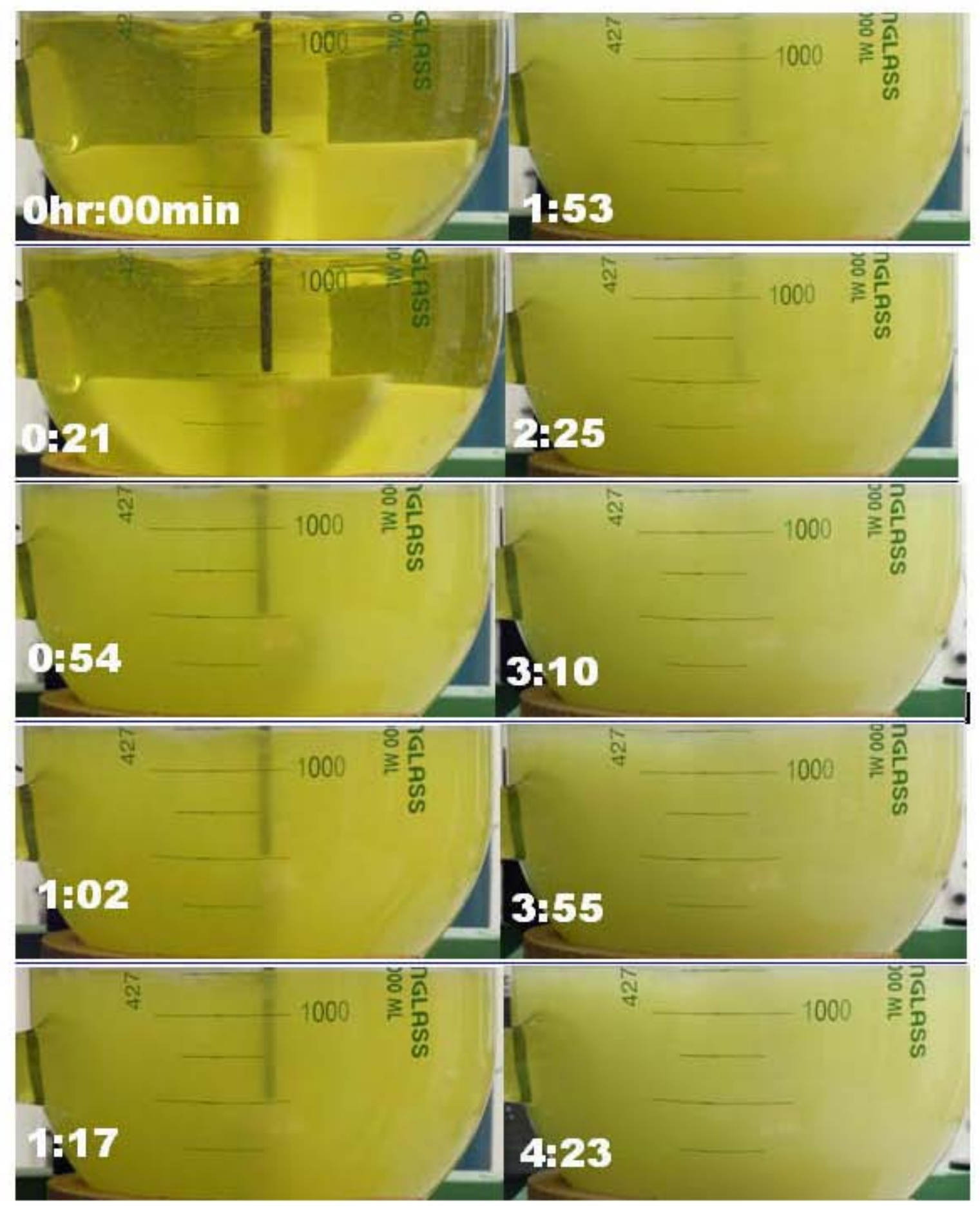

Figure 5. DST \#2 Reaction Progressions and Elap sed Time from Start of Lithium Hydroxide Addition.

After approximately 21 hours of crystal ripening at ambient temperatures, the slurry was filtered using a Büchner funnel and $0.45 \mu \mathrm{m}$ PVDF filter paper. Samples of the filtrate and solids were taken for analysis as noted in the Test Procedure. The cake produced was an off-white color due to the presence of sodium dichromate and resembled soft clay. The product filtered readily and 
was easily removed from the Büchner funnel. All filtrates were clear and showed no signs of unfiltered solids.

The XRD spectra of the unwashed solids compared to the reference spectra indicates LiHT in the carbonate form as the major species, with only trace unknowns (Figure 6).

\begin{tabular}{lccc}
\hline Phase & Composition & Concentration & PDF Number \\
\hline Lithium Aluminum & $\left(\mathrm{Al}_{2} \mathrm{Li}(\mathrm{OH})_{6}\right)_{2} \mathrm{CO}_{3} \cdot \mathrm{xH}_{2} \mathrm{O}$ & Major & $00-042-0729$ \\
Carbonate Hydroxide & & & \\
Hydrate & - & Trace & \\
Unknown(s) & - & & \\
\hline
\end{tabular}

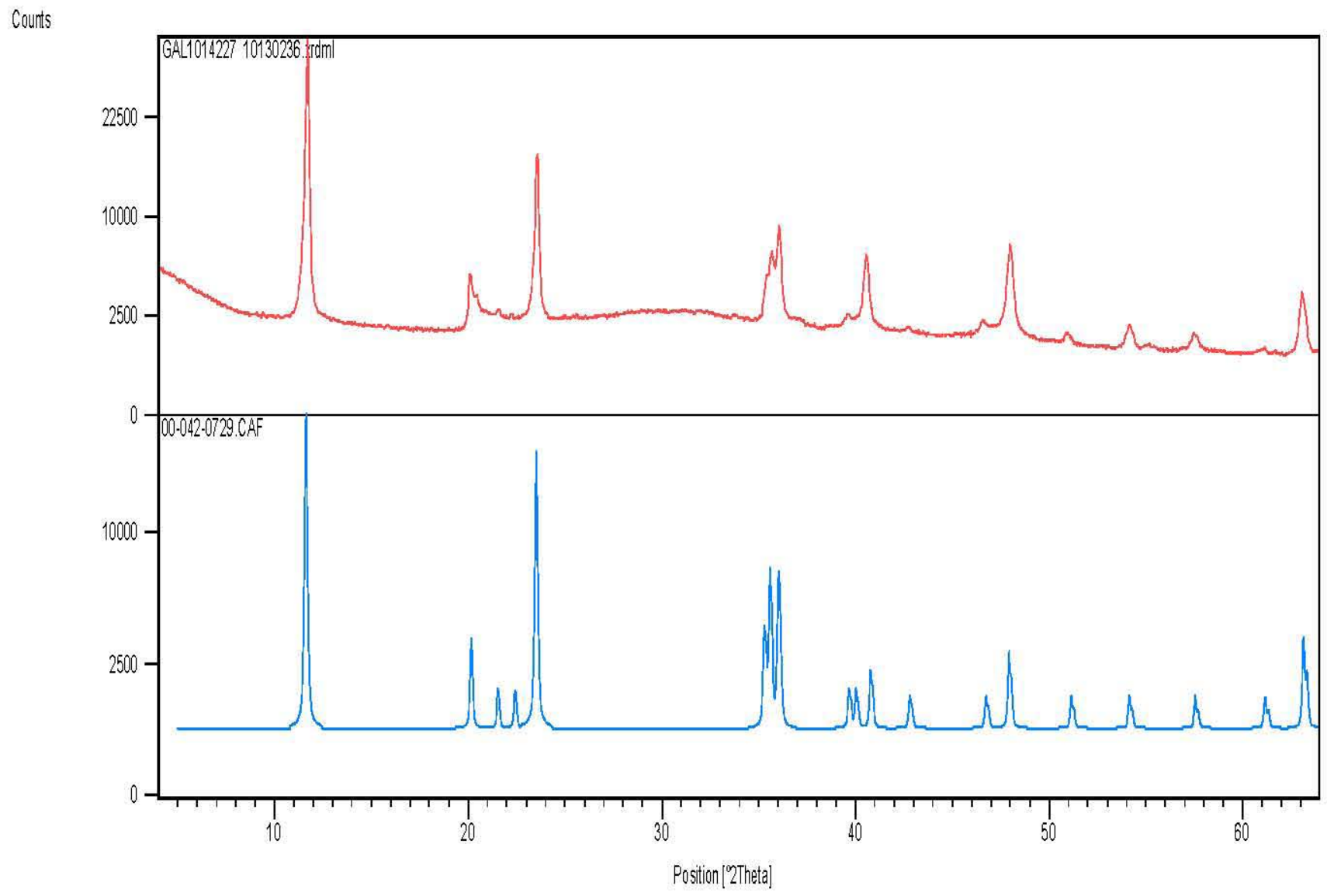

Figure 6. X-Ray Diffraction Pattern of Sample "DST \#2 Initial Filter Cake" in red, and the reference pattern 00-042-0729 in blue with Degrees $2 \theta$ Along the $X$-Axis and Intensity (Counts) Along the Y-Axis. 


\subsubsection{DST TEST \#2 SOLIDS WASHING}

The same solids washing steps were followed as in the previous run. Samples of both the filtrate and the filter cake were taken for analysis after each filtration step. Appendix B contains the analysis results. The final washed cake was a white, fluffy, highly crystalline material. The second through the fourth wash filtrates were water clear, indicating the majority of residual dichromate was washed out in the first wash (Figure 7). This is verified by analytical results showing the dichromate readily washes from the cake.

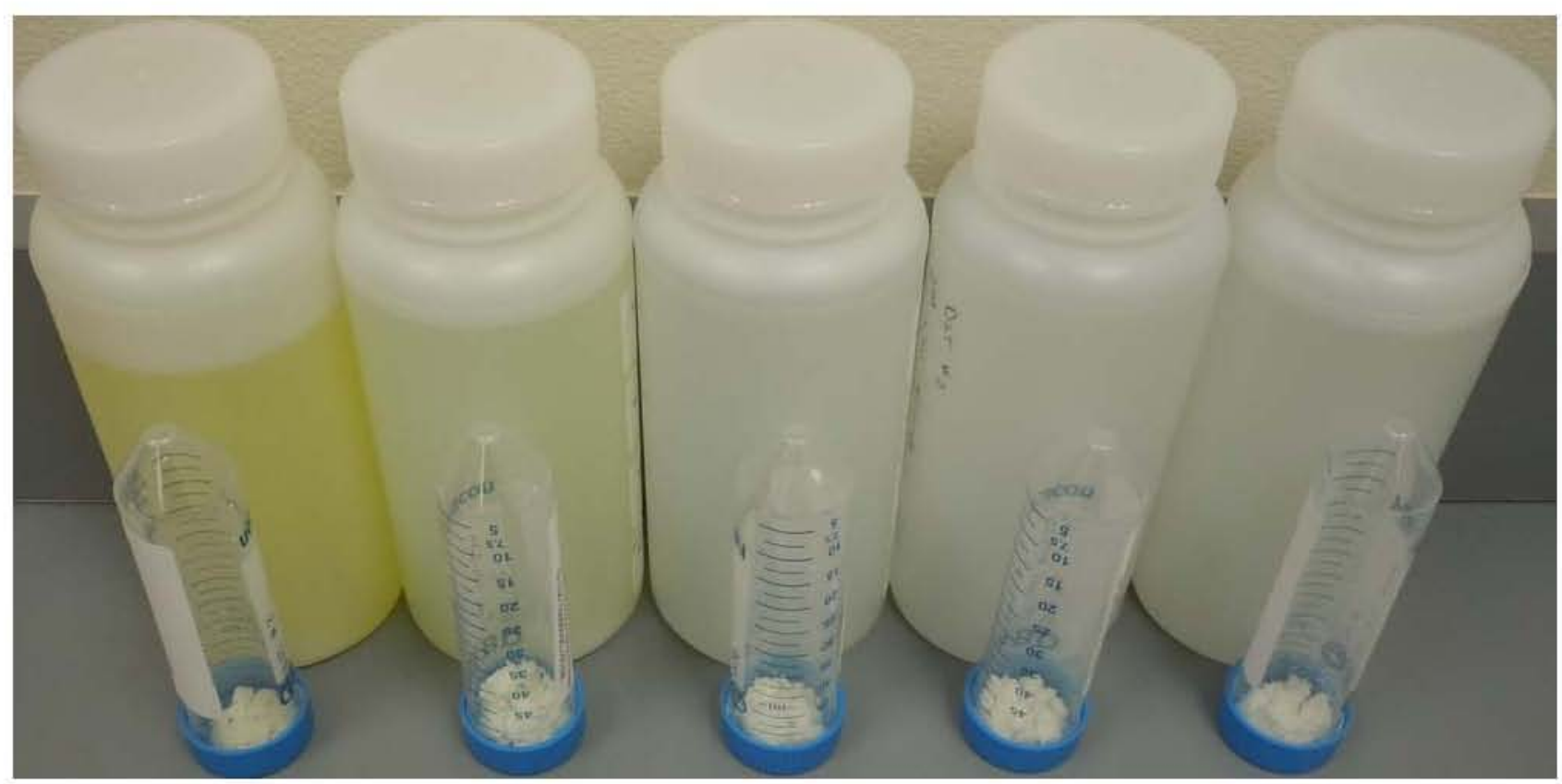

Figure 7. Filtrate and Cake Samples from DST \#2 Test.

(Left to Right: Mother Liquor and Initial Cake, 1st, 2nd, 3rd, 4th Wash Filtrates and Filter Cake Samples)

$\mathrm{XRD}$ analysis of the unwashed solids again indicates LiHT as the major species, with only trace unknowns (Figure 8). 


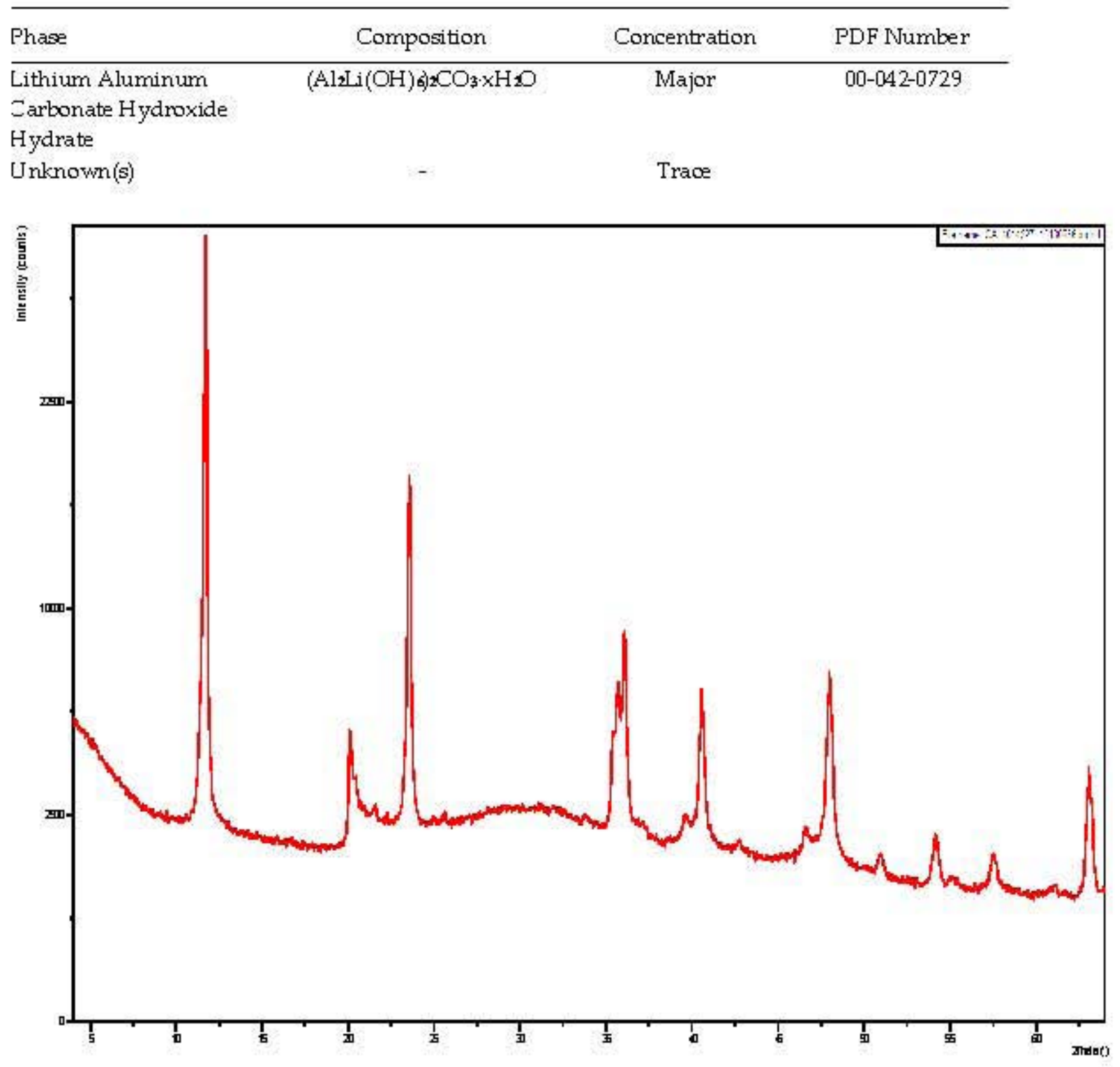

Figure 8. X-Ray Diffraction Pattern of Sample "DS T \#2 Initial Filter Cake" 10130236, with Degrees 29 Along with $\mathrm{X}$-Axis and Intensity (Counts) Along the $\mathrm{Y}$-Axis. 
XRD analysis of the filter cake was performed on the cake after the fourth wash. The XRD pattern for the washed cake is provided in Figure 9. No change in the spectrum was noted after washing.

\begin{tabular}{lccc}
\hline Phase & Composition & Concentration & PDF Number \\
\hline Lithium Aluminum & $\left(\mathrm{Al}_{2} \mathrm{Li}(\mathrm{OH})_{6}\right)_{2} \mathrm{CO}_{3} \cdot \mathrm{xH}_{2} \mathrm{O}$ & Major & $00-042-0729$ \\
Carbonate Hydroxide & & & \\
Hydrate & - & Trace & \\
Unknown(s) & - & & \\
\hline
\end{tabular}

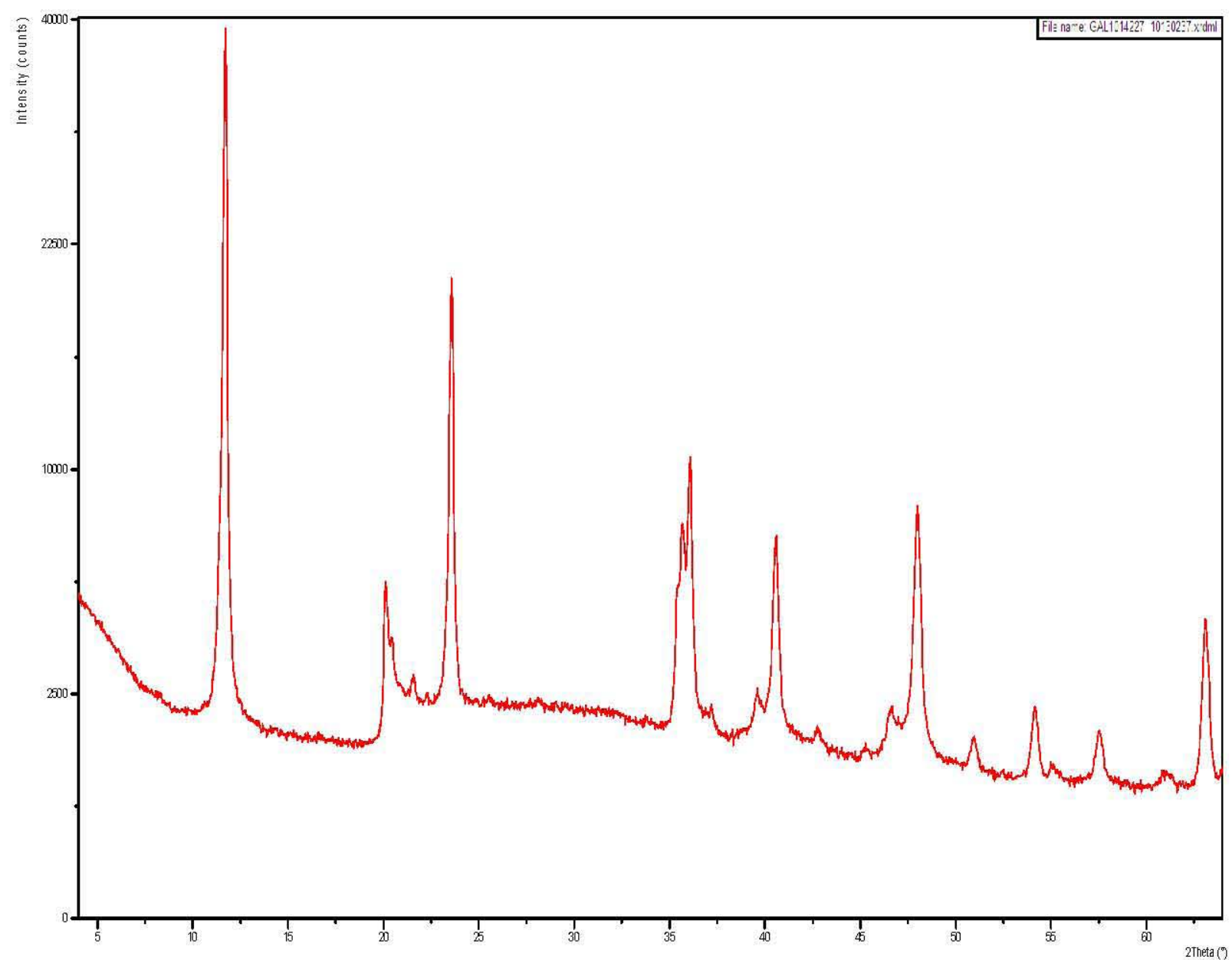

Figure 9. X-Ray Diffraction Pattern of Sample "DST \#2 $4^{\text {th }}$ Wash Filter Cake" 10130237, with Degrees $2 \theta$ Along with $\mathrm{X}$-Axis and Intensity (Counts) Along the $\mathrm{Y}$-Axis.

\subsubsection{DST TEST \#2 ALUMINUM REMOVAL}

The initial damp filter cake weighed 146.16 grams. A portion of the cake was dried at $60^{\circ} \mathrm{C}$ overnight and indicates that the cake was $50.3 \%$ solids. In addition, reactor scale totaled 
3.46 grams, dry basis. A small amount of precipitates formed in the mother liquor after the initial filtration and were determined to be the equivalent of 6.80 grams of dry cake in addition to the above. Net dry LiHT cake was 83.8 grams. The estimated gravimetric product yield is $86.4 \%$ based on a theoretical yield of 97.0 grams.

ICP-AES results show that for DST Test \#2 the initial LiHT filter cake retained 93.8 mole\% of the total aluminum in the initial product slurry. Slurry volume from the reactor was $985 \mathrm{ml}$. Initial filtrate (mother liquor) volume was $865 \mathrm{ml}$.

\subsubsection{DST TEST \#2 FILTER CAKE IMAGES}

Final washed cake samples were imaged with SEM (Figure 10). In these images, as in other tests, it is evident that the LiHT "sand rose" crystal shape has been broken down by the washing process. Crystallite edge joining that is the hallmark of the LiHT structure is not apparent. Instead, the platelets have agglomerated into large spherical particles composed of small shards and pieces roughly $1 \mu \mathrm{m} \mathrm{X} 2 \mu \mathrm{m}$, with thickness $50 \mathrm{~nm}$ to $100 \mathrm{~nm}$.
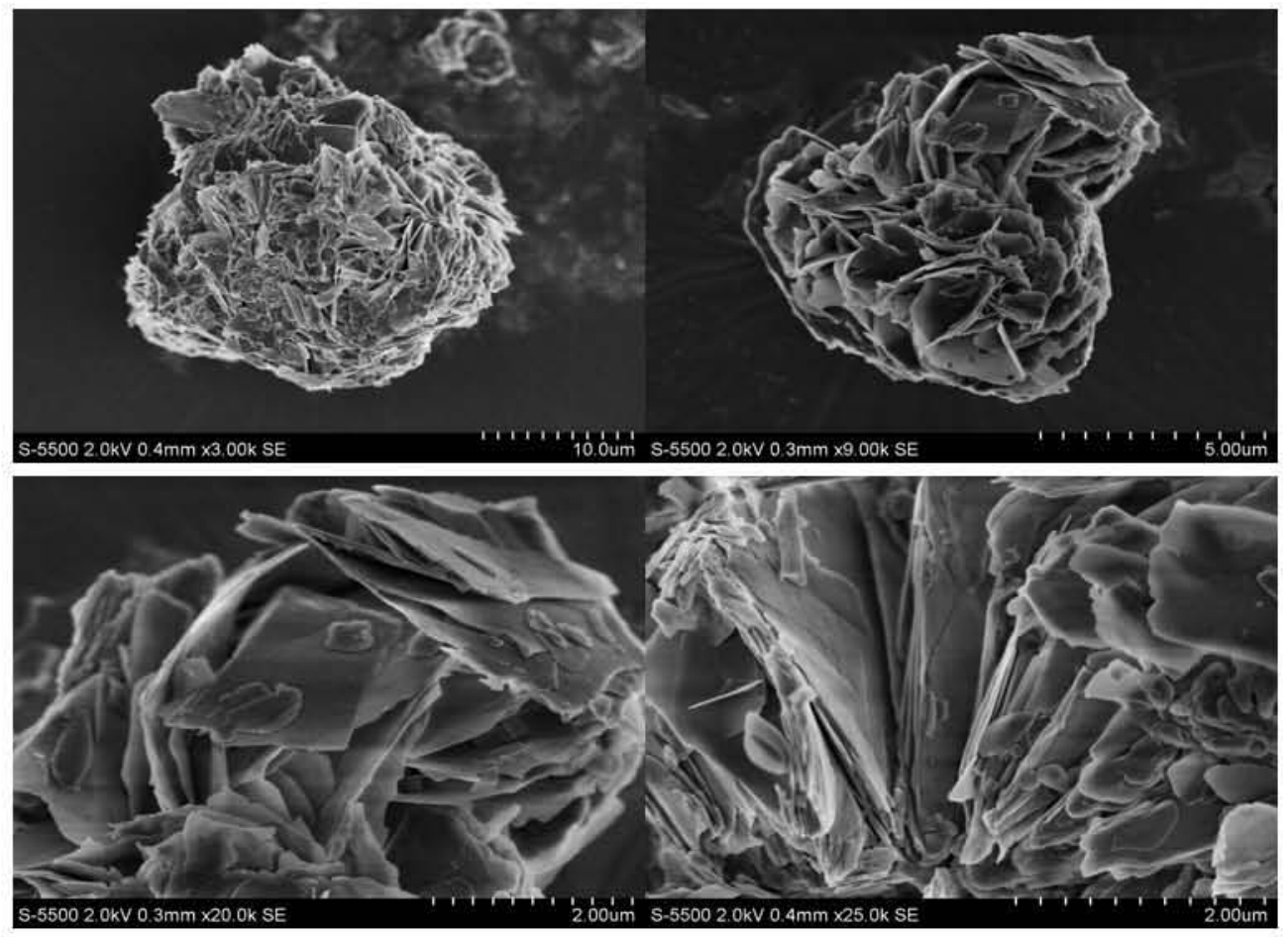

Figure 10. SEM Images of DST \#2 $4^{\text {th }}$ Wash.

The EDS spectrums (Figure 11) for the sample indicates that carbon, sodium, oxygen, aluminum, silicon, and phosphorous are the major constituents. Lithium is too small to be seen with Energy Dispersive Spectroscopy and is, therefore, not indicated in the spectrum. The presence of

phosphorous likely indicates what is believed to be the thermodynamically stable phosphate form of LiHT. The carbon peak indicates the carbonate form of LiHT is also present, as there is a stoichiometric deficit with respect to phosphorous. 


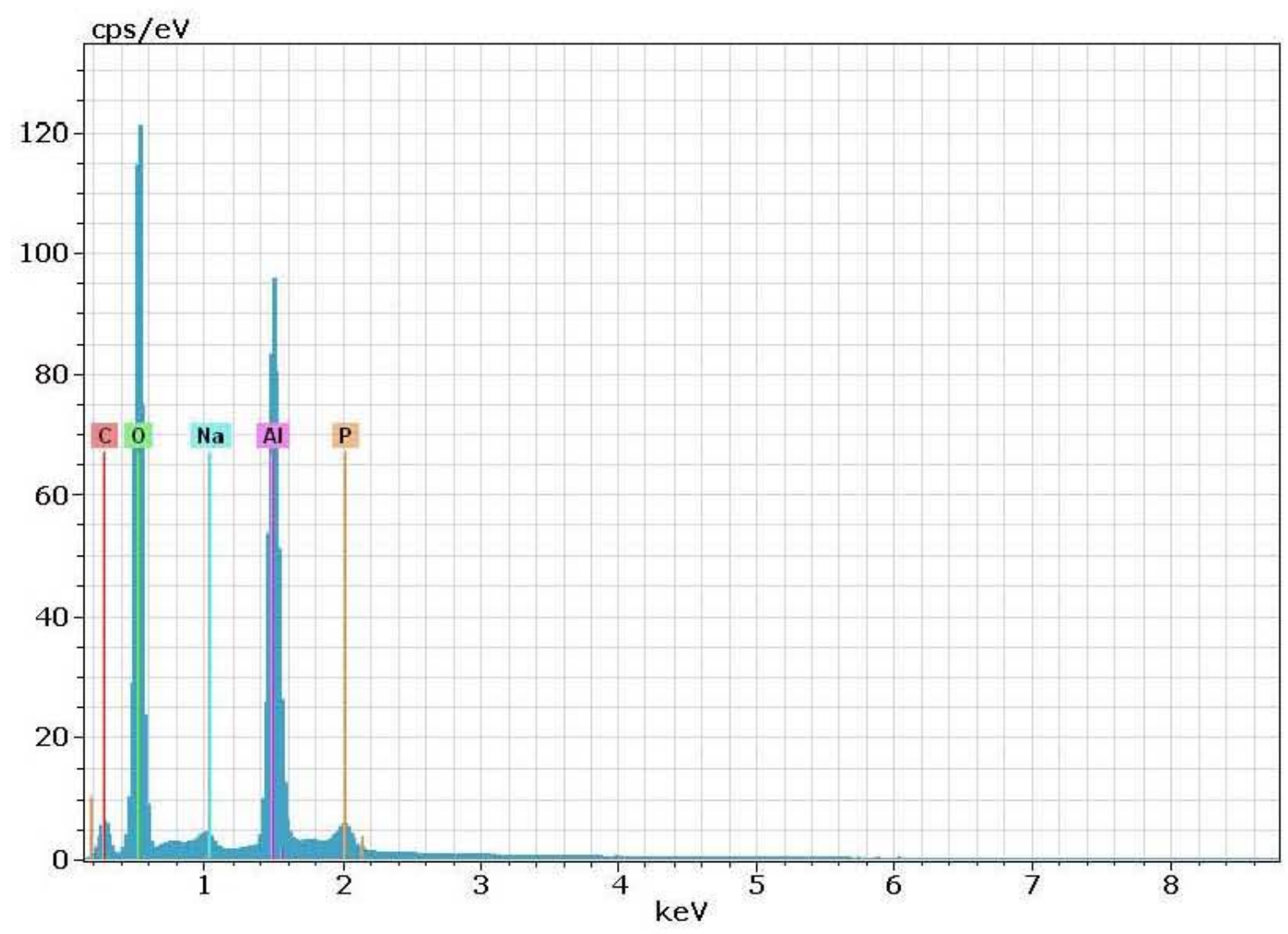

Figure 11. Characteristic EDS Spectrum of Sample "DST \#2 $4^{\text {th }}$ Wash Filter.

\subsubsection{DST TEST \#2 CESIUM DECONTAMINATION}

Decontamination of the LiHT product will be necessary to eventually dispose of the cake derived from Hanford wastes as LAW. In order to test the ability to decontaminate the filter cakes, the test runs included ${ }^{133} \mathrm{Cs}$ in the simulant composition.

From the ease with which the cesium was able to be washed from the product, the cesium appears not to be incorporated into the structure of the hydrotalcite.

DF is calculated by the following equation:

$$
\text { Cesium DF }=\frac{\text { Mass Cs in } / \text { Mass Al in }}{\text { Mass Cs out/Mass Al out }}
$$

Cesium DF is calculated for incremental (between washes) and cumulative cases and are presented in Table 2 . 
Table 2. DST \#2 Incremental and Cumulative Filter Cake Cesium DF.

\begin{tabular}{|c|c|c|c|c|}
\hline & Aluminum & Cesium & $\begin{array}{c}\text { Incremental } \\
\text { DF }\end{array}$ & $\begin{array}{c}\text { Cumulative } \\
\text { DF }\end{array}$ \\
\hline Simulant (mg) & 23796 & 2.04 & N/A & N/A \\
\hline $\begin{array}{c}\text { Initial Cake } \\
(\mathrm{mg} / \mathrm{kg})\end{array}$ & 197200 & 1.64 & & \\
\hline $\begin{array}{c}1^{\text {st }} \text { wash Cake } \\
(\mathrm{mg} / \mathrm{kg})\end{array}$ & 200400 & 0.079 & 21.1 & 217 \\
\hline $2^{\text {nd }} \begin{array}{c}\text { wash Cake } \\
(\mathrm{mg} / \mathrm{kg})\end{array}$ & 116200 & 0.0028 & 16.4 & 3558 \\
\hline $3^{\text {rd }} \begin{array}{c}\text { wash Cake } \\
(\mathrm{mg} / \mathrm{kg})\end{array}$ & 273300 & 0.0016 & 4.1 & 14644 \\
\hline $4^{\text {th }} \begin{array}{c}\text { wash Cake } \\
(\mathrm{mg} / \mathrm{kg})\end{array}$ & 268800 & 0.001 & 1.6 & 23044 \\
\hline
\end{tabular}

As can be seen from the data in the table above, the washing of the DST \#2 solids were very effective with respect to cesium. The reasons(s) for this remarkably high decontamination compared to the other tests are unknown; however, it is apparent that LiHT does not retain alkali metals and is easily decontaminated.

\subsubsection{DST TEST \#2 PARTICLE SIZE DISTRIBUTION}

Volume-based and number-based PSD curves and histograms are presented in Figures 12 and 13. The volume-based histogram indicates a bimodal distribution, with the primary population centered at $200 \mu \mathrm{m}$ to $300 \mu \mathrm{m}$, and a large fraction of particles at $10 \mu \mathrm{m}$ to $100 \mu \mathrm{m}$. The number-based distribution histogram indicate a large number of particles $\leq 1 \mu \mathrm{m}$, and are likely the cause of the increased filtration times as the washing progressed that is assumed to be caused by filter media fouling. This can be attributed to the effect of particle washing in the Teflon beaker with magnetic stir bar, as well as the effect of vacuum filtration, causing breakup of the LiHT crystal structure and re-agglomeration into large particles. 


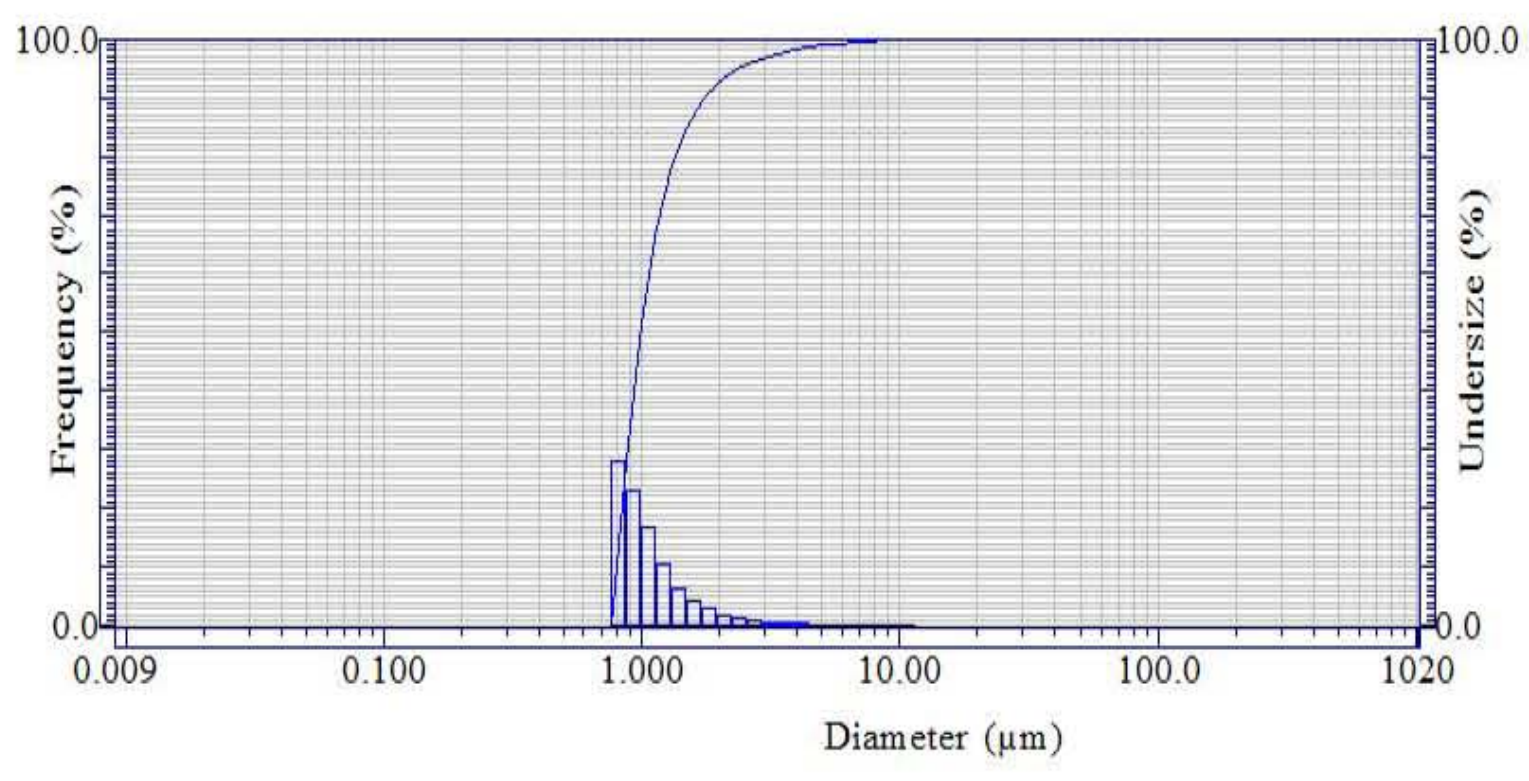

Figure 12. Sample "DST $\# 24^{\text {th }}$ Wash Filter" 10130237 Represented as a Number-Based Description.

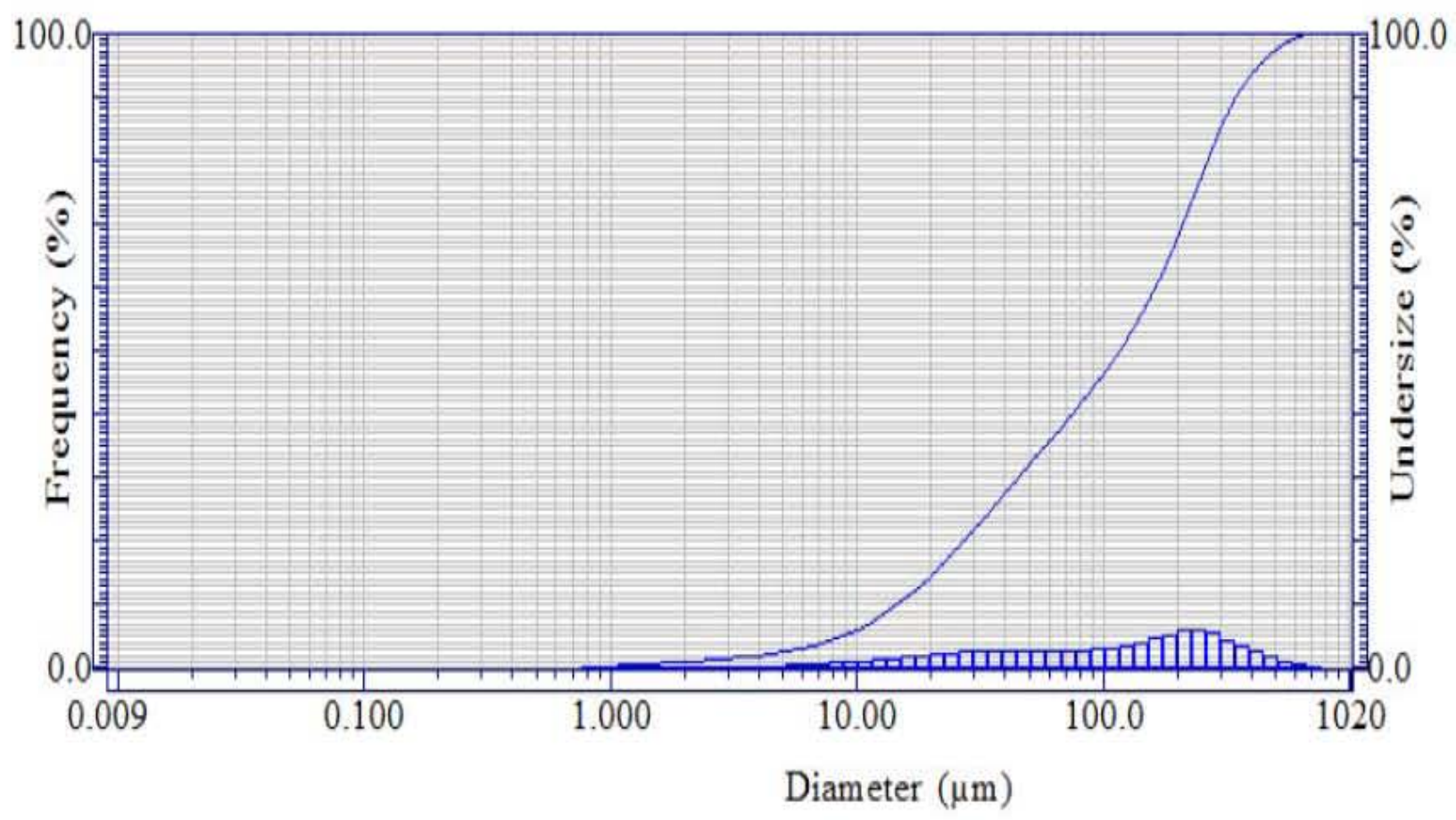

Figure 13. Sample "DST \#2 $4^{\text {th }}$ Wash Filter" 10130237 Represented as a Volume-Based Description. 


\subsubsection{DST TEST \#2 THERMO GRAVIMETRIC ANALYSIS}

The TGA analysis indicates approximately $57 \%$ LiHT solids (43\% free water). This compares with oven dried samples $\left(60^{\circ} \mathrm{C}\right)$ that indicate $50.3 \%$ solids.

The analysis further indicates that $31 \%$ solids remains after calcining at $1000^{\circ} \mathrm{C}$. Degradation of the LiHT structure is likely at this temperature, and the resulting mineral forms are assumed to be $\mathrm{Li}_{2} \mathrm{O}$ and $\mathrm{Al}_{2} \mathrm{O}_{3}$. In future work, this should be confirmed with XRD analysis.

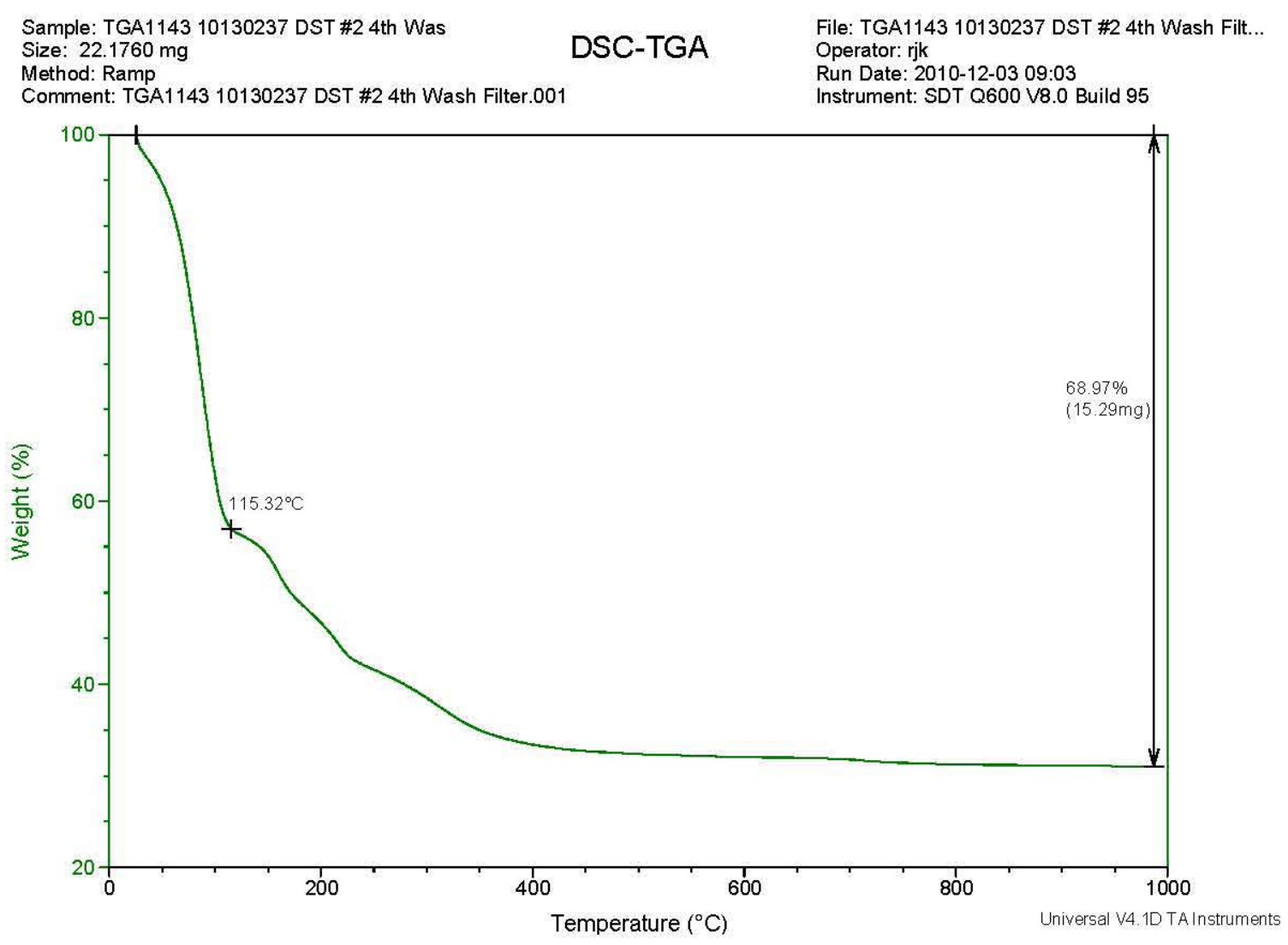

Figure 14. TGA Analysis of Sample "DST \#2 $4^{\text {th }}$ Wash Filter.

\subsection{DST TEST \#3}

Several modifications to the testing protocol were made to facilitate this test:

- Partial use of ANN for simulant make up instead of all gibbsite. To accomplish this, the nitrate source was changed from sodium nitrate to ANN. To balance the hydroxide, the total sodium hydroxide was increased stoichiometrically. For the purpose of improving 
the leaching process for the balance of the aluminum (from gibbsite), the entire quantity of $\mathrm{NaOH}$ was used, resulting in a caustic-to-gibbsite ratio of 3 to 1 , rather than 6 to 1 as in the original recipe. When the leachate was combined with the remainder of the chemicals in the simulant, the integrity of the original recipe was maintained. The DST \#3 recipe is shown in Table 3.

- Previous testing indicated that lithium phosphate (Li3PO4) preferentially precipitates over LiHT. In order to ensure that adequate lithium ion was present for complete conversion of aluminum to LiHT, the total lithium added was determined by first satisfying the stoichiometric aluminum demand, followed by the stoichiometric phosphate demand, and adding $10 \%$ excess.

- Rapid addition of the $10 \% \mathrm{LiOH}$ solution to determine the effect on particle size distribution and yield.

Table 3. DST Test \#3 Simulant Chemical Makeup (1-L Batch).

\begin{tabular}{|c|c|c|c|c|}
\hline Reagent & MW & $\begin{array}{c}\text { Target } \\
\text { Molarity }\end{array}$ & $\begin{array}{c}\text { Target Weight } \\
\text { or Volume }\end{array}$ & $\begin{array}{c}\text { Actual } \\
\text { Weight or } \\
\text { Volume }\end{array}$ \\
\hline $\mathrm{NaOH}$ & 40 & 3.51 & $140.26 \mathrm{~g}$ & 140.305 \\
\hline $\mathrm{Na}_{2} \mathrm{CO}_{3}$ & 106 & 0.06 & $6.86 \mathrm{~g}$ & 6.86 \\
\hline$\overline{\mathrm{Na}_{2} \mathrm{C}_{2} \mathrm{O}_{4}}$ & 134 & 0.003 & $0.38 \mathrm{~g}$ & 0.381 \\
\hline $\mathrm{KNO}_{3}$ & 101 & 0.19 & $19.68 \mathrm{~g}$ & 19.861 \\
\hline $\mathrm{NaNO}_{3}$ & 85 & $\mathrm{~N} / \mathrm{A}$ & $\mathrm{N} / \mathrm{A}$ & $\mathrm{N} / \mathrm{A}$ \\
\hline $\mathrm{NaNO}_{2}$ & 69 & 1.15 & $79.44 \mathrm{~g}$ & 79.441 \\
\hline $\mathrm{Na}_{2} \mathrm{SO}_{4}$ & 142 & 0.007 & $1.02 \mathrm{~g}$ & 1.021 \\
\hline $\begin{array}{c}\mathrm{Na}_{3} \mathrm{PO}_{4} . \\
12 \mathrm{H}_{2} \mathrm{O}\end{array}$ & 380.1 & 0.007 & $2.74 \mathrm{~g}$ & 2.81 \\
\hline $\mathrm{NaCl}$ & 58.4 & 0.12 & $6.73 \mathrm{~g}$ & 6.731 \\
\hline $\mathrm{NaF}$ & 42 & 0.011 & $0.46 \mathrm{~g}$ & 0.46 \\
\hline $\begin{array}{c}\mathrm{Na}_{2} \mathrm{Cr}_{2} \mathrm{O}_{7} \\
2 \mathrm{H}_{2} \mathrm{O} \\
\end{array}$ & 298 & 0.001 & $0.43 \mathrm{~g}$ & 0.432 \\
\hline $\begin{array}{c}\mathrm{NaC}_{2} \mathrm{H}_{3} \mathrm{O}_{2} \\
3 \mathrm{H}_{2} \mathrm{O} \\
\end{array}$ & 136.1 & 0.04 & $5.48 \mathrm{~g}$ & 5.481 \\
\hline $\mathrm{CsNO}_{3}$ solution & NA & $1.05 \mathrm{E}-05$ & $2.43 \mathrm{~mL}$ & $2.43 \mathrm{~mL}$ \\
\hline $\mathrm{Al}(\mathrm{OH})_{3}$ & 78 & 0.577 & $45.01 \mathrm{~g}$ & 45.02 \\
\hline $\mathrm{Al}\left(\mathrm{NO}_{3}\right)_{3} \cdot 9 \mathrm{H}_{2} \mathrm{O}$ & 375.1 & 0.305 & $114.41 \mathrm{~g}$ & 114.38 \\
\hline $\mathrm{LiOH} \cdot \mathrm{H}_{2} \mathrm{O}$ & 42 & 0.509 & $21.37 \mathrm{~g}$ & 21.371 \\
\hline
\end{tabular}


For the DST Test \#3, the leaching protocol employed for the reduced quantity of gibbsite was to add water, caustic, and gibbsite for extended, agitated leaching at $105^{\circ} \mathrm{C}$ in a Teflon beaker. Use of the Teflon beaker eliminated the silica that was produced from the caustic etching of the glass reactor during the leach process. This, in combination with the higher caustic-to-aluminum ratio produced a clear leachate in about 45 minutes.

$10 \mathrm{wt} \% \mathrm{LiOH}$ was rapidly added to the reactor over a 30 second period. LiHT formed with approximately 10 seconds after the start of the addition, and the precipitation was well underway at the end of the brief addition period. The white precipitate appeared to gradually form through a 4-hour ripening period. The test sequence for DST \#3 is indicated in the flowchart as shown in Figure 15.

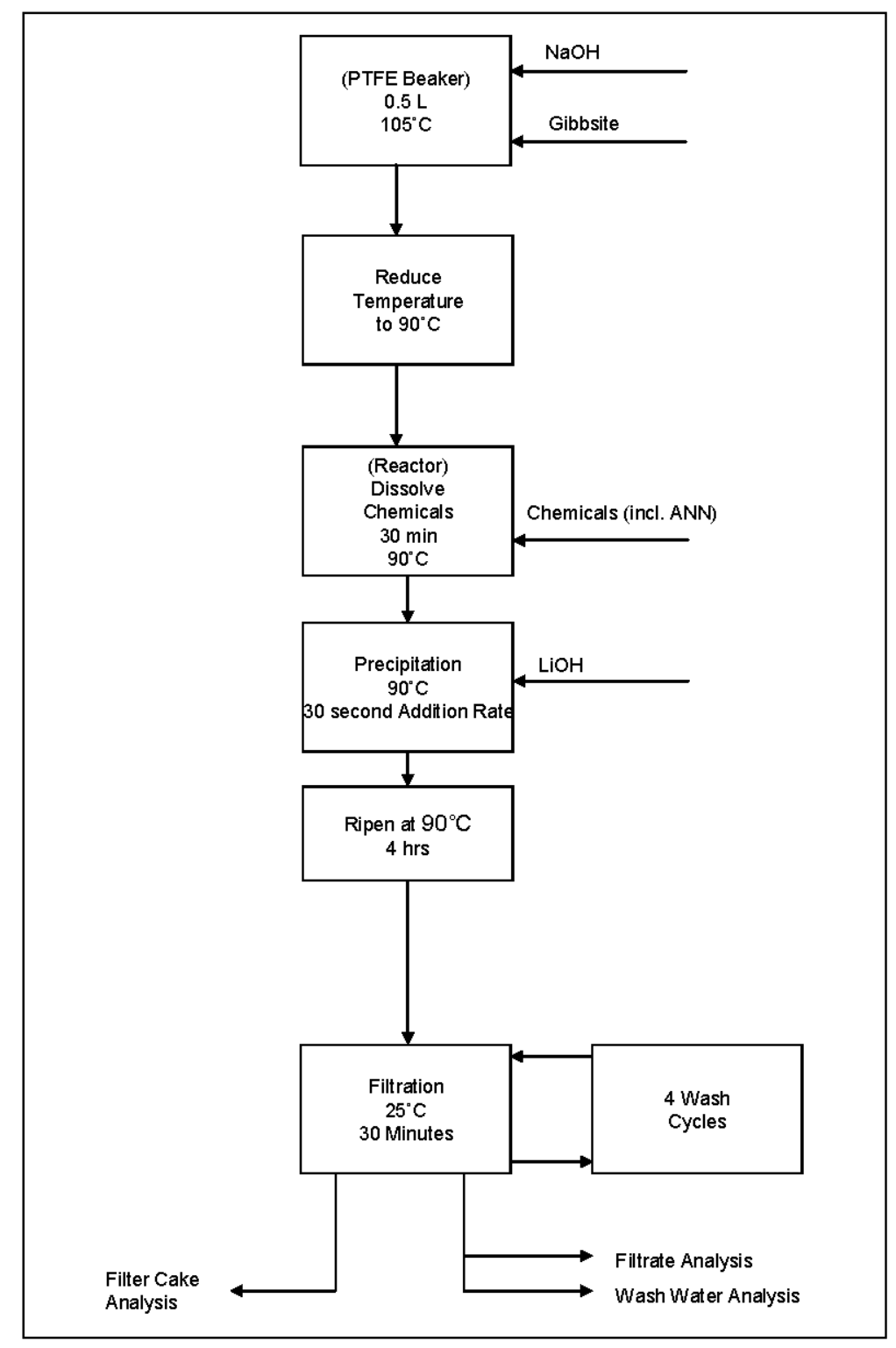

Figure 15. Experiment Flow Chart for DST Test \#3. 
Reactor contents were cooled to $50^{\circ} \mathrm{C}$ after the ripening period, and the product slurry ( $\left.1000 \mathrm{ml}\right)$ was filtered with a Büchner funnel and $0.45 \mu \mathrm{m}$ pore size PVDF filter media samples of the filtrate and solids were taken for analysis as noted in the Sample Schedule (Figure 3). The cake produced was an off-white color due to the presence of sodium dichromate and resembled soft clay. The product filtered readily and was easily removed from the Büchner funnel. All filtrates were clear and showed no signs of unfiltered solids.

The XRD spectrum of the washed solids compared to the reference spectrum indicates LiHT in the carbonate form as the major species, with only trace unknowns (Figure 16).

\begin{tabular}{lccc}
\hline Phase & Composition & Concentration & PDF Number \\
\hline Lithium Aluminum & $\left(\mathrm{Al}_{2} \mathrm{Li}(\mathrm{OH})_{6}\right)_{2} \mathrm{CO}_{3} \cdot \mathrm{xH}_{2} \mathrm{O}$ & Major & $00-042-0729$ \\
Carbonate Hydroxide & & & \\
Hydrate & - & Trace & \\
Unknown(s) & - & & \\
\hline
\end{tabular}

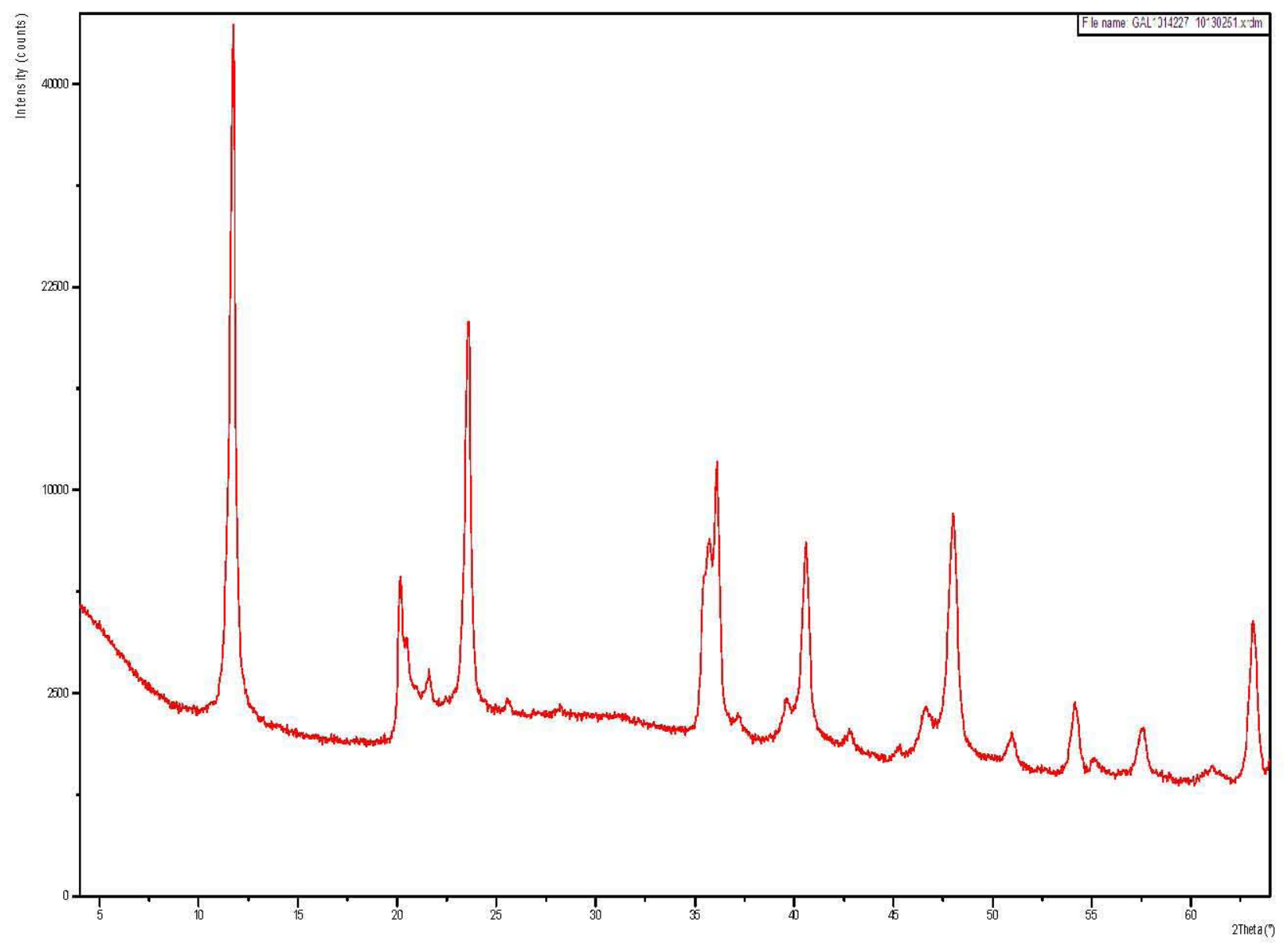

Figure 16. X-Ray Diffraction Pattern of Sample "DST $\# 34^{\text {th }}$ Wash Cake 10130251 with Degrees $2 \theta$ Along the $\mathrm{X}$-Axis and Intensity (Counts) Along the $\mathrm{Y}$-Axis. 


\subsubsection{DST TEST \#3 ALUMINUM REMOVAL}

The initial damp filter cake weighed 192.62 grams. A portion of the cake was dried at $60^{\circ} \mathrm{C}$ overnight and indicates that the cake was $60.01 \%$ solids. In addition, reactor scale totaled 5.34 grams, dry basis. A small amount of precipitates formed in the mother liquor after the initial filtration and was determined to be the equivalent of 11.63 grams of dry cake in addition to the above. Net dry LiHT cake was 132.6 grams.

ICP-AES results show that for DST Test \#3 the initial LiHT filter cake retained 96 mole\% of the total aluminum in the initial product slurry. Slurry volume from the reactor was $1000 \mathrm{ml}$. Initial filtrate (mother liquor) volume was $800 \mathrm{ml}$.

\subsubsection{DST TEST \#3 FILTER CAKE IMAGES}

Final washed cake samples were taken and imaged with SEM (Figure 17). In these images, as in other tests, it is evident that the LiHT "sand rose" crystal shape has been broken down by the washing process. Crystallite edge joining that is the hallmark of the LiHT structure is not apparent. Instead, the platelets have agglomerated into large spherical particles composed of small shards and pieces roughly $1 \mu \mathrm{m}$ X $2 \mu \mathrm{m}$, with thickness $50 \mathrm{~nm}$ to $100 \mathrm{~nm}$.
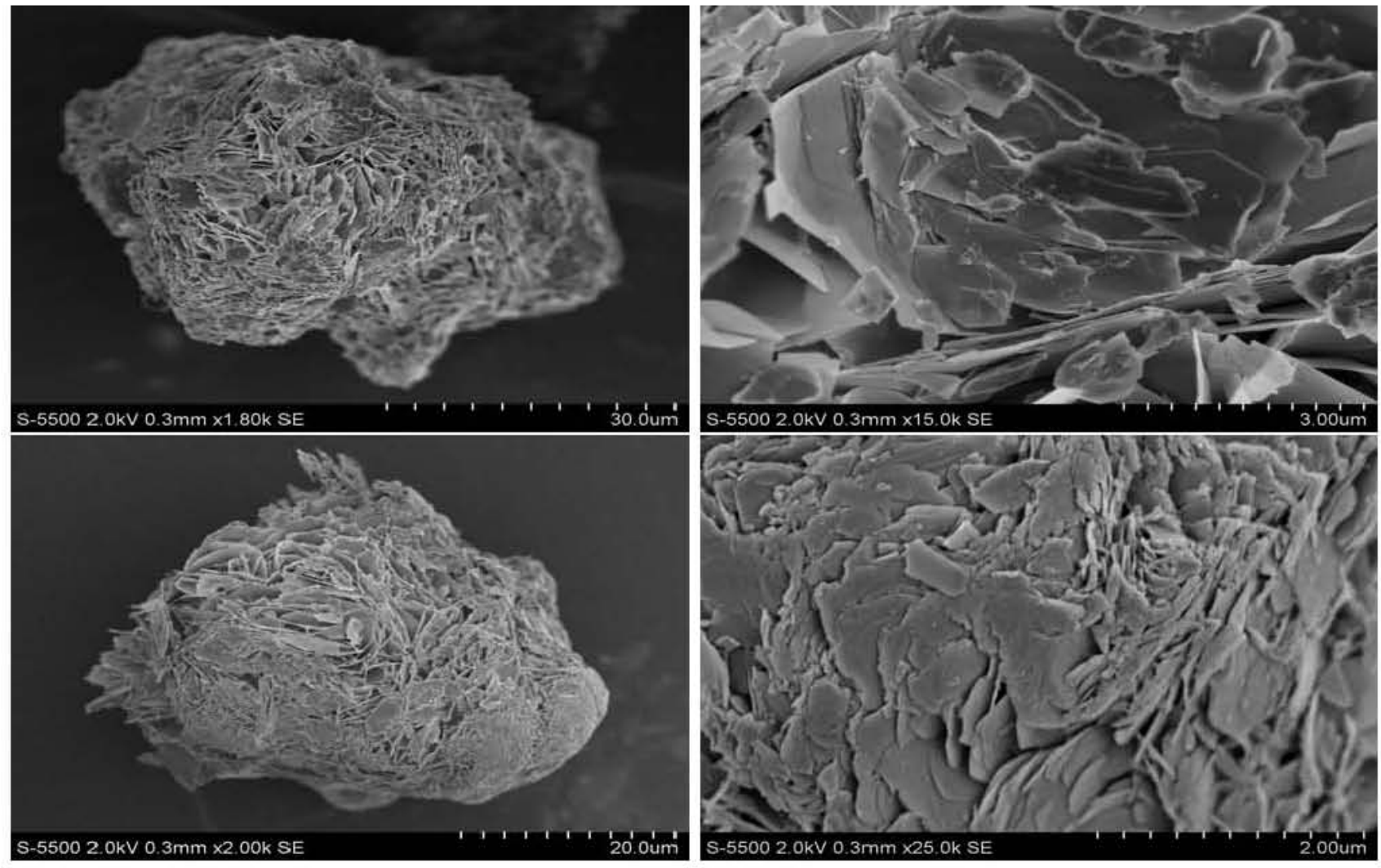

Figure 17. SEM Images of Sample "DST \#3 $4^{\text {th }}$ Wash Cake." 
The EDS spectrum for the sample indicates that carbon, sodium, oxygen, aluminum, silicon, and phosphorous are the major constituents (Figure 18). The silicon originates from the elevated temperature etching of the reactor vessel by sodium hydroxide, while the presence of phosphorous likely indicates the thermodynamically stable phosphate form of LiHT. The carbon peak indicates the carbonate form of LiHT is also present, as there is a stoichiometric deficit with respect to phosphorous.

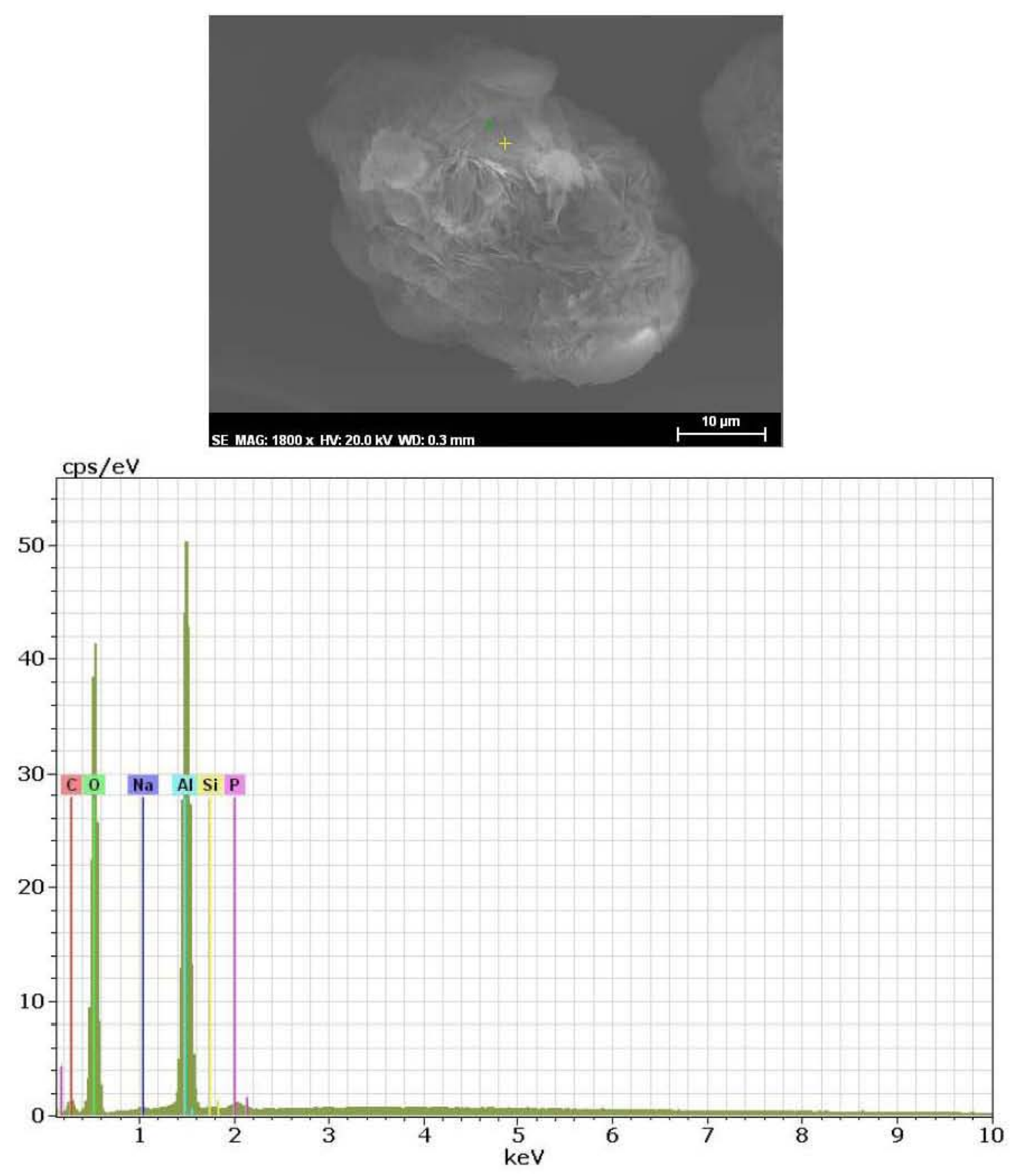

Figure 18. Characteristic EDS Spectrum of Sample "DST \#3 $4^{\text {th }}$ Wash Cake." 


\subsubsection{DST TEST \#3 CESIUM DECONTAMINATION}

Decontamination of the LiHT product will be necessary to eventually dispose of the cake derived from Hanford wastes as LAW. In order to test the ability to decontaminate the filter cakes, the test runs included ${ }^{133} \mathrm{Cs}$ in the simulant composition.

From the ease with which the cesium was able to be washed from the product, the cesium appears not to be incorporated into the structure of the hydrotalcite.

DF is calculated by the following equation:

$$
\text { Cesium DF }=\frac{\text { Mass Cs in } / \text { Mass } A 1 \text { in }}{\text { Mass Cs out } / \text { Mass } A 1 \text { out }}
$$

Cesium DFs are calculated for incremental (between washes) and cumulative cases, and are presented in Table 4.

Table 4. DST Test \#2 Filter Cake Cesium Decontamination

\begin{tabular}{|c|c|c|c|c|}
\hline & Aluminum & Cesium & $\begin{array}{c}\text { Incremental } \\
\text { DF }\end{array}$ & $\begin{array}{c}\text { Cumulative } \\
\text { DF }\end{array}$ \\
\hline Simulant $(\mathrm{mg})$ & 23796 & 1.40 & & \\
\hline $\begin{array}{c}\text { Initial Cake } \\
(\mathrm{mg} / \mathrm{kg})\end{array}$ & 196000 & 1.97 & 5.8 & 6 \\
\hline $\begin{array}{c}1^{\text {st }} \text { wash Cake } \\
(\mathrm{mg} / \mathrm{kg})\end{array}$ & 241800 & 0.296 & & 48 \\
\hline $2^{\text {nd }} \begin{array}{c}\text { wash Cake } \\
(\mathrm{mg} / \mathrm{kg})\end{array}$ & 202300 & 0.098 & & 121 \\
\hline $3^{\text {rd }} \begin{array}{c}\text { wash Cake } \\
(\mathrm{mg} / \mathrm{kg})\end{array}$ & 260600 & 0.071 & & 2.5 \\
\hline $4^{\text {th }} \begin{array}{c}\text { wash Cake } \\
(\mathrm{mg} / \mathrm{kg})\end{array}$ & 127800 & 0.027 & & 21.8 \\
\hline
\end{tabular}

As can be seen from the data in the table above, the washing of the DST \#3 solids was very effective with respect to cesium. It is apparent that LiHT does not retain alkali metals and is easily decontaminated.

\subsubsection{DST TEST \#3 PARTICLE SIZE DISTRIBUTION}

Volume-based and number-based PSD curves and histograms are presented in Figures 19 and 20. The volume based histogram indicates a normal distribution curve, centered around particle volume of $100 \mu \mathrm{m}$ to $200 \mu \mathrm{m}$. The number based distribution histogram indicates a large 
population of particles $\leq 1 \mu \mathrm{m}$ and are likely the cause of the increased filtration times as the washing progressed. This can be attributed to the effect of particle washing in the Teflon beaker with magnetic stir bar, as well as the effect of vacuum filtration, causing breakup of the LiHT crystal structure and re-agglomeration into large particles.

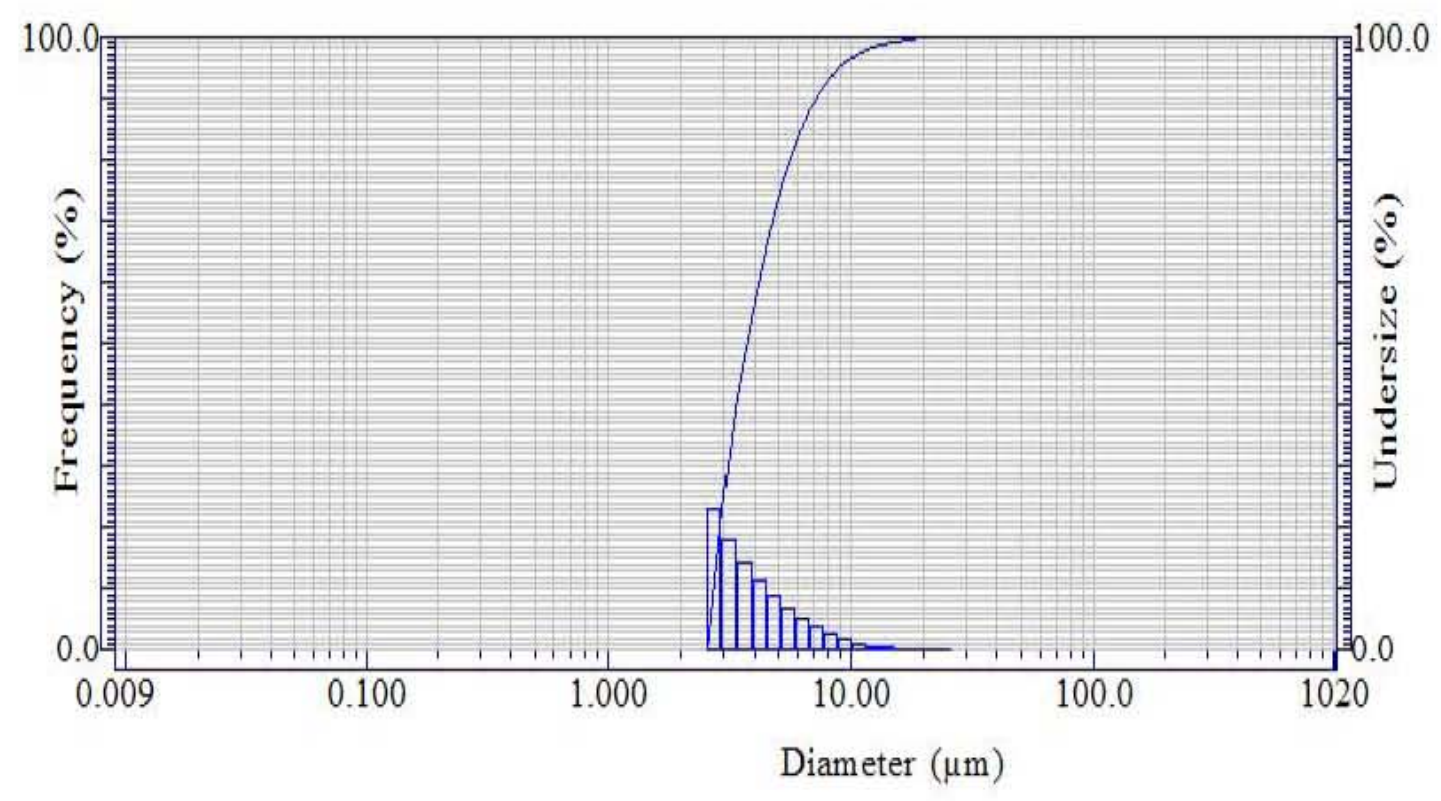

Figure 19. Sample "DST \#3 $4^{\text {th }}$ Wash Cake" Represented as a Number-Based Distribution.

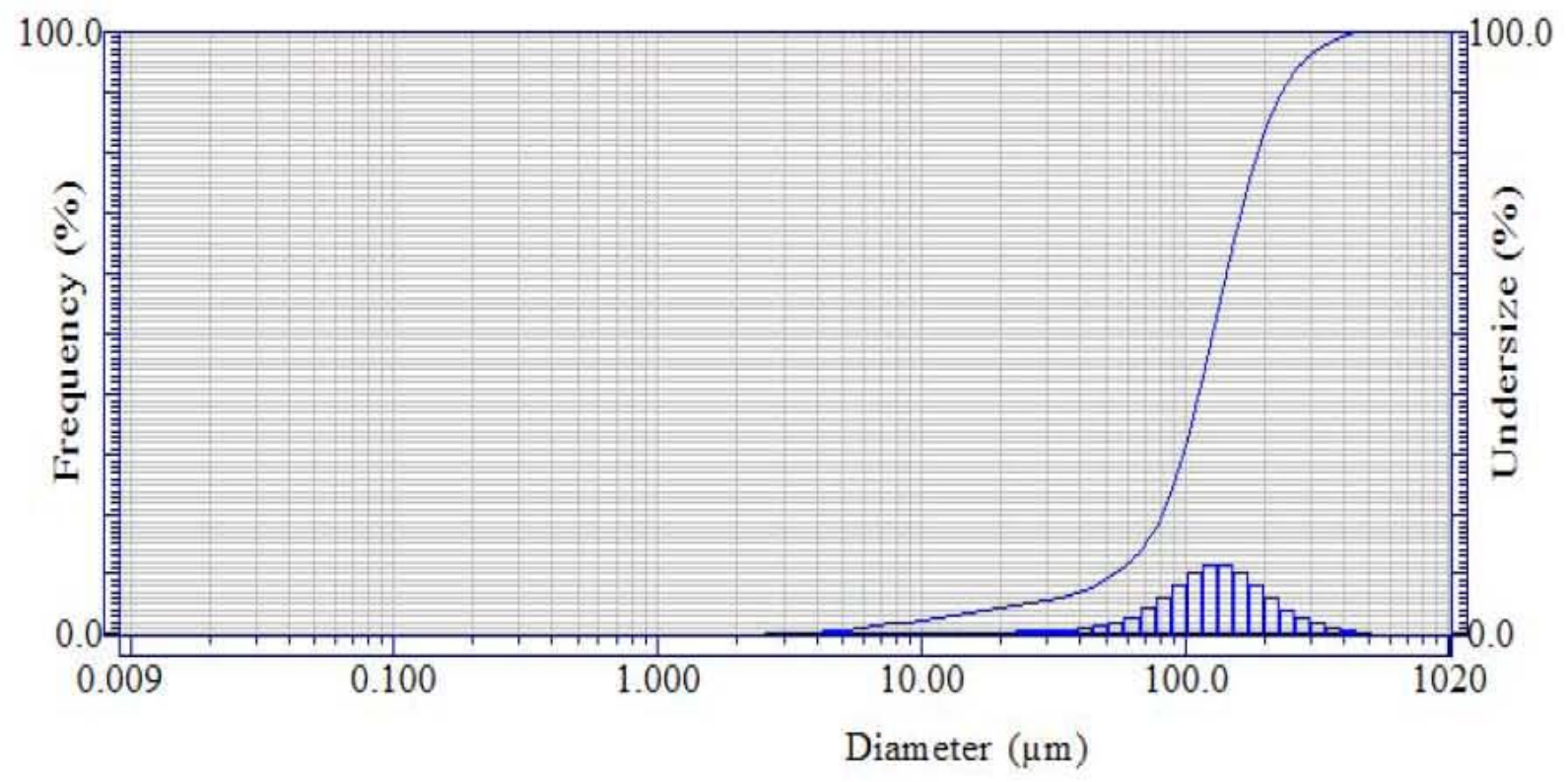

Figure 20. Sample "DST $\# 34^{\text {th }}$ Wash Cake" Represented as a Volume-Based Distribution. 


\subsubsection{DST TEST \#3 THERMO GRAVIMETRIC ANALYSIS}

The TGA analysis (Figure 21 ) indicates approximately $48 \%$ LiHT solids ( $52 \%$ free water). This compares with oven dried samples $\left(60^{\circ} \mathrm{C}\right)$ that indicate $60.01 \%$ solids. The discrepancy may be that decarboxylation or dehydration of the LiHT waters of hydration may take place at the TGA analysis conditions.

The analysis further indicates that $26.2 \%$ solids remains after calcining at $1000^{\circ} \mathrm{C}$. Degradation of the LiHT structure is likely at this temperature, and the resulting mineral forms are assumed to be $\mathrm{Li}_{2} \mathrm{O}$ and $\mathrm{Al}_{2} \mathrm{O}_{3}$. In future work, this should be confirmed with XRD analysis.

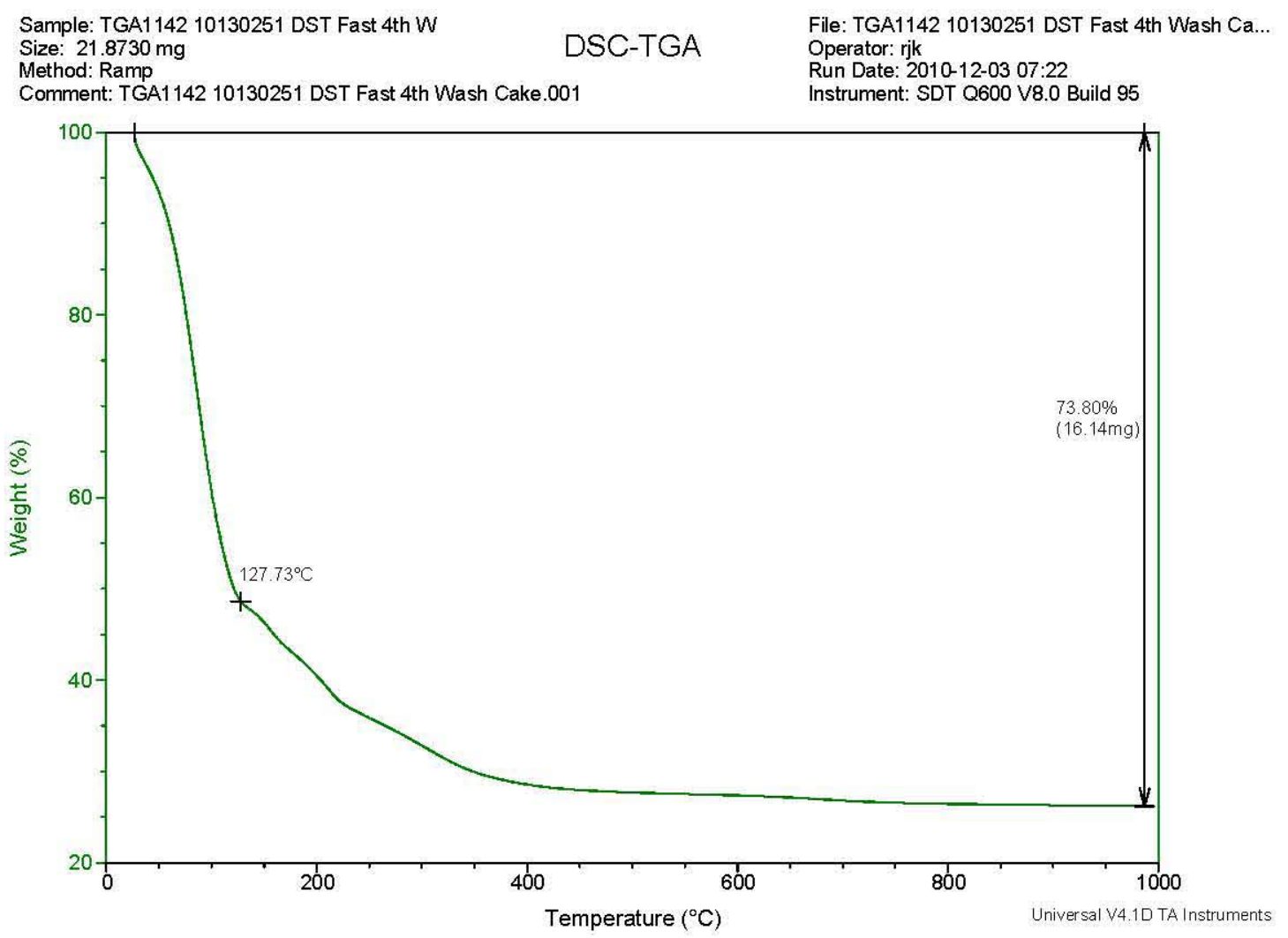

Figure 21. TGA Analysis of Sample "DST \#3 $4^{\text {th }}$ Wash Cake."

\subsection{SST TEST}

Several modifications to the testing protocol were made to facilitate this test:

- Full use of ANN for simulant make up instead of gibbsite. To accomplish this, the nitrate source was changed from sodium nitrate to ANN. To balance the hydroxide, the total sodium hydroxide was increased stoichiometrically. When the leachate was combined 
with the remainder of the chemicals in the simulant, the integrity of the original recipe was maintained. The SST recipe is shown in Table 5.

- Overnight ripening at ambient conditions to capture excess slow forming precipitates as noted in DST Test \#1.

- Previous testing indicated that lithium phosphate $\left(\mathrm{Li}_{3} \mathrm{PO}_{4}\right)$ preferentially precipitates over LiHT. In order to ensure that adequate lithium ion was present for complete conversion of aluminum to LiHT, the total lithium to be added was determined by first satisfying the stoichiometric aluminum demand, followed by the stoichiometric phosphate demand, and finally adding $10 \%$ excess.

- The SST Test LiOH was added over a one hour period.

Table 5. SST Test Simulant Chemical Makeup (2 Liter Batch).

\begin{tabular}{|c|c|c|c|c|}
\hline Reagent & MW & Target Molarity & $\begin{array}{c}\text { Target Weight or } \\
\text { Volume }^{(1)}\end{array}$ & $\begin{array}{l}\text { Actual Weight } \\
\text { or Volume }^{(1)}\end{array}$ \\
\hline $\mathrm{NaOH}$ & 40 & 2.57 & $205.4 \mathrm{~g}$ & 205.41 \\
\hline $\mathrm{Na}_{2} \mathrm{CO}_{3}$ & 106 & 0.34 & $71.26 \mathrm{~g}$ & 71.26 \\
\hline $\mathrm{Na}_{2} \mathrm{C}_{2} \mathrm{O}_{4}$ & 134 & 0.01 & $1.56 \mathrm{~g}$ & 1.561 \\
\hline $\mathrm{KNO}_{3}$ & 101 & 0.02 & $3.54 \mathrm{~g}$ & 3.541 \\
\hline $\mathrm{NaNO}_{3}$ & 85 & 0.93 & $158.18 \mathrm{~g}$ & 158.18 \\
\hline $\mathrm{NaNO}_{2}$ & 69 & 0.48 & $65.82 \mathrm{~g}$ & 65.82 \\
\hline $\mathrm{Na}_{2} \mathrm{SO}_{4}$ & 142 & 0.08 & $23.10 \mathrm{~g}$ & 23.1 \\
\hline $\mathrm{Na}_{3} \mathrm{PO}_{4} \cdot 12 \mathrm{H}_{2} \mathrm{O}$ & 380.1 & 0.02 & $17.74 \mathrm{~g}$ & 17.74 \\
\hline $\mathrm{NaCl}$ & 58.4 & 0.05 & $5.46 \mathrm{~g}$ & $\overline{5.461}$ \\
\hline $\mathrm{NaF}$ & 42 & 0.01 & $0.72 \mathrm{~g}$ & 0.721 \\
\hline $\mathrm{Na}_{2} \mathrm{Cr}_{2} \mathrm{O}_{7} \cdot 2 \mathrm{H}_{2} \mathrm{O}$ & 298 & 0.02 & $13.88 \mathrm{~g}$ & 13.881 \\
\hline $\mathrm{CsNO}_{3}$ solution & $\mathrm{N} / \mathrm{A}$ & 1.05E-05 & $4.86 \mathrm{~mL}$ & 4.86 \\
\hline $\mathrm{Al}(\mathrm{OH})_{3}$ & 78 & $\mathrm{~N} / \mathrm{A}$ & $\mathrm{N} / \mathrm{A}$ & $\mathrm{N} / \mathrm{A}$ \\
\hline $\mathrm{Al}\left(\mathrm{NO}_{3}\right)_{3} \cdot 9 \mathrm{H}_{2} \mathrm{O}$ & 375.1 & 0.440 & $331.19 \mathrm{~g}$ & $321.9^{(2)}$ \\
\hline $\mathrm{LiOH} \cdot \mathrm{H}_{2} \mathrm{O}$ & 42 & 0.320 & $26.865 \mathrm{~g}^{(3)}$ & 26.865 \\
\hline
\end{tabular}

"Mass for 2 liter batch, rather than 1 liter batch

${ }^{(2)}$ Available ANN supply was slightly less than the amount required

${ }^{(3)} \mathrm{LiOH}$ was added at $12.4 \%$ excess in the SST run, due to a slight shortage of ANN during the simulant make up

In order to produce enough filter cake for the extensive number of analyses requiring a sample, a two-liter batch of SST simulant was formulated.

As the $10 \mathrm{wt} \% \mathrm{LiOH}$ was dripped slowly into the reactor (one hour addition), a precipitate formed rapidly at the droplet location. The same phenomenon was observed in the DST tests, but to a much smaller degree. Since the SST simulant contained much higher levels of phosphate, this may indicate the rapid formation of lithium phosphate. The white precipitate 
appeared to form continually during the 4-hour ripening period (Figure 22). Reactor contents were cooled to $50^{\circ} \mathrm{C}$ after the ripening period, and the product slurry $(2205 \mathrm{ml})$ was filtered using a Büchner funnel and $0.45 \mu \mathrm{m}$ PVDF filter medium. Total damp, unwashed cake produced during the initial filtration was 145.58 grams. A dried sample of the filter cake indicates that the cake was $42.3 \%$ solids. Filtrate (mother liquor) volume was $2110 \mathrm{ml}$. Samples of the filtrate and solids were taken for analysis, as noted in the Sample Schedule (Figure 3). The cake produced was a yellow color due to the presence of sodium dichromate and resembled soft clay. The product filtered readily and was easily removed from the Büchner funnel. All filtrates were clear and showed no signs of unfiltered solids. $10 \mathrm{wt} \% \mathrm{LiOH}$ was added to the reactor at a predetermined rate that would ensure a one-hour addition period.

The test sequence for the SST Test is indicated in the flowchart as shown in Figure 22.

Time lapse photographs of the SST simulant reaction progression are presented in Figure 23. The SST LiHT reaction is characterized by the rapid onset of precipitation as the LiOH droplets contacted the surface of the simulant. This may indicate the rapid precipitation of lithium phosphate. Using the black thermocouple as a reference, the accumulation of solids as the reaction progresses can be seen. Scaling on the reactor walls is responsible for some of the indicated lack of clarity, but reaction precipitates are the primary cause.

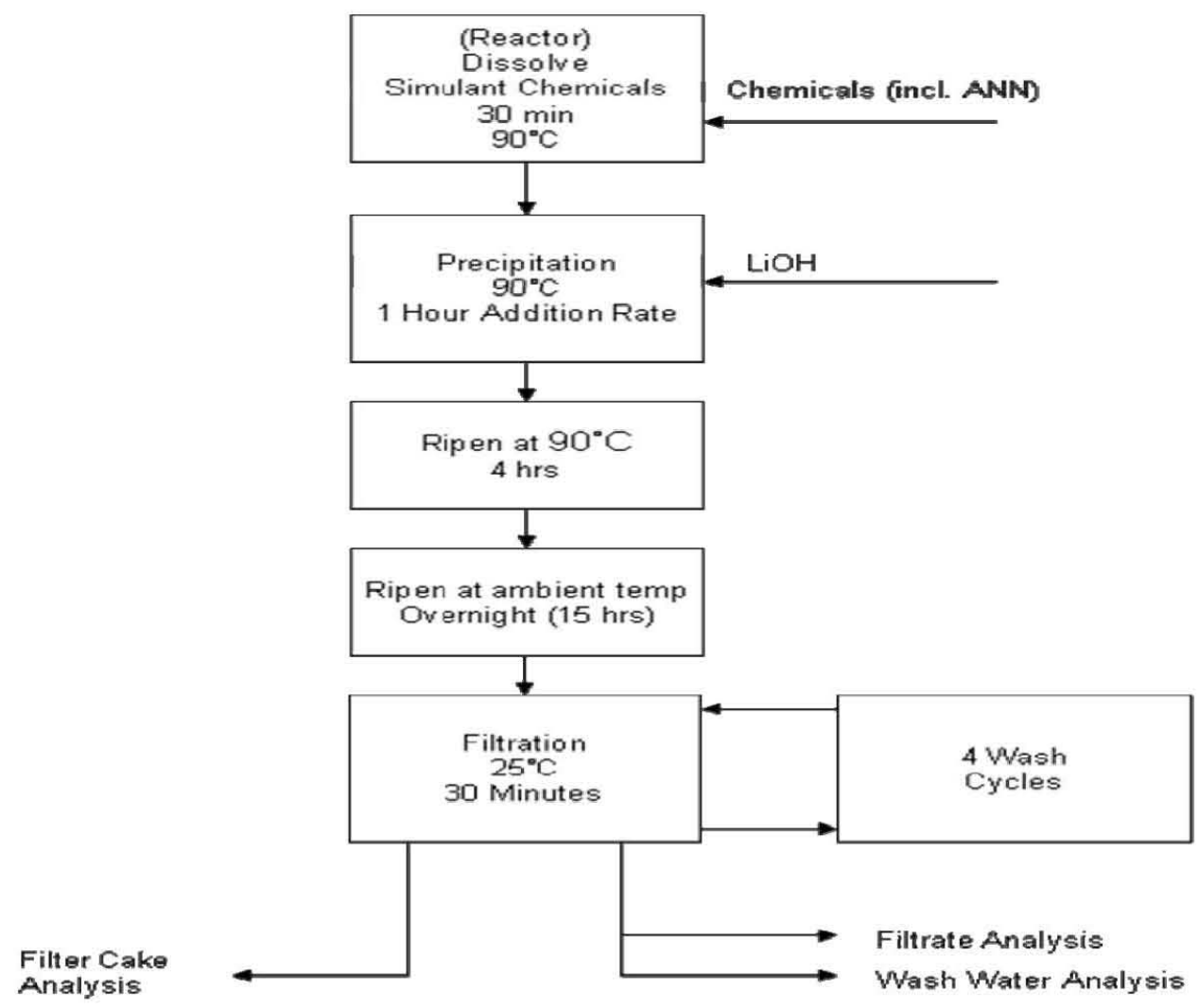

Figure 22. Flow Chart for SST Test. 
RPP-RPT-48380, Rev. 0

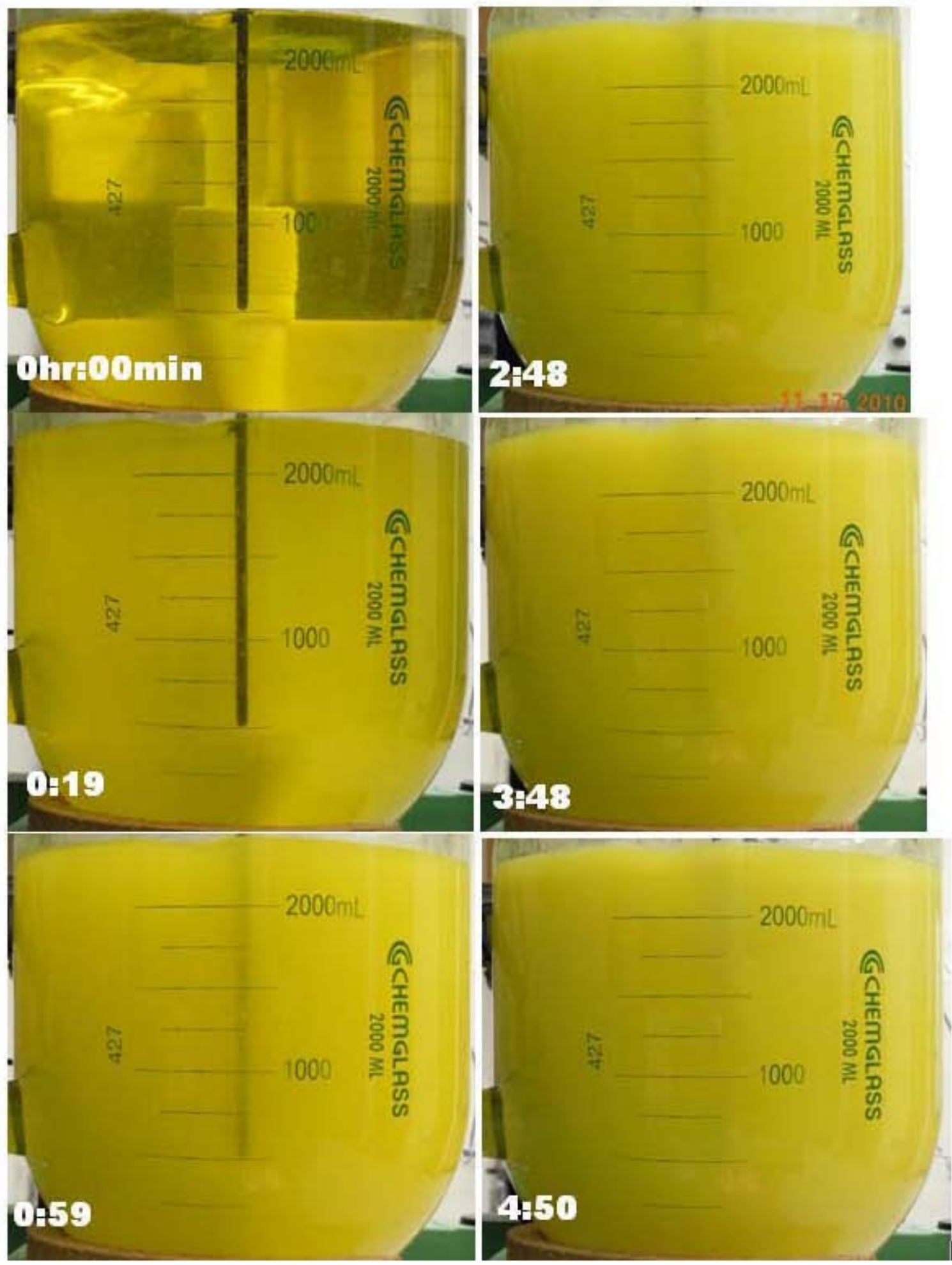

Figure 23. SST Reaction Progression and Elap sed Tim efrom Start of Lithium Hydroxide Addition. 


\subsubsection{SST TEST SOLIDS WASHING}

The same solids washing steps were followed as in the previous runs. Samples of both the filtrate and the filter cake were taken for analysis after each filtration step (Figure 24). Appendix B contains the analysis results. The final washed cake was a white, fluffy, highly crystalline material. The third and fourth filtrates were water clear, indicating the majority of residual dichromate was washed out in the first two washes. This is verified by analytical results, showing the dichromate readily washes from the cake.

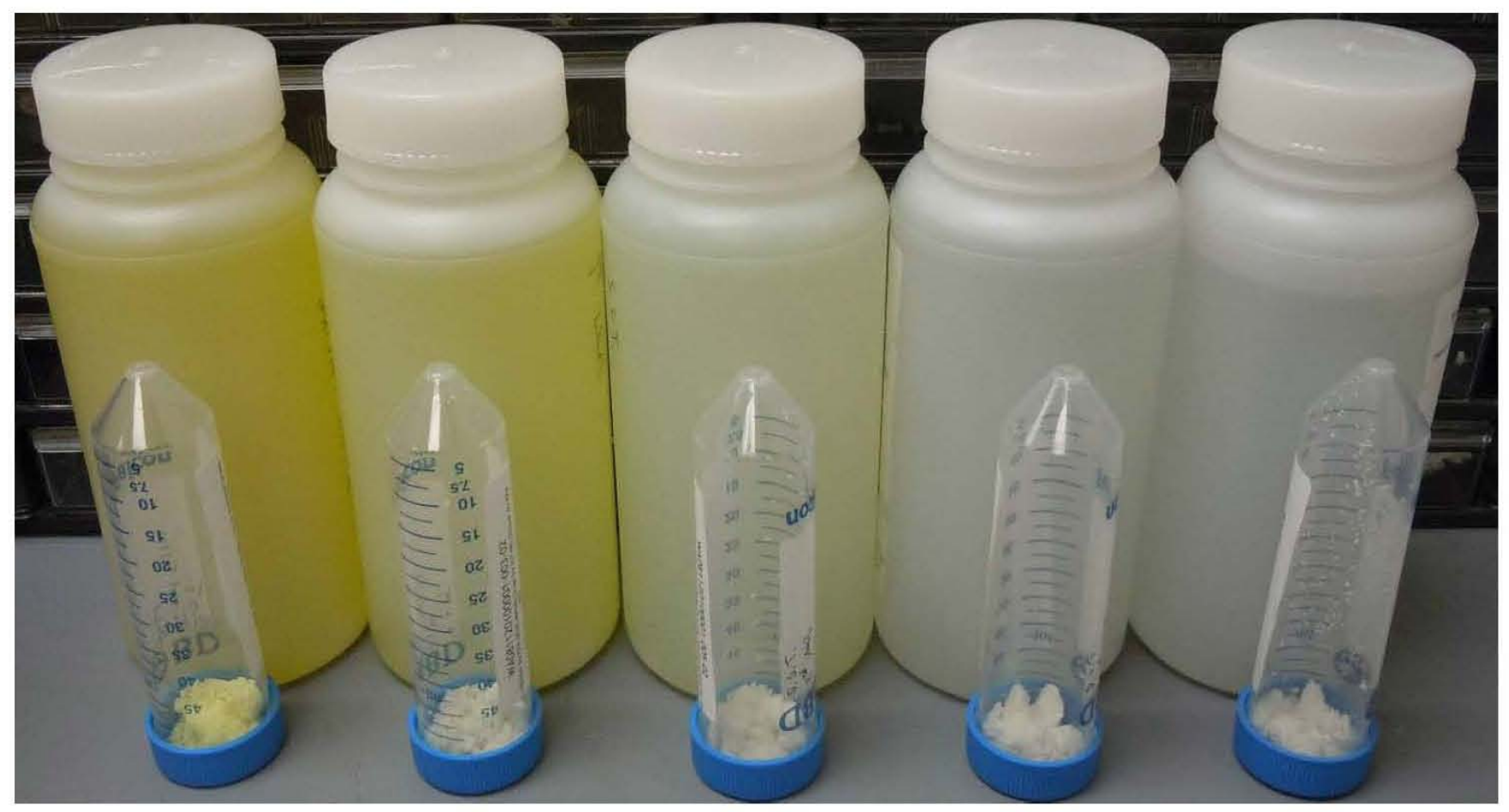

Figure 24. Filtrate and Cake Samples from SST Test.

(Left to right: Mother Liquor and initial cake, $1^{\text {st }}, 2^{\text {nd }}, 3^{\text {rd }}, 4^{\text {th }}$ wash filtrates and filter cake samples.)

XRD analysis of the unwashed cake indicates LiHT as the major species, with sodium carbonate as a minor component. Lithium phosphate is noted as a possible match to one of the unknown phases (Figure 25). 
RPP-RPT-48380, Rev. 0

\begin{tabular}{lccc}
\hline Phase & Composition & Concentration & PDF Number \\
\hline $\begin{array}{l}\text { Lithium Aluminum } \\
\text { Carbonate Hydroxide }\end{array}$ & $\left(\mathrm{Al}_{2} \mathrm{Li}(\mathrm{OH})_{6}\right)_{2} \mathrm{CO}_{3} \times \mathrm{xH}_{2} \mathrm{O}$ & Major & $00-042-0729$ \\
$\begin{array}{l}\text { Hydrate } \\
\text { Sodium Carbonate }\end{array}$ & & \\
Unknown $(\mathrm{s})^{*}$ & $\mathrm{Na}_{2} \mathrm{CO}_{3}$ & $\begin{array}{c}\text { Minor } \\
\text { Trace }\end{array}$ & $00-025-0815$ \\
\hline
\end{tabular}

"Lithium Phosphate ( $\mathrm{Li}_{3} \mathrm{PO}_{4}$ ) (01-072-1963) is a possible match to one of the unknown phases. Further testing is necessary to confirm the phase.

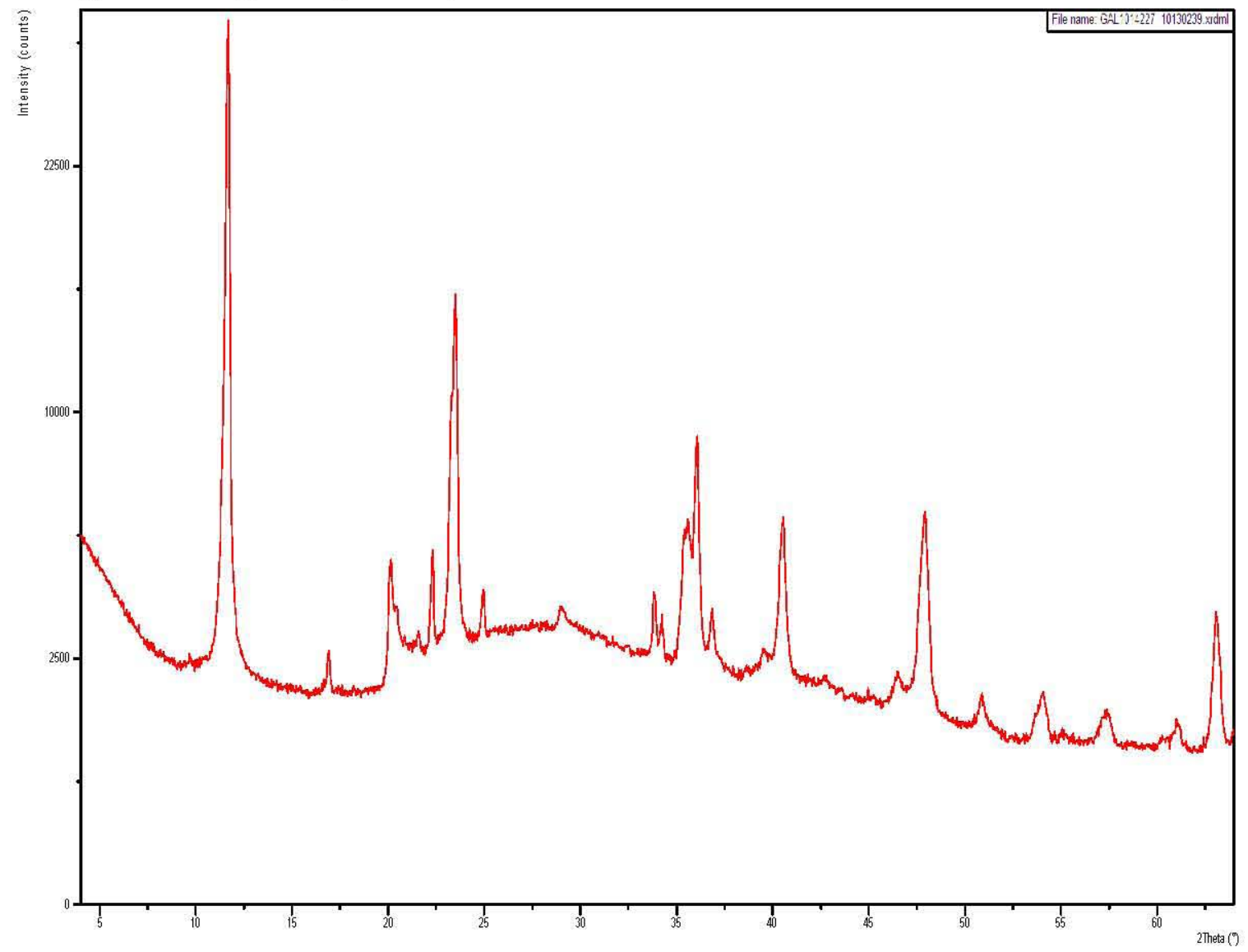

Figure 25. X-Ray Diffraction Pattern of Sample "SST $4^{\text {th }}$ Wash Filter Cake" with Degrees $2 \theta$ Along the $\mathrm{X}$-Axis and Intensity (Counts) Along the Y-Axis.

\subsubsection{SST TEST ALUMINUM REMOVAL}

The initial damp filter cake weighed 145.58 grams. A portion of the cake was dried at $60^{\circ} \mathrm{C}$ overnight and indicates that the cake was $42.3 \%$ solids. A quantity of precipitates formed in the mother liquor after the initial filtration. This additional dried filter cake from continuing precipitation brought the total quantity of dried, unwashed cake to 123.1 grams. 
ICP-AES results show that for the SST Test the initial LiHT filter cake retained $91.3 \mathrm{~mole} \%$ of the total aluminum in the initial product slurry. Slurry volume from the reactor was $2205 \mathrm{ml}$. Initial filtrate (mother liquor) volume was $2110 \mathrm{ml}$.

\subsubsection{SST TEST FILTER CAKE IMAGES}

Final washed cake samples were taken and imaged with SEM (Figure 26). In these images, as in other tests, it is evident that the LiHT "sand rose" crystal shape has been broken down by the washing process. Crystallite edge joining that is the hallmark of the LiHT structure is not apparent. Instead, the platelets have agglomerated into large spherical particles $(100-500 \mu \mathrm{m})$, composed of small shards and pieces roughly $1 \mu \mathrm{m}$ X $2 \mu \mathrm{m}$, with thickness $50 \mathrm{~nm}$ to $100 \mathrm{~nm}$. The EDS spectrum (Figure 27) for the sample indicates that carbon, sodium, oxygen, aluminum, and phosphorous are the major constituents. The presence of phosphorous indicates the thermodynamically stable phosphate form of LiHT. The carbon peak indicates the carbonate form of LiHT is also present, as there is a stoichiometric deficit with respect to phosphorous.

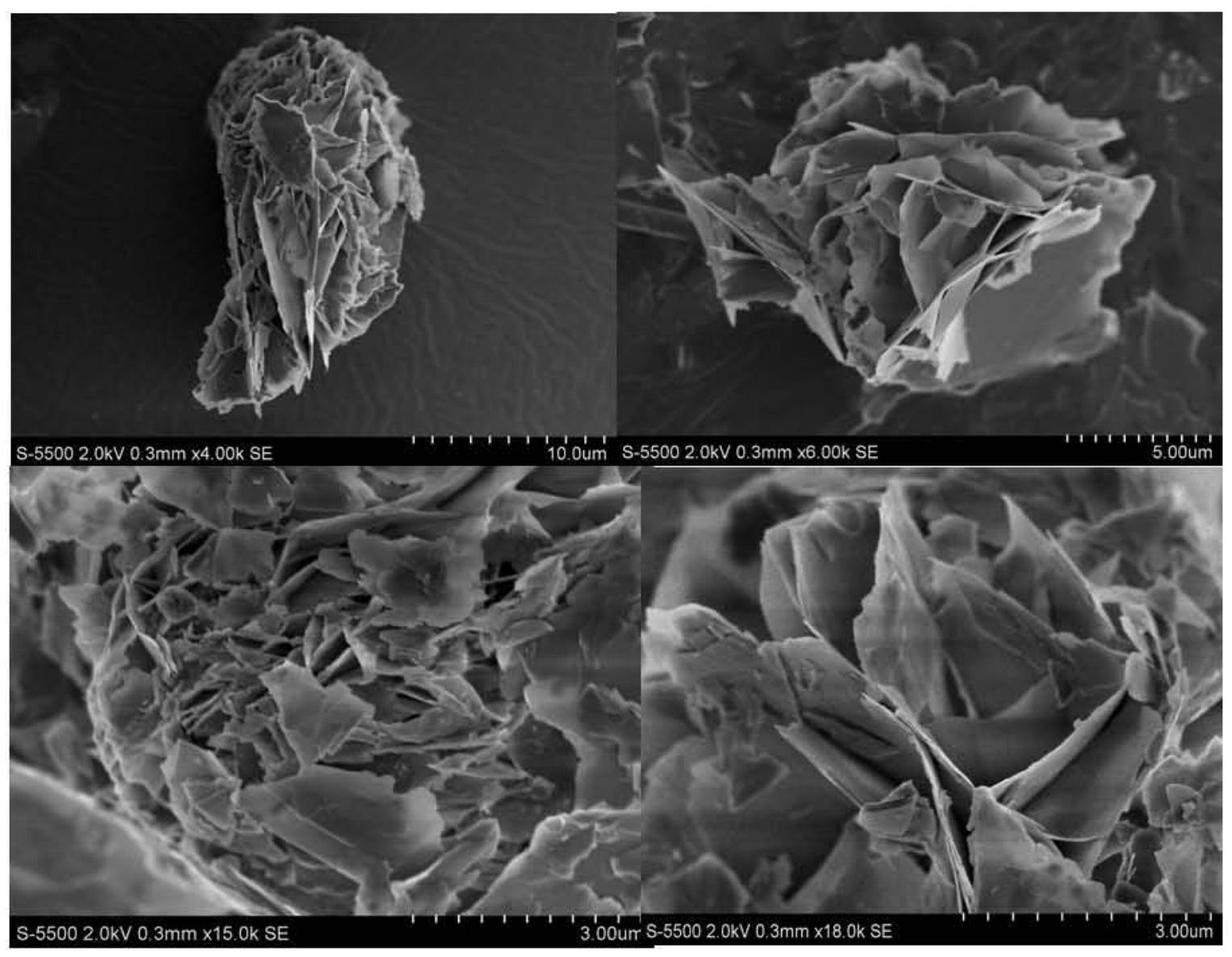

Figure 26. SEM Images of Sample "SST $4^{\text {th }}$ Wash Filter Cake." 

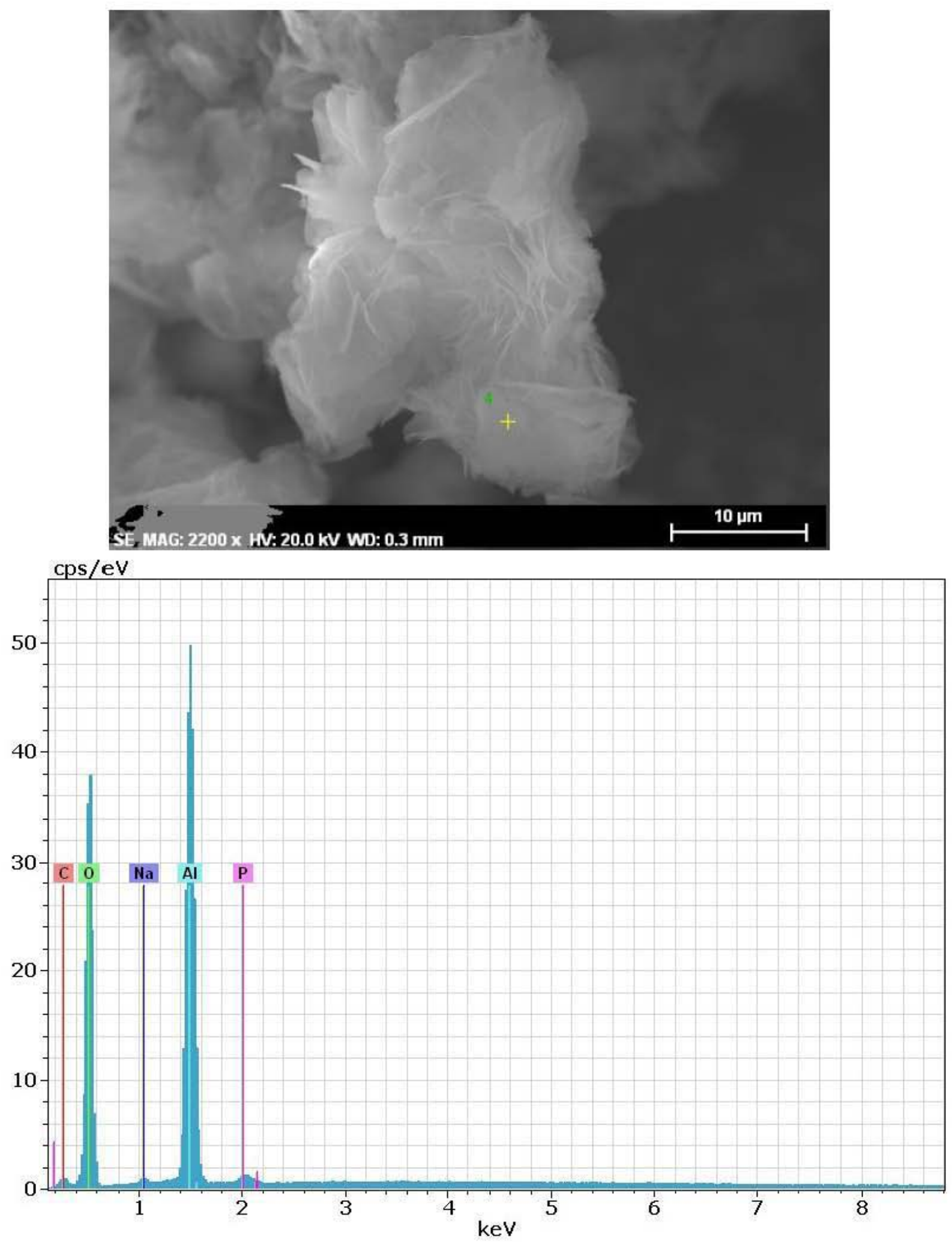

Figure 27. Characteristic EDS Spectrum of Sample "SST $4^{\text {th }}$ Wash Filter Cake." 


\subsubsection{SST TEST CESIUM DECONTAMINATION}

The SST test, as in the other tests, contained ${ }^{133} \mathrm{Cs}$ in the simulant composition as a surrogate for ${ }^{137} \mathrm{Cs}$ present in actual waste.

Cesium DF is calculated by the following equation:

$$
\text { Cesium DF }=\frac{\text { Mass Cs in } / \text { Mass Al in }}{\text { Mass Cs out } / \text { Mass Al out }}
$$

Cesium DFs for the SST tests are calculated for incremental (between washes) and cumulative cases and are presented in Table 6.

\begin{tabular}{|c|c|c|c|c|}
\hline & Aluminum & Cesium & $\begin{array}{c}\text { Cesium } \\
\text { Incremental DF }\end{array}$ & $\begin{array}{c}\text { Cesium } \\
\text { Cumulative DF }\end{array}$ \\
\hline Simulant (mg) & 23154 & 4.08 & & \\
\hline $\begin{array}{c}\text { Initial Cake } \\
(\mathrm{mg} / \mathrm{kg})\end{array}$ & 140900 & 1.76 & 14.1 & 14 \\
\hline $\begin{array}{c}1^{\text {st }} \text { wash Cake } \\
(\mathrm{mg} / \mathrm{kg})\end{array}$ & 221000 & 0.107 & 25.8 & 364 \\
\hline $\begin{array}{c}2^{\text {nd }} \text { wash Cake } \\
(\mathrm{mg} / \mathrm{kg})\end{array}$ & 205700 & 0.04 & 2.5 & 906 \\
\hline $\begin{array}{c}3^{\text {rd }} \text { wash Cake } \\
(\mathrm{mg} / \mathrm{kg})\end{array}$ & 206500 & 0.02 & 2.0 & 1819 \\
\hline $\begin{array}{c}4^{\text {th }} \text { wash Cake } \\
(\mathrm{mg} / \mathrm{kg})\end{array}$ & 217600 & 0.017 & 1.2 & 2256 \\
\hline
\end{tabular}

Table 6. SST Test Cesium Contamination.

As can be seen from the data in the table above, the washing of the SST test solids was very effective with respect to cesium. LiHT does not retain alkali metals as part of the crystal structure and is easily decontaminated.

\subsubsection{SST PARTICLE SIZE DISTRIBUTION}

Volume-based and number-based PSD curves and histograms are presented in Figures 28 and 29. The volume-based histogram indicates the bulk of the particle mass/volume is $100 \mu \mathrm{m}$ to $200 \mu \mathrm{m}$, with a substantial amount of particles down to $1 \mu \mathrm{m}$. Previous PSD curves of unwashed LiHT indicate a normal distribution should be expected. The difference between the curves can be attributed to the effect of particle washing in the Teflon beaker with magnetic stir bar, as well as the effect of vacuum filtration causing breakup of the LiHT crystal structure and re-agglomeration into large particles. 


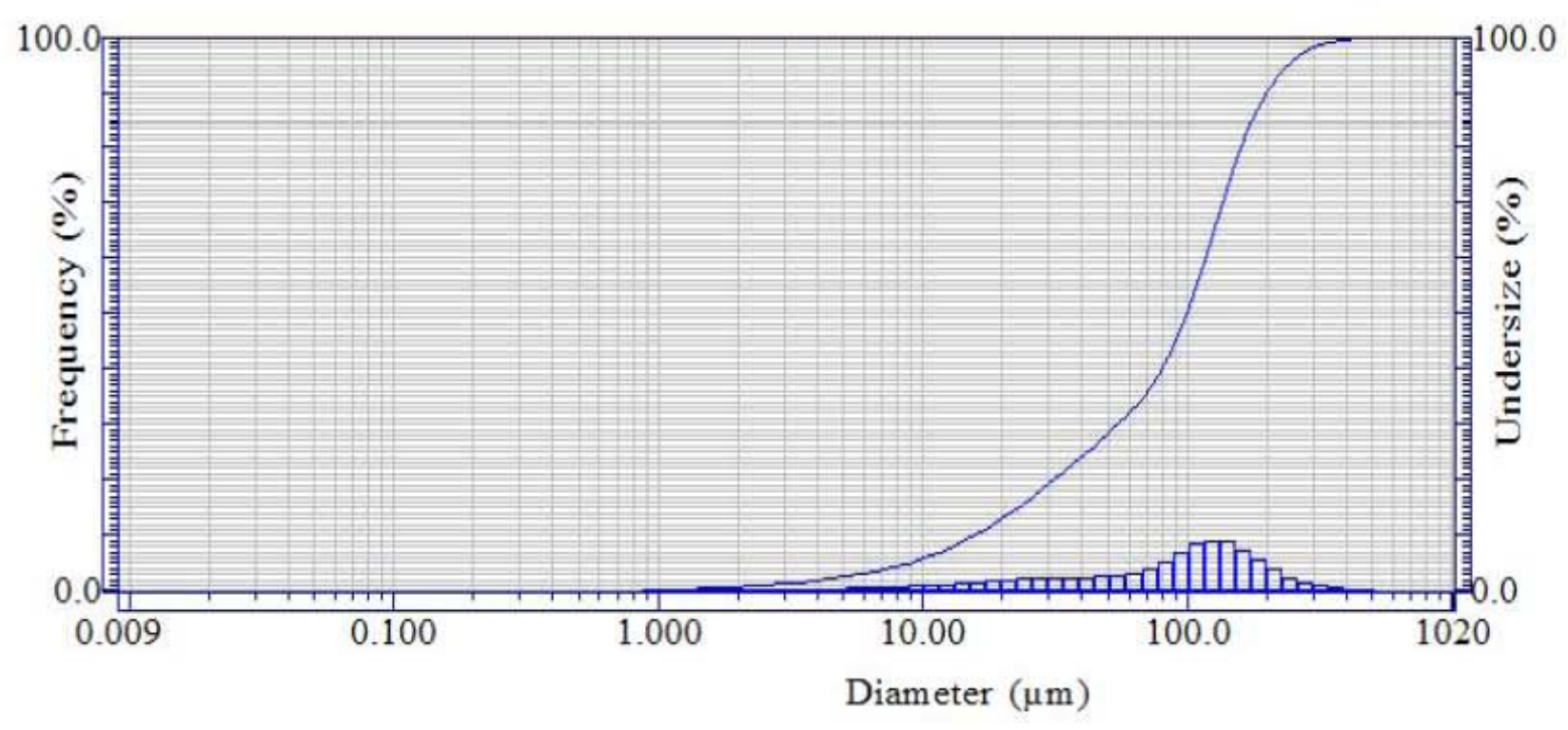

Figure 28. Sample "SST $4^{\text {th }}$ Wash Filter Cake" 10130239 Represented as a Volume-Based Distribution.

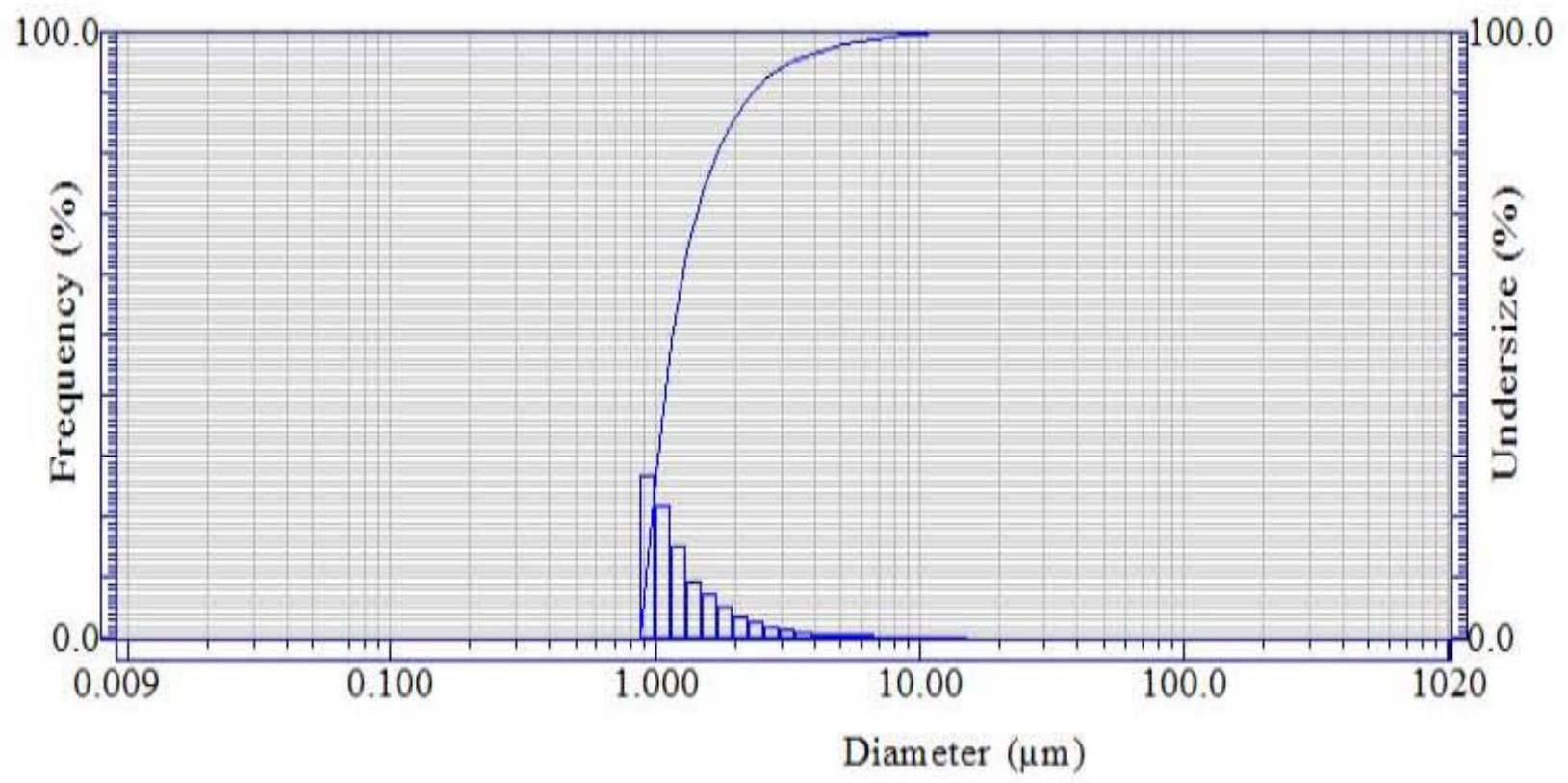

Figure 29. Sample "SST $4^{\text {th }}$ Wash Filter Cake" 10130239 Represented as a Number-Based Distribution. 


\subsubsection{SST Thermo Gravimetric Analysis}

The TGA analysis indicates (Figure 30 ) approximately $36.2 \%$ LiHT solids (63.8\% free water). This compares with oven dried samples $\left(60^{\circ} \mathrm{C}\right)$ that indicate $42.3 \%$ solids. The discrepancy may be that decarboxylation or dehydration of the LiHT waters of hydration may take place at the TGA analysis conditions.

The analysis further indicates that $20.6 \%$ solids remains after calcining at $1000^{\circ} \mathrm{C}$. Degradation of the LiHT structure is likely at this temperature, and the resulting mineral forms are assumed to be $\mathrm{Li}_{2} \mathrm{O}$ and $\mathrm{Al}_{2} \mathrm{O}_{3}$. In future work, this should be confirmed with XRD analysis.

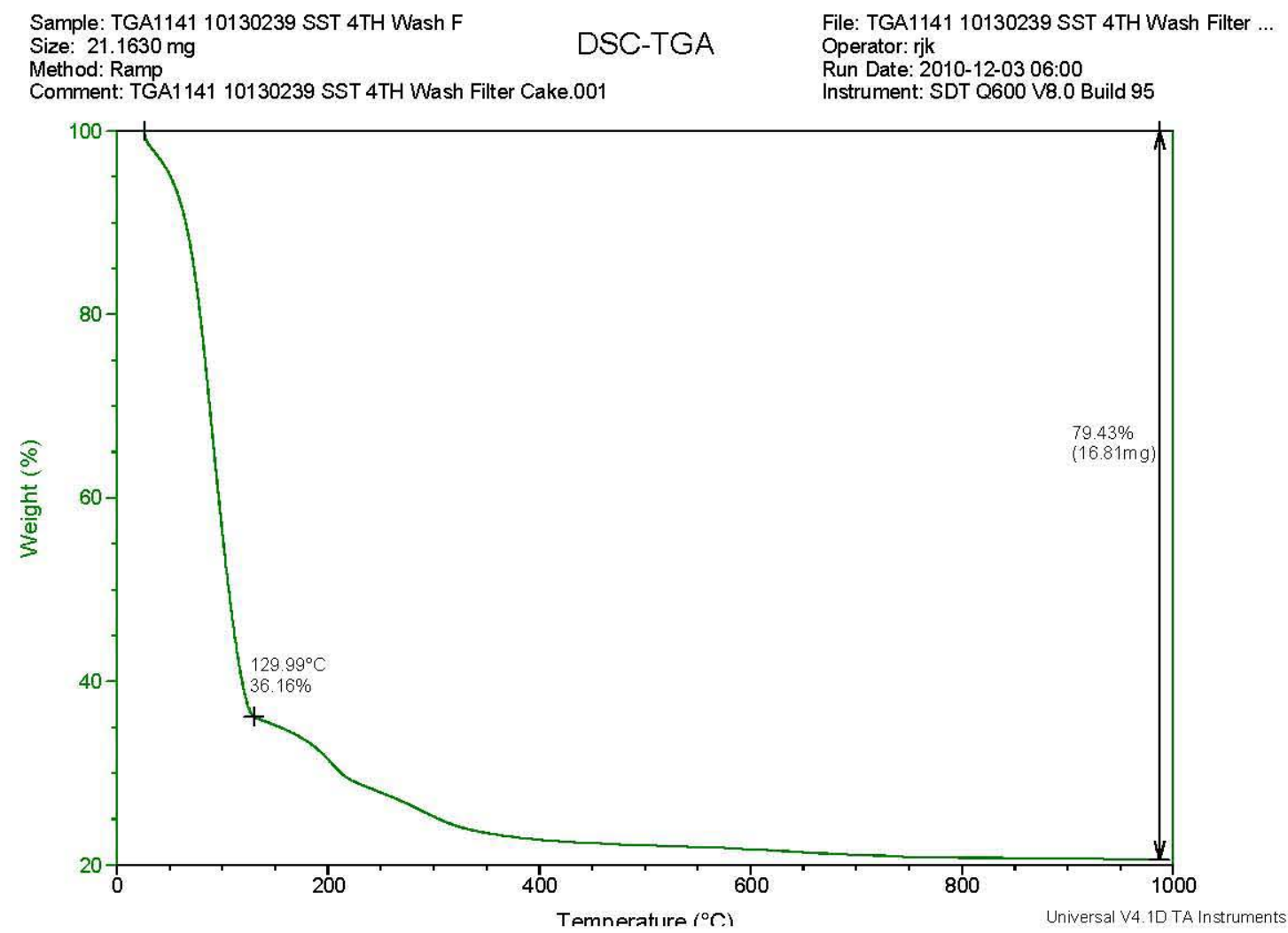

Figure 30. TGA Analysis of Sample "SST 4" Wash Filter Cake" 10130239.

\subsubsection{SST TEST FILTER CAKE SOLIDS SPECIATION}

Phosphate analyses indicate that, following precipitation, nearly all of the phosphate remains in the filter cake. XRD analysis of the filter cake indicates the major component is the carbonate intercalated $\mathrm{LiHT}\left(\mathrm{LiHT}-\mathrm{C}\right.$; $\left.\mathrm{Li}_{2} \mathrm{CO}_{3} \bullet 4 \mathrm{Al}(\mathrm{OH})_{3} \bullet 3 \mathrm{H}_{2} \mathrm{O}\right)$, with the possibility of lithium phosphate as one of the trace compounds. There is no existing XRD spectrum for the phosphate intercalated $\mathrm{LiHT}\left(\mathrm{LiHT}-\mathrm{P}\right.$; $\mathrm{Li}_{3} \mathrm{PO}_{4} \cdot 6 \mathrm{Al}(\mathrm{OH})_{3} \bullet \mathrm{nH}_{2} \mathrm{O}$ ), and the potential exists for the actual phosphate containing compound to be LiHT-P, rather than lithium phosphate. In order to determine which 
species is predominant, a simple mass balance considering each case can be performed utilizing analysis results.

The two cases considered are:

- Assuming all of the phosphorous in the cake is in the form LiHT-P, the cake would contain $\sim 63$ grams of LiHT-P and would also contain 0.6 mole of aluminum. The balance of the aluminum, 0.14 moles, is in the LiHT-C form. The carbonate demand for the 0.14 moles of LiHT-C is 0.035 moles, which balances very closely with the measured carbonate of 0.04 moles.

- Assuming all of the phosphorous is the lithium phosphate form, the cake would contain $\sim 12$ grams of lithium phosphate, leaving the entire balance of the aluminum, 0.74 moles, in the LiHT-C form. The carbonate demand for the 0.74 moles of LiHT-C is 0.184 moles, which is more than four times the quantity of carbonate in the cake analysis.

Since LiHT is known to be the major phase present in the cake from XRD analysis, it is clear from the two cases presented above that the filter cake phosphorous solids are in the LiHT-P form.

\subsection{SUMMARY}

A series of laboratory scale bench top tests were conducted to examine the ability of the LiHT precipitation process to remove aluminum from Hanford waste simulants. Three experiments utilizing a DST simulant, and one with a SST simulant were conducted. The results of these experiments proved that aluminum could be removed from the simulants with high efficiency, that the precipitate product was easily filterable, and that cesium was not integral to the precipitate and could be removed. In addition, phosphates present in the simulant were also retained in the LiHT solids (Table 7).

Table 7. Selected Initial Filter Cake Analytes.

\begin{tabular}{|c|c|c|c|c|}
\hline Analyte & $\begin{array}{c}\text { DST \#1 Initial } \\
\text { Cake } \\
(\mathrm{mole} \%)\end{array}$ & $\begin{array}{c}\text { DST \#2 } \\
\text { Initial Cake } \\
(\text { mole\% })\end{array}$ & $\begin{array}{c}\text { DST \#3 } \\
\text { Initial Cake } \\
(\text { mole\%) }\end{array}$ & $\begin{array}{c}\text { SST } \\
\text { Initial } \\
\text { Cake }\end{array}$ \\
\hline $\mathrm{Al}$ & 82.7 & 93.8 & 95.8 & 91.3 \\
\hline $\mathrm{Li}$ & 89.0 & 91.1 & 92.0 & 91.5 \\
\hline $\mathrm{Na}$ & 7.7 & 13.6 & 21.6 & 8.6 \\
\hline $\mathrm{Cs}$ & 9.1 & 15.0 & 25.7 & 9.0 \\
\hline $\mathrm{P}$ & 97.5 & 98.3 & 99.2 & 99.8 \\
\hline
\end{tabular}

Note: Values are calculated as a fraction of total ICP-AES results for the initial cake and mother liquor

The generation of sodium hydroxide could not be verified by the analytical techniques selected for the tests, but can be qualitatively inferred from the fact that LiHT was created in the process as indicated by XRD analysis and reaction stoichiometry. 
Examples of the identification of the solids by XRD is shown in Figure 31 for two of the experimental runs.

\begin{tabular}{lccc}
\hline Phase & Composition & Concentration & PDF Number \\
\hline $\begin{array}{l}\text { Lithium Aluminum } \\
\text { Carbonate }\end{array}$ & $\left(\mathrm{Al}_{2} \mathrm{Li}(\mathrm{OH})_{6}\right)_{2} \mathrm{CO}_{3} \cdot \mathrm{xH}_{2} \mathrm{O}$ & Major & $00-042-0729$
\end{tabular}

Hydroxide Hydrate

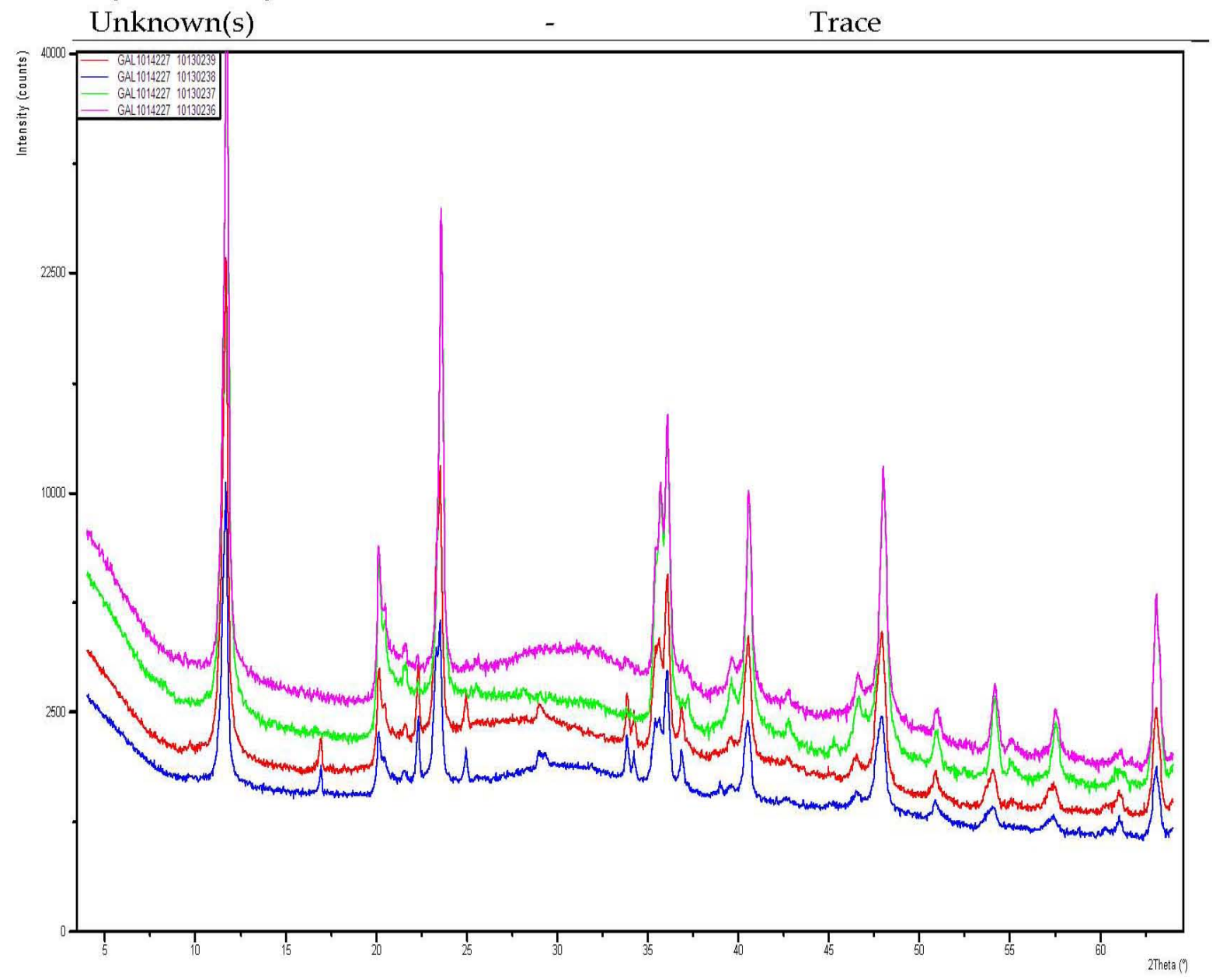

Figure 31. Overlay of X-Ray Diffraction Patterns of Samples.

"DST \#2 Initial Filter Cake" (in pink), "DST \#2 $4{ }^{\text {th }}$ Wash Filter (in green), "SST Initial Filter Cake" (in blue), and "SST $4^{\text {th }}$ Wash Filter Cake" (in red) with Degrees $2 \theta$ Along the X-Axis and Intensity (Counts) Along the Y-Axis. 


\subsection{ALUMINUM REMOVAL}

Aluminum was removed with a high efficiency from the simulants and did not dissolve into the wash water during product decontamination (Figure 32).

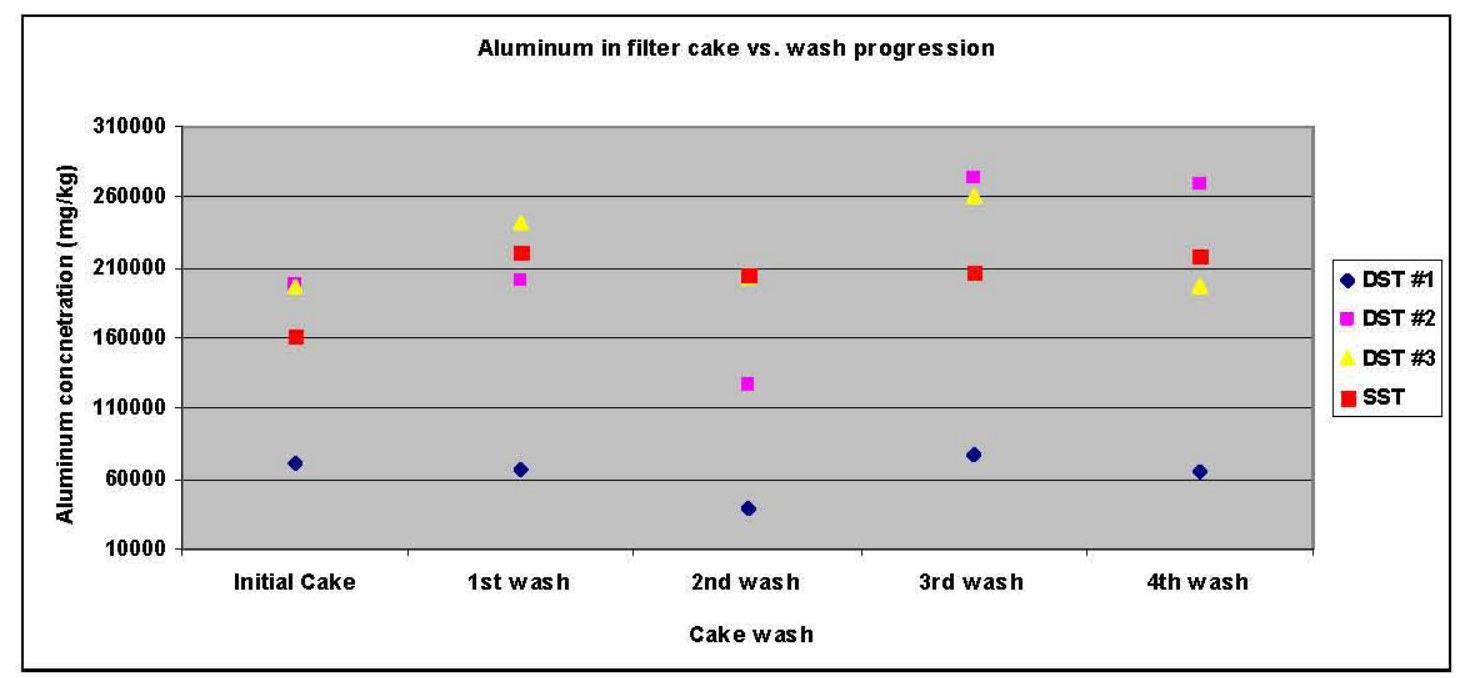

Figure 32. Aluminum Concentration in Filter Cakes During Wash Progression.

Any residual aluminum in the filter cake interstitial liquid was readily washed out, as illustrated in Figure 33.

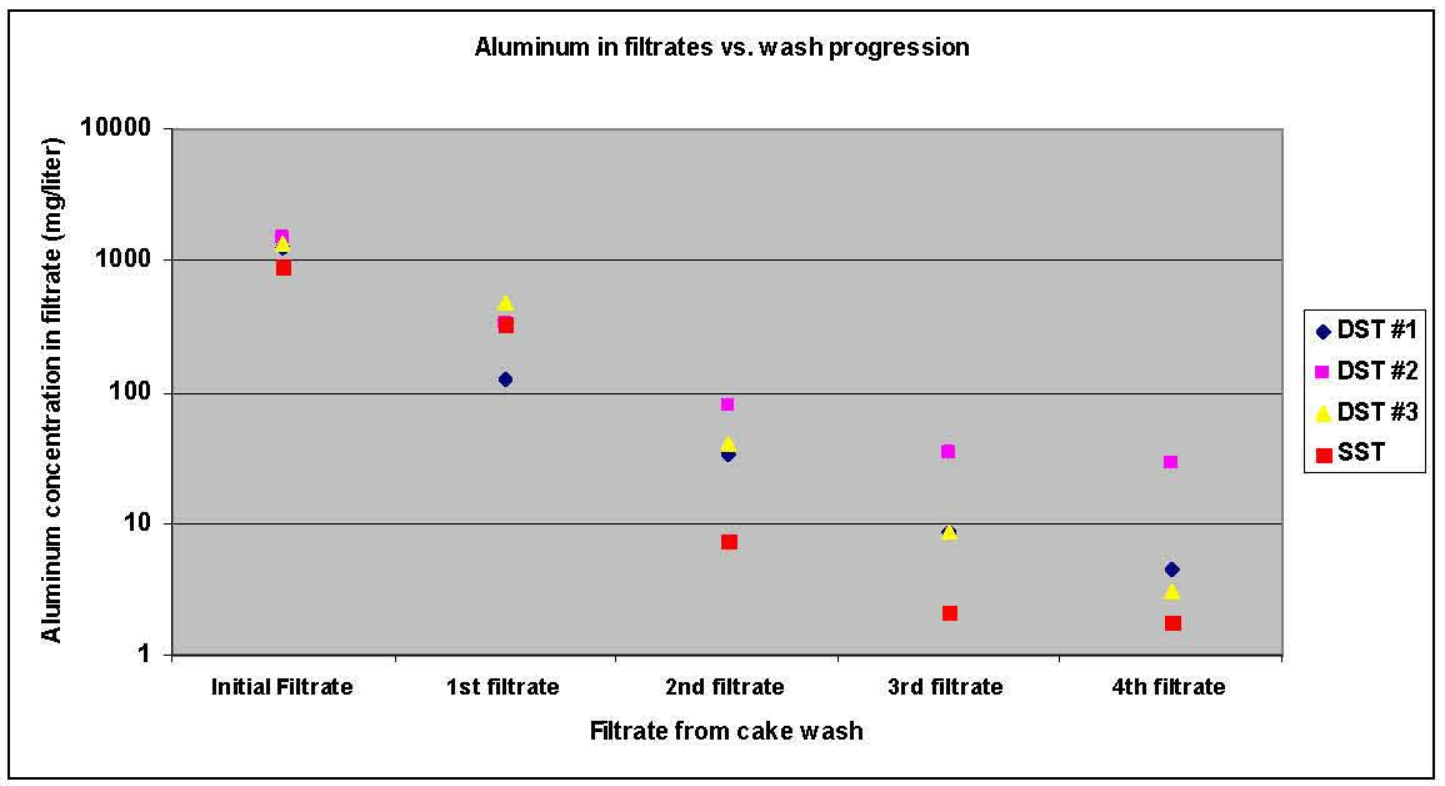

Figure 33. Aluminum Concentration in Filtrates During Wash Progression. 


\section{$5.2 \quad$ LIHT FILTRATION}

The initial LiHT product slurry filtered rapidly through a $0.45 \mu \mathrm{m}$ pore size PVDF filter medium. As the washing stages progressed, however, the filtration times increased substantially. This is likely due to the breakup of the well-ordered crystal structure into smaller platelets. The majority of the crystals re-agglomerated into large $(100-500 \mu \mathrm{m})$ particles; however, a small portion of the product remained as submicron fragments (this is indicated by the bimodal distribution in some of the PSD histograms, and the large fraction of submicron particles in the number based distributions). These small particles are likely the cause of some degree of filter blinding, resulting in a gradual increase in filtration times to achieve a dewatered cake. In addition, the process of vacuum filtration in the Büchner funnel likely contributed to the fracturing of the crystallites. Figure 34 shows the filtration times required to remove free liquid from the DST \#3 filter cake in the Büchner funnel during the wash progression. New filter papers were used for each wash iteration. The reduced dewatering time required for the final wash may be an indicator as to the extent of re-agglomeration of the crystallites.

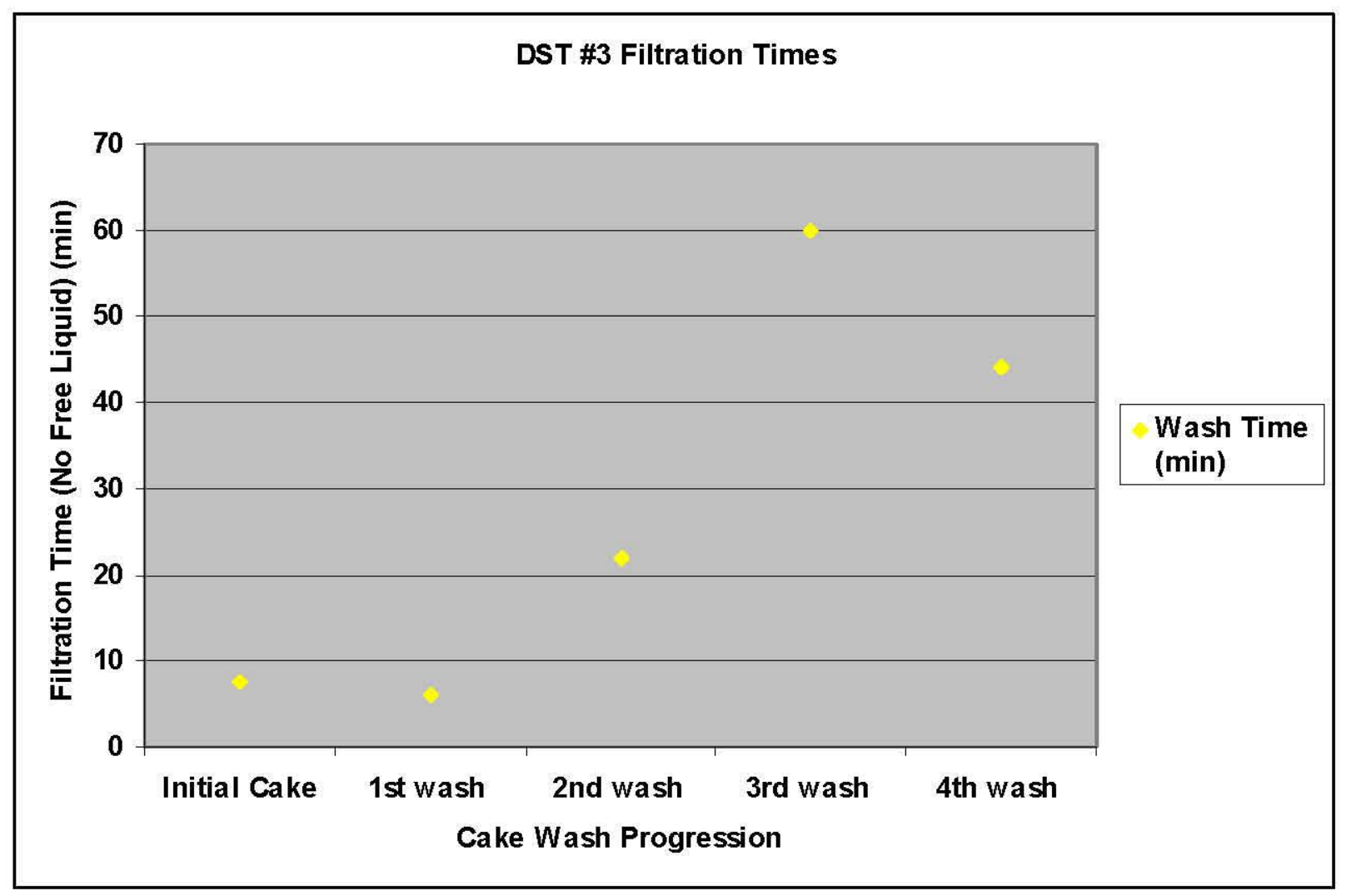

Figure 34. DST Test \#3 Filtration Times During Wash Progression.

A comparison of the PSD before washing (from previous Georgia Tech testing) to the final washed product from the SST Test illustrates the effect that the solids washing had on the particle sizes (Figures 35 and 36). 


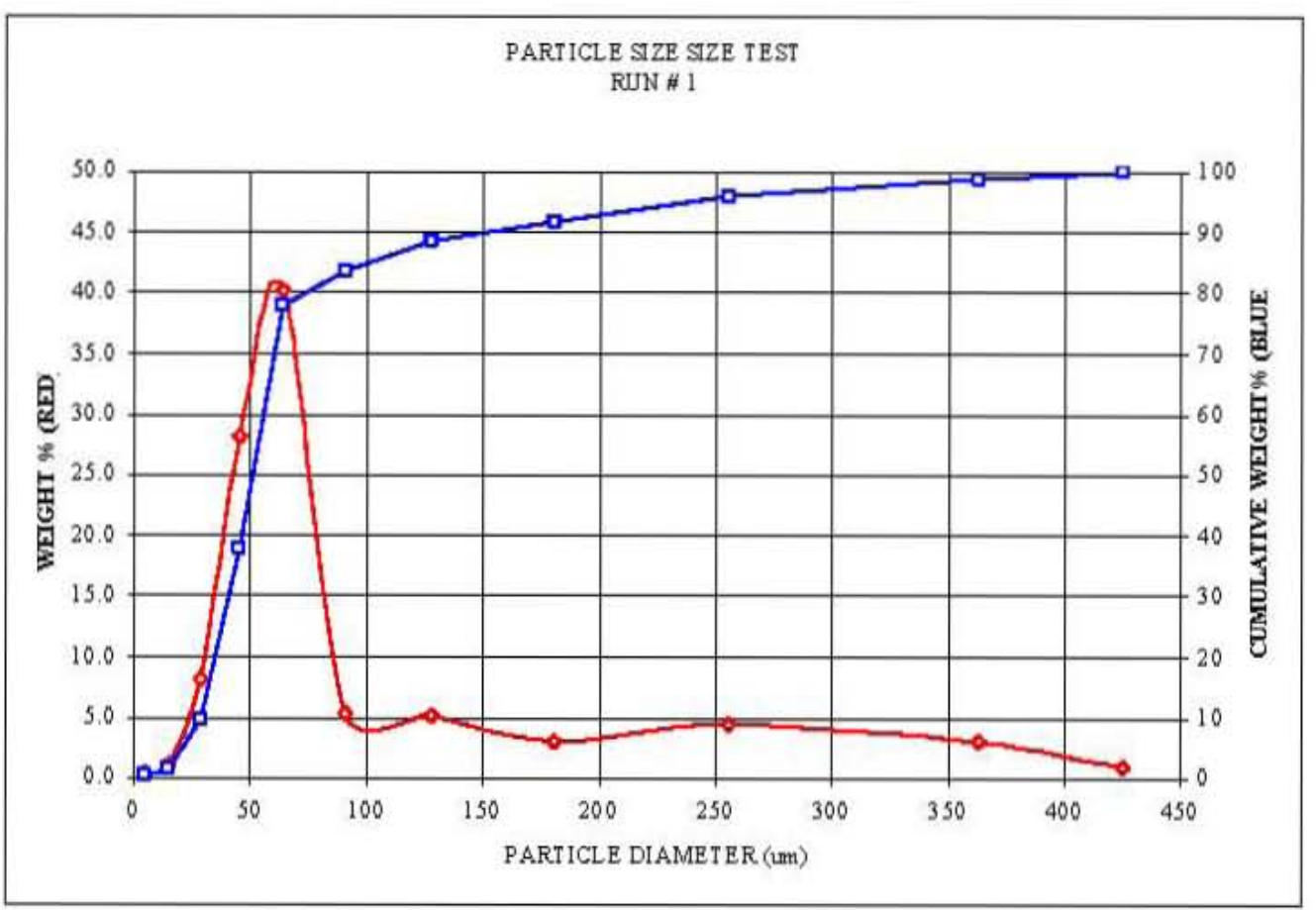

Figure 35. Unwashed Cake Particle Size Distribution from Georgia Tech Experiments.

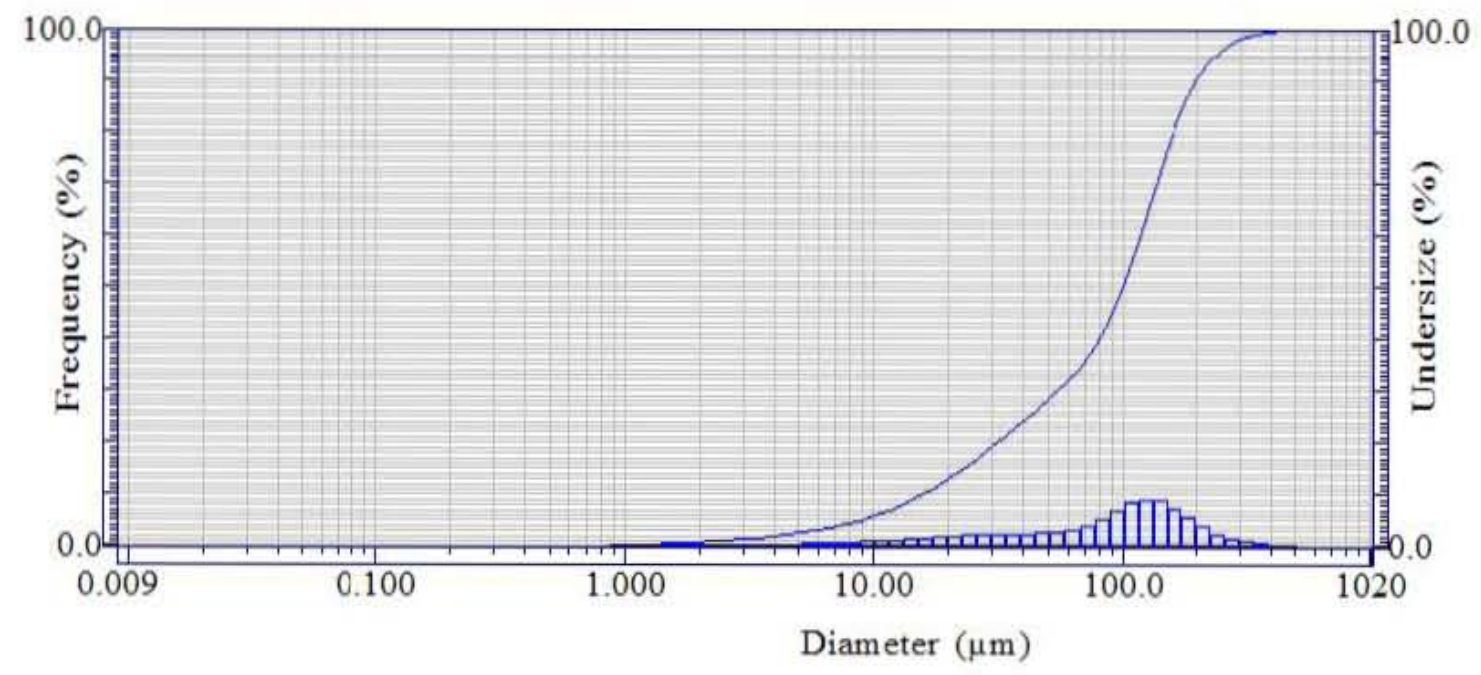

Figure 36. Final Washed Cake from SST Test Particle Size Distribution (Volume Based).

\subsubsection{CESIUM DECONTAMINATION}

The filter cake solids were readily decontaminated by water washing. Figure 37 illustrates the effect of the ambient temperature water washing of the filter cakes. Again, the effect of the 
crystallite breakup and re-agglomeration can be seen in the gradually decreasing decontamination efficiency as the washing stages progressed. Washing efficiency is a function of particle size and morphology as well as the salt concentration gradient between the wash liquid and the crystal interstitial liquid. The result is that larger particles with a more compact structure are less susceptible to the effects of the washing.

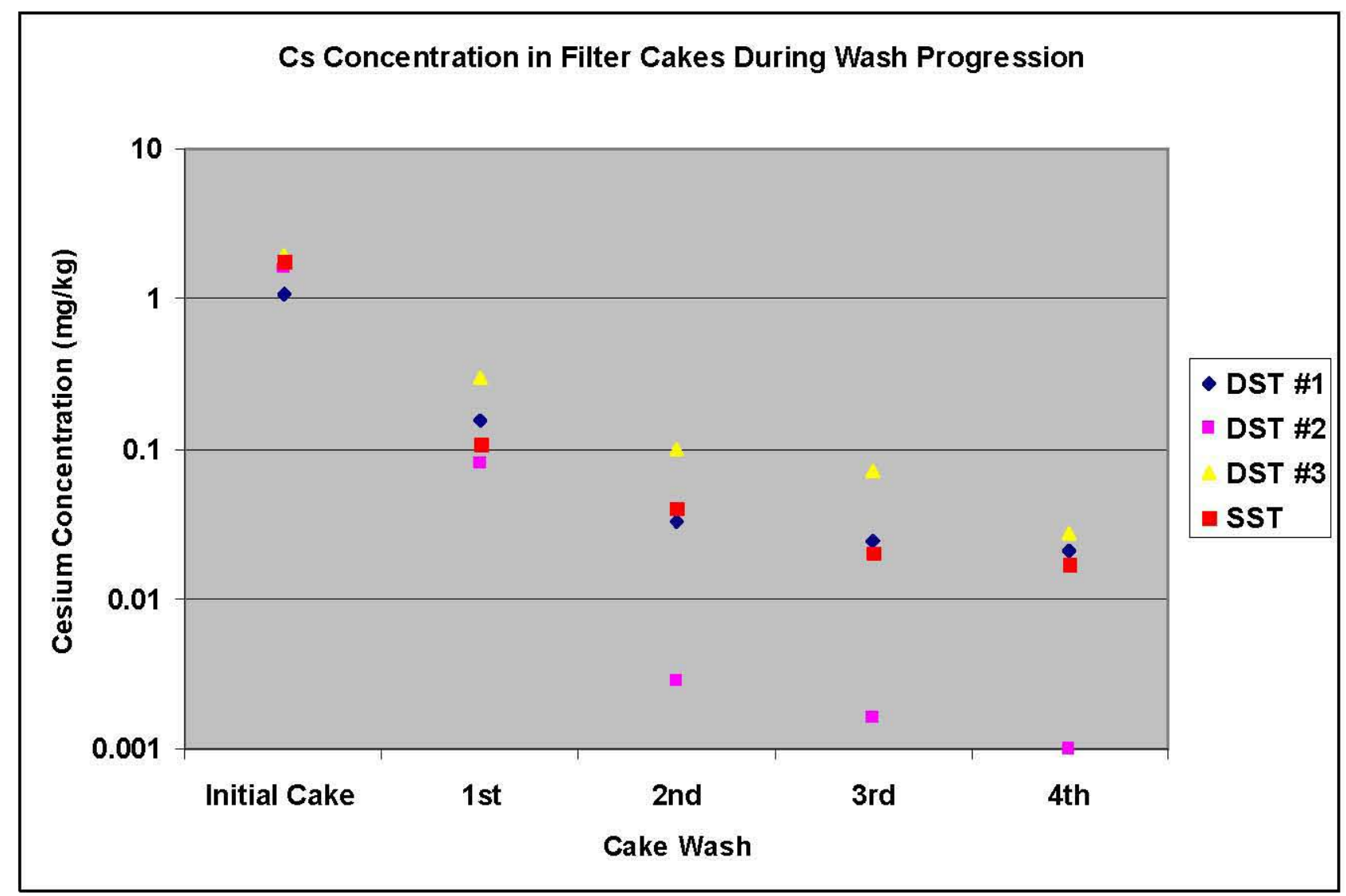

Figure 37. Filter Cake Cesium Decontamination During Wash Progression.

The exception to the general trend is DST Test \#2, which indicates a very high level of Cs decontamination. What distinguishes the very high decontamination of DST \#2 is the effectiveness of the second wash. For unknown reasons, the second wash in DST Test \#2 achieved the same magnitude of decontamination as the first wash.

As a method to verify the validity of cesium removal for DST \#2, both sodium and potassium reductions during the wash stages are plotted in Figure 38 along with cesium. This indicates that all alkali metals present in the simulant behave similarly, with the exception of lithium, which remains incorporated into the LiHT structure. Again, as the wash conditions for all of the tests were virtually identical, the reason(s) for the high removal efficiency are unknown. The results of this test do, however, demonstrate the potential to remove cesium to a high degree, even with the relatively crude washing method employed. 


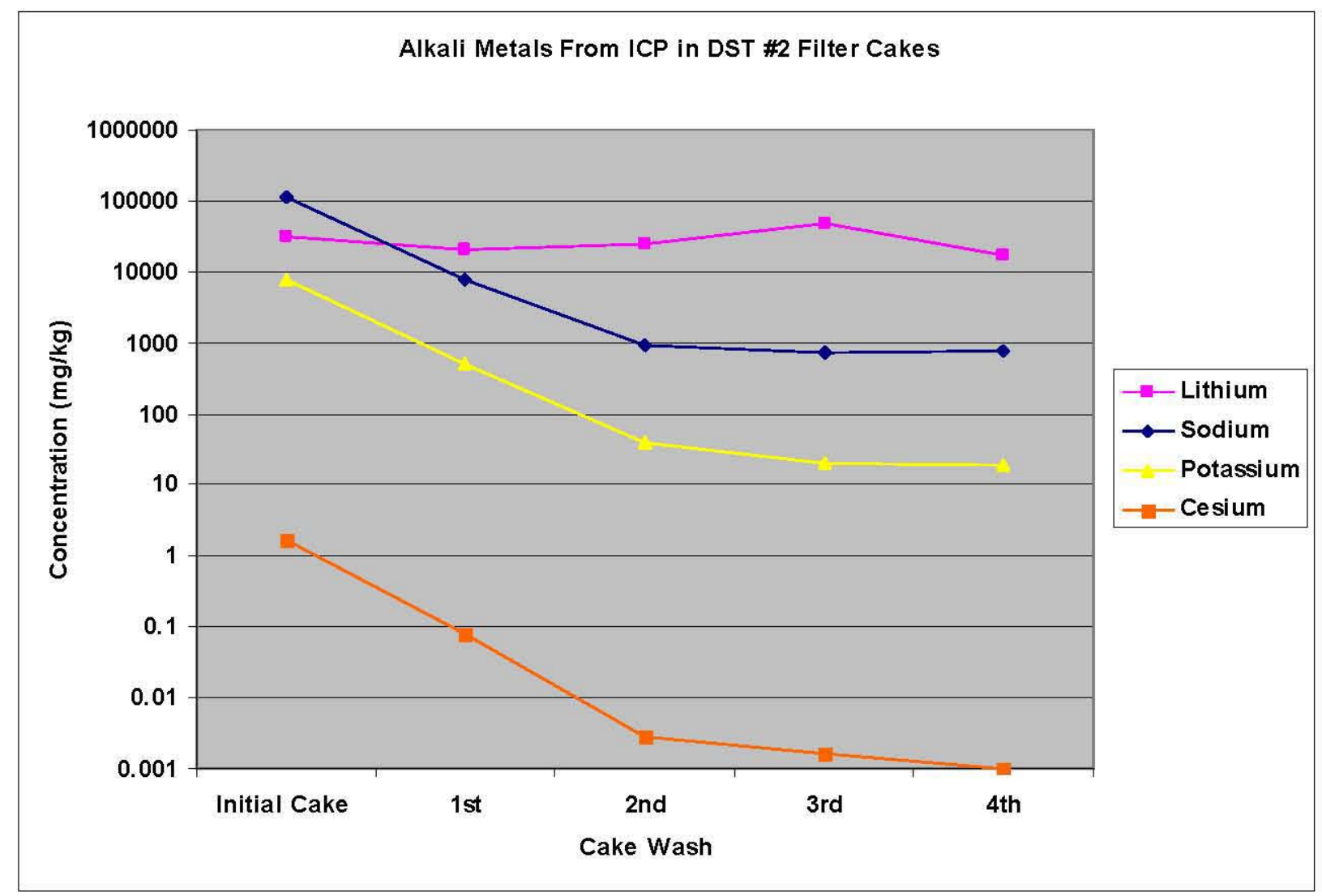

Figure 38. Alkali Metals from ICP in DST \#2 Filter Cakes.

Waste classifications for disposal path determinations are located in 10CFR61.55, Table 2. For Class A waste, the cesium concentration must not exceed 1 curie per cubic meter. The stable isotope ${ }^{133} \mathrm{Cs}$ was used as a surrogate for ${ }^{137} \mathrm{Cs}$ in the LiHT tests, and the ICP-MS analytical results in $\mathrm{mg} / \mathrm{kg}$ were converted to curies $/ \mathrm{m}^{3}$ of ${ }^{137} \mathrm{Cs}$. Calculated values in the final washed cakes from the four tests are presented in Table 8 . Note that these calculations use the TWINS database ratio of ${ }^{137} \mathrm{Cs}$ to ${ }^{133} \mathrm{Cs}$ of $\sim 20 \%$. All final washed cakes indicate that they will meet Class A disposal requirements for ${ }^{137} \mathrm{Cs}$, with the DST \#2 filter cake meeting the limit by a wide margin. These calculations are inherently conservative, in that a LiHT particle density of $1.79 \mathrm{~g} / \mathrm{cm}^{3}$ was used in the calculations, rather than the bulk density.

Table 8. Analogous ${ }^{137}$ Cs Concentrations in Final Washed Cakes.

\begin{tabular}{|c|c|c|c|c|}
\hline & DST \#1 & DST \#2 & DST \#3 & SST \\
\hline $\begin{array}{c}\text { Final washed Cake } \\
\left(\mathrm{mg}^{133} \mathrm{Cs} / \mathrm{kg}\right)\end{array}$ & 0.021 & 0.001 & 0.027 & 0.017 \\
\hline $\begin{array}{c}\text { Final washed Cake } \\
\left(\mathrm{Ci}^{137} \mathrm{Cs} / \mathrm{m}^{3}\right)\end{array}$ & 0.66 & 0.03 & 0.85 & 0.54 \\
\hline
\end{tabular}




\subsection{RECOMMENDATIONS}

Additional laboratory scale testing is required to advance the LiHT process. Specific areas of investigation should include:

- Determine precipitation methods that increase yield while reducing cycle times.

Examples of techniques that might be investigated to accomplish this include:

- Reaction at higher temperatures.

- Introduction of nucleation agents.

- Use of ultrasound to increase crystallization rate.

- Continuous precipitation with recycle.

- Concentrate reactants during precipitation to increase super saturation.

- Cooling reaction slurry after ripening.

- Ripening at reduced temperatures.

- Determine solids washing methodologies that maintain the LiHT crystal structure, allowing further improvement to the already high degree of decontamination. Examples of techniques that might be investigated to accomplish this include:

- Counter current solids washing.

- Fluidized bed washing.

- Elevated temperature washing.

- Verification of the formation of the phosphate intercalated LiHT compound, as well as other anionic species. Development of the XRD spectra for each of these species with the Rietveld refinement technique should be conducted to aid in the identification of the conditions leading to their formation. 


\section{APPENDIX A \\ DST TEST \#1}

This test was conducted with DST simulant components and protocol as specified in the Test Procedure. The specified gibbsite leaching protocol was followed; however, some undissolved gibbsite remained in the reactor after the specified leaching time had elapsed. Additional leaching time did not alleviate the remaining turbidity of the solution.

The test sequence for DST \#1 is indicated in the flow chart as shown in Figure A-1. It contains all steps including gibbsite leaching, $\mathrm{LiOH}$ addition, crystal ripening at $90^{\circ} \mathrm{C}$ (for 4 hours), filtration, and wash steps.

Table A-1. DST Test \#1 Simulant Chemical Makeup (1-L Batch).

\begin{tabular}{|c|c|c|c|}
\hline Reagent & MW & Target Molarity & $\begin{array}{c}\text { Weight or } \\
\text { Volume }\end{array}$ \\
\hline $\mathrm{NaOH}$ & 40 & 2.59 & $103.66 \mathrm{~g}$ \\
\hline $\mathrm{Na}_{2} \mathrm{CO}_{3}$ & 106 & 0.06 & $6.86 \mathrm{~g}$ \\
\hline $\mathrm{Na}_{2} \mathrm{C}_{2} \mathrm{O}_{4}$ & 134 & 0.003 & $0.38 \mathrm{~g}$ \\
\hline $\mathrm{KNO}_{3}$ & 101 & 0.19 & $19.68 \mathrm{~g}$ \\
\hline $\mathrm{NaNO}_{3}$ & 85 & 0.91 & $77.76 \mathrm{~g}$ \\
\hline $\mathrm{NaNO}_{2}$ & 69 & 1.15 & $79.44 \mathrm{~g}$ \\
\hline $\mathrm{Na}_{2} \mathrm{SO}_{4}$ & 142 & 0.007 & $1.02 \mathrm{~g}$ \\
\hline $\mathrm{Na}_{3} \mathrm{PO}_{4} \cdot 12 \mathrm{H}_{2} \mathrm{O}$ & 380.1 & 0.007 & $2.81 \mathrm{~g}$ \\
\hline $\mathrm{NaCl}^{\mathrm{NaF}}$ & 58.4 & 0.12 & $6.73 \mathrm{~g}$ \\
\hline $\mathrm{NaF}_{2}$ & 42 & 0.011 & $0.46 \mathrm{~g}$ \\
\hline $\mathrm{Na}_{2} \mathrm{Cr}_{2} \mathrm{O}_{7} \cdot 2 \mathrm{H}_{2} \mathrm{O}$ & 298 & 0.001 & $0.43 \mathrm{~g}$ \\
\hline $\mathrm{NaC}_{2} \mathrm{H}_{3} \mathrm{O}_{2} \cdot 3 \mathrm{H}_{2} \mathrm{O}$ & 136.1 & 0.04 & $5.48 \mathrm{~g}$ \\
\hline $\mathrm{CsNO}_{3} \mathrm{solution}$ & $\mathrm{NA}$ & $1.05 \mathrm{E}-05$ & $2.43 \mathrm{~mL}$ \\
\hline & & & $6.80 \mathrm{~g}$ \\
\hline $\mathrm{Al}(\mathrm{OH})_{3}$ & 78 & 0.882 & $18.52 \mathrm{~g}$ \\
\hline $\mathrm{LiOH}_{3} \mathrm{H}_{2} \mathrm{O}$ & 42 & 0.441 & \\
\hline
\end{tabular}

Note: CsNO3 solution is prepared by dissolving $210 \mathrm{mg}$ reagent CsNO3 salt in $250 \mathrm{~mL}$ water. 


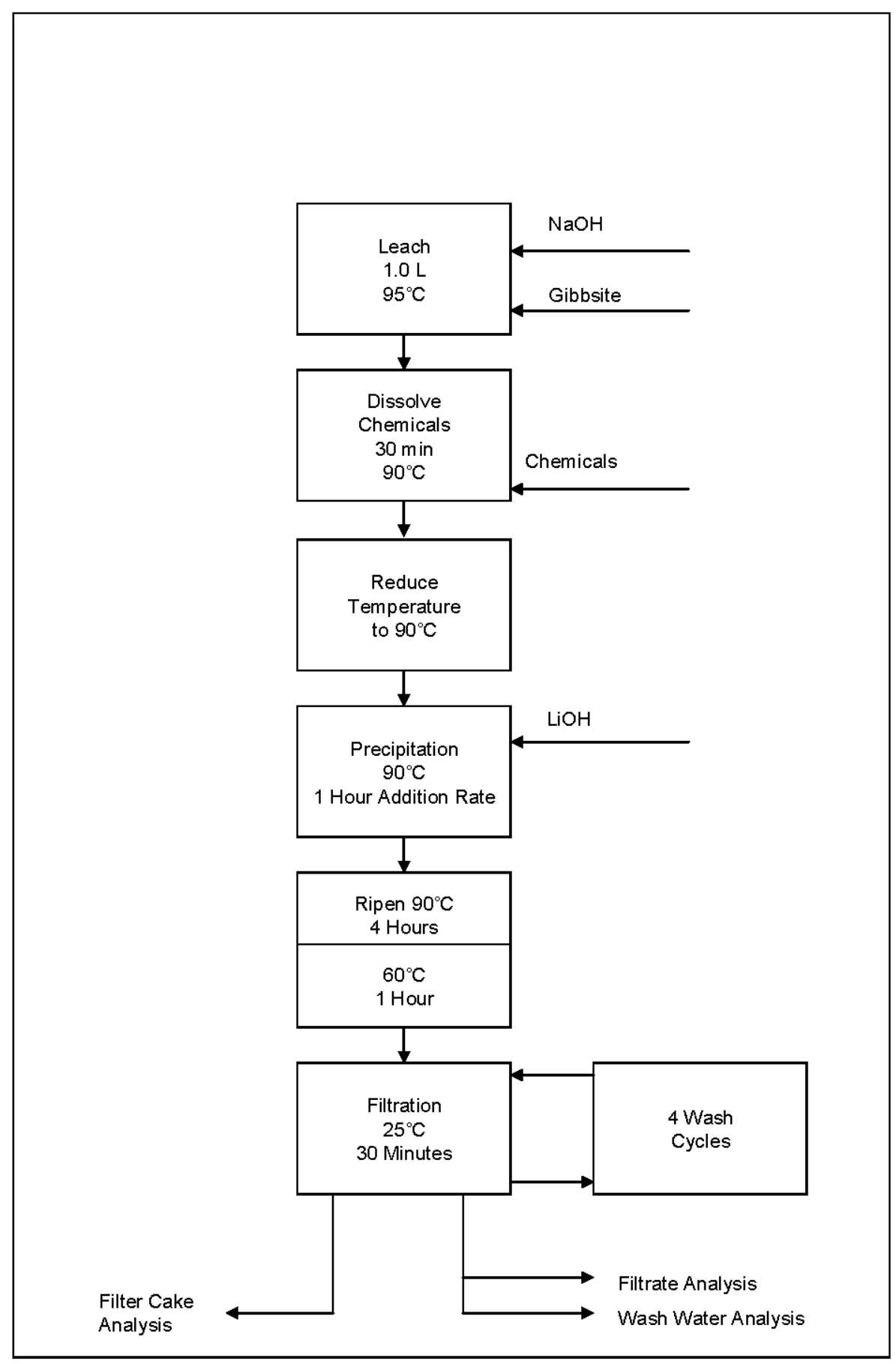

Figure A-1. Experiment Flow Chart for DST Test \#1. 


\section{A.1 DST TEST \#1 LiHT REACTION}

In DST Test \#1, the gibbsite leaching protocol employed was to add water, caustic, and gibbsite for extended, agitated leaching at $95^{\circ} \mathrm{C}$. These conditions were maintained for 16 hours followed by one hour at $100{ }^{\circ} \mathrm{C}$. At the end of this leach process, the solution was still not entirely clear, indicating that residual gibbsite remained in suspension (Figure A-2)

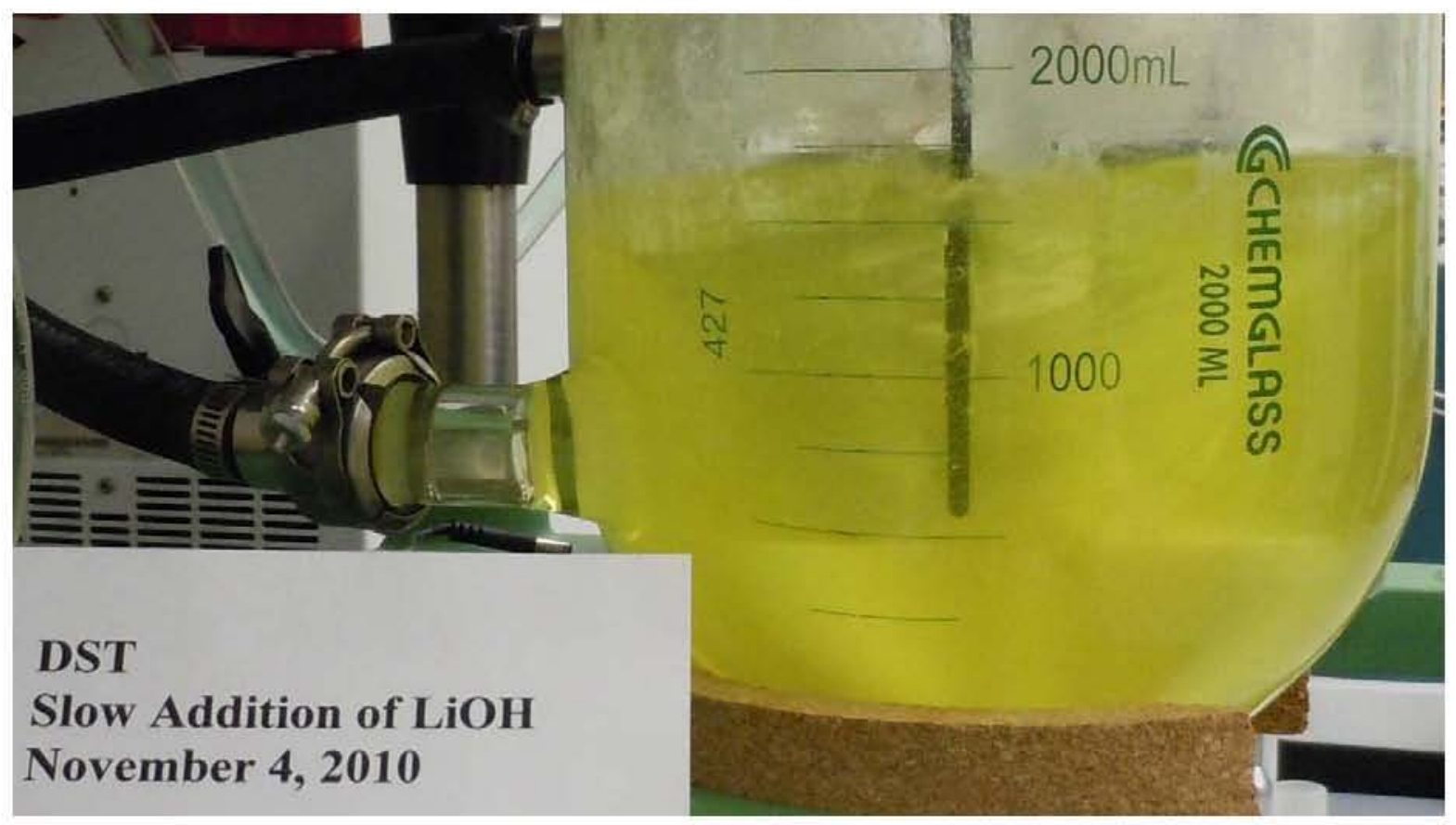

Figure A-2. DST Test \#1 Simulant in the Reactor.

$10 \mathrm{wt} \% \mathrm{LiOH}$ was added to the reactor at a predetermined rate to provide a one-hour addition period. Approximately 25 minutes after the start of the $\mathrm{LiOH}$ addition, a rapid formation of precipitate ensued, caused by the super saturated conditions in the reactor. The white precipitate continued to gradually form through the remainder of the $\mathrm{LiOH}$ addition, as well as the 4-hour ripening period.

Reactor contents were cooled to $60^{\circ} \mathrm{C}$ after the ripening period and the product slurry $(1125 \mathrm{ml})$ was filtered through a $0.45 \mu \mathrm{m}$ pore size PVDF filter, using vacuum filtration and a preheated Büchner funnel. Total damp, unwashed cake produced during this first run was 153 grams. Filtrate (mother liquor) volume was $940 \mathrm{ml}$. Samples of the filtrate and solids were taken for analysis as noted in the Test Procedure. The cake produced was yellowish in color due to the presence of sodium dichromate and physically resembled loose soft clay. The product filtered readily and was easily removed from the Büchner funnel. All filtrates were clear, with no indication of unfiltered solids. The XRD pattern of the solids indicates that the crystalline form of the material is LiHT, with only trace quantities of unknown compounds (Figure A-3). 


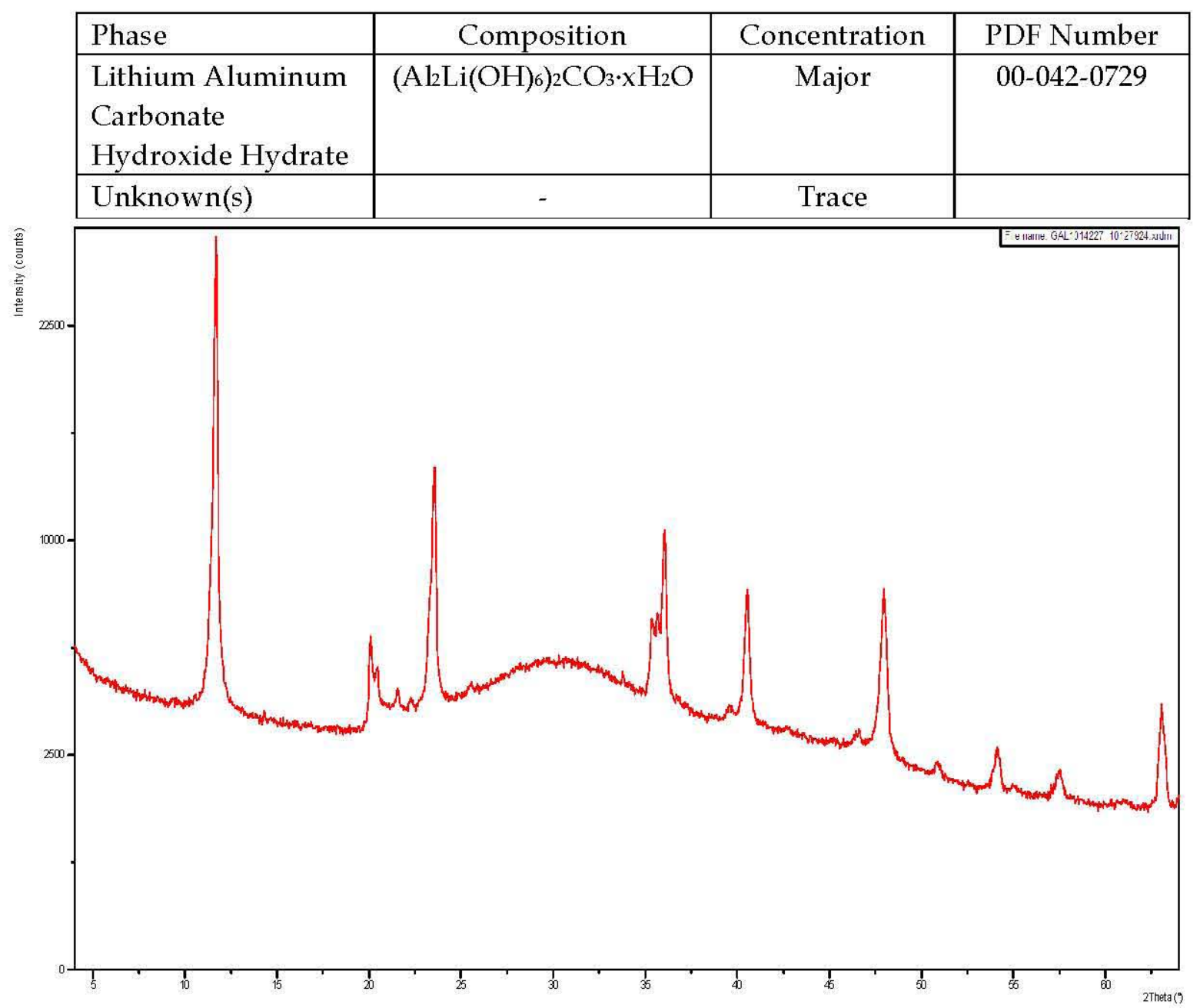

Figure A-3. X-Ray Diffraction Pattern of Sample "DST Test \#1" 10127924 with Degrees $2 \theta$ Along the $\mathrm{X}$-Axis and Intensity (Counts) Along the Y-Axis.

\section{A.2 DST TEST \#1 SOLIDS WASHING}

The solids filtered readily and were easily dewatered. Filtration time gradually increased during each successive wash cycle, likely due to the magnetic stir bar acting as a grinding media and abrading the LiHT product against the surface of the beaker. The final washed cake was a white, fluffy, highly crystalline material. The second through the fourth wash filtrates were water clear, indicating the majority of residual dichromate was washed out in the first wash (Figures A-4 and A-5). This is verified by analytical results showing the dichromate readily washes from the cake. Samples of both the filtrate and the filter cake were taken for analysis after each filtration step. Appendix B contains the analysis results. 


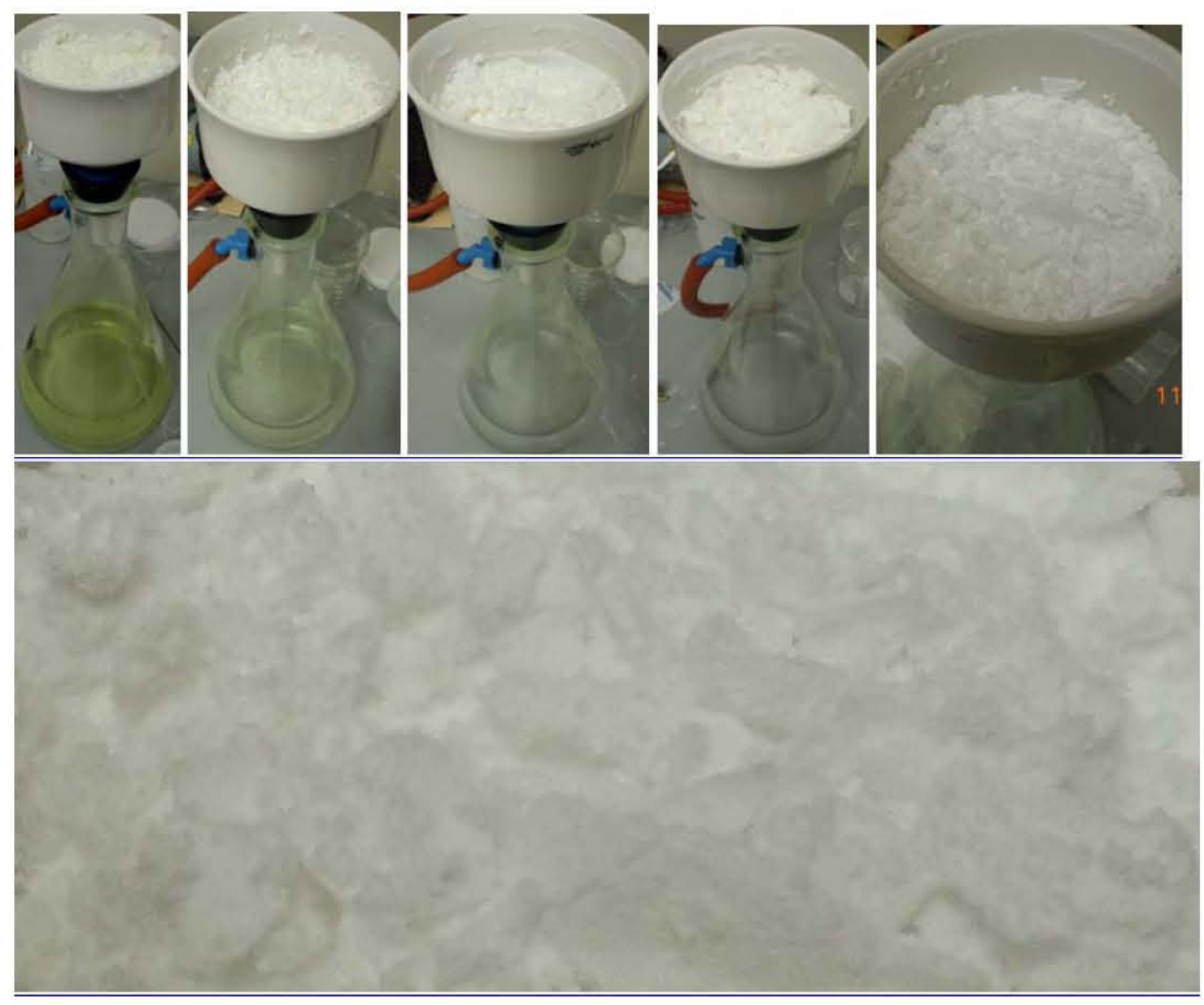

Figure A-4. Filtration Apparatus, Washing Progression, and Final Washed Cake from DST \#1. (Left to Right: Mother Liquor and Initial Cake, $1^{\text {st }}, 2^{\text {nd }}, 3^{\text {rd }}, 4^{\text {th }}$ wash filtrates and filter cakes, final washed filter cake close up.)
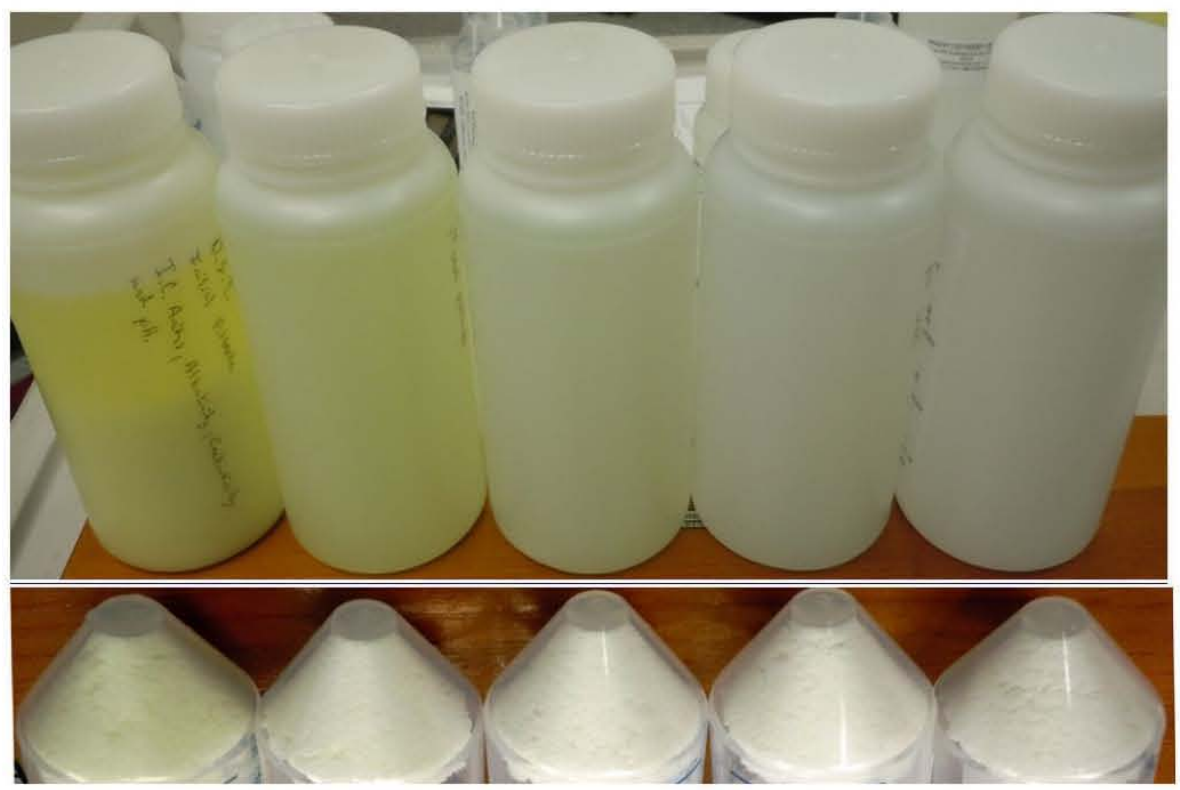

Figure A-5. Filtrate and Cake Samples from DST Test \#1.

(Left to Right: Mother Liquor and Initial Cake, $1^{\text {st }}, 2^{\text {nd }}, 3^{\text {rd }}, 4^{\text {th }}$ wash filtrates and filter cake samples.) 
XRD and EDS analysis of the filter cake was performed on the filter cake after the fourth wash. Results for the initial filter cake are provided in Appendix B. No change in the spectra was noted after washing (Figure A-6).

\begin{tabular}{lccc}
\hline Phase & Composition & Concentration & PDF Number \\
\hline $\begin{array}{l}\text { Lithium Aluminum } \\
\text { Carbonate Hydroxide }\end{array}$ & $\left(\mathrm{Al}_{2} \mathrm{Li}(\mathrm{OH})_{6}\right)_{2} \mathrm{CO}_{3} \cdot \mathrm{xH}_{2} \mathrm{O}$ & Major & $00-042-0729$ \\
$\begin{array}{l}\text { Hydrate } \\
\text { Unknown(s) }\end{array}$ & - & & \\
\hline
\end{tabular}

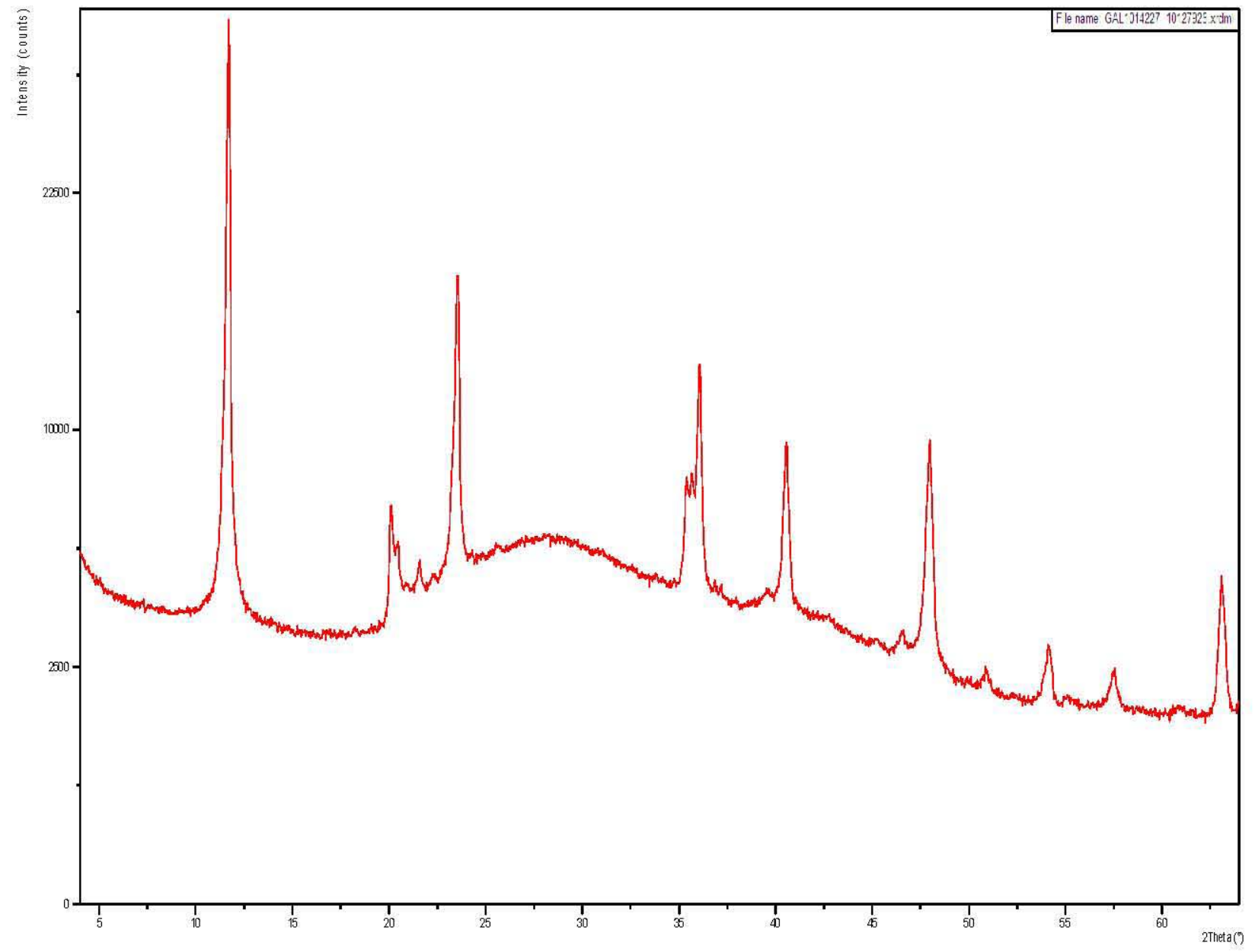

Figure A-6. X-Ray Diffraction Pattern of Sample "DST \#1 $4^{\text {th }}$ Wash" 10127925 with Degrees $2 \theta$ Along the $\mathrm{X}$-Axis and Intensity (Counts) Along the Y-Axis.

The XRD image indicates that the major constituent of the cake is LiHT with only trace unknowns. 
RPP-RPT-48380, Rev. 0

\section{A.3 DST TEST \#1 ALUMINUM REMOVAL}

The initial damp filter cake weighed 152.9 grams. A portion of the cake was dried at $60^{\circ} \mathrm{C}$ overnight and indicated that the cake was $46.3 \%$ solids. Net dry LiHT cake was 70.79 grams.

Theoretical yield is 96.80 grams dry cake ( 0.2205 mole LiHT), making actual yield, gravimetric basis of $73.1 \%$. ICP-AES results show that for DST Test \#1, the initial LiHT filter cake retained 78 mole $\%$ of the total aluminum in the initial product slurry.

The source of the relatively low aluminum removal stems from the continued precipitation in the mother liquor overnight. Visual observations indicate that the sample bottles contained approximately 50 vol\% solids (Figure A-5), in what had been clear filtered liquid the day before. The reason for the incomplete precipitation at the completion of the ripening period is unknown. Since the large number of samples for the test required the utilization of all of the clarified mother liquor, it was not possible to quantify the solids in the sample bottles from DST Test \#1 after precipitation occurred.

\section{A.4 DST TEST \#1 HYDROXIDE GENERATION}

Free hydroxide is generated in the LiHT reaction by stripping carbonate and/or phosphate anions from its respective sodium salt. The reaction generates 2 moles of sodium hydroxide for every mole of LiHT product. Total alkalinity analysis by titration was performed for determination of carbonate and hydroxide concentrations, and TIC was used for determination of carbonate. The difference between the two yields the free hydroxide concentration.

The expected results for hydroxide generation were not able to be verified by the analysis methods that were selected. Qualitatively, the generation of hydroxide can be inferred from the fact that LiHT was actually generated in the reaction (as verified by XRD) and by the reaction stoichiometry.

\section{A.5 DST TEST \#1 FILTER CADE IMAGES}

Final washed cake samples were taken and imaged with SEM/EDS (Figure A-7). In these images, as in other tests, it is evident that the LiHT "sand rose" crystal shape has been broken down by the washing process. Crystallite edge joining that is the hallmark of the LiHT structure is not apparent. Instead, the platelets have agglomerated into large spherical particles composed of small shards and pieces roughly $1 \mu \mathrm{m}$ X $2 \mu \mathrm{m}$, with thickness $50 \mathrm{~nm}$ to $100 \mathrm{~nm}$. A side-by-side comparison of the effect of solids washing can be seen in Figure A-8.

The EDS spectrum for the sample indicates that carbon, sodium, oxygen, aluminum, silicon, and phosphorous are the major constituents. The silicon originates from the elevated temperature etching of the reactor vessel by sodium hydroxide, while the presence of phosphorous likely indicates what is believed to be the thermodynamically stable phosphate form of LiHT. The carbon peak indicates the carbonate form of LiHT is also present, as there is a stoichiometric deficit with respect to phosphorous. 


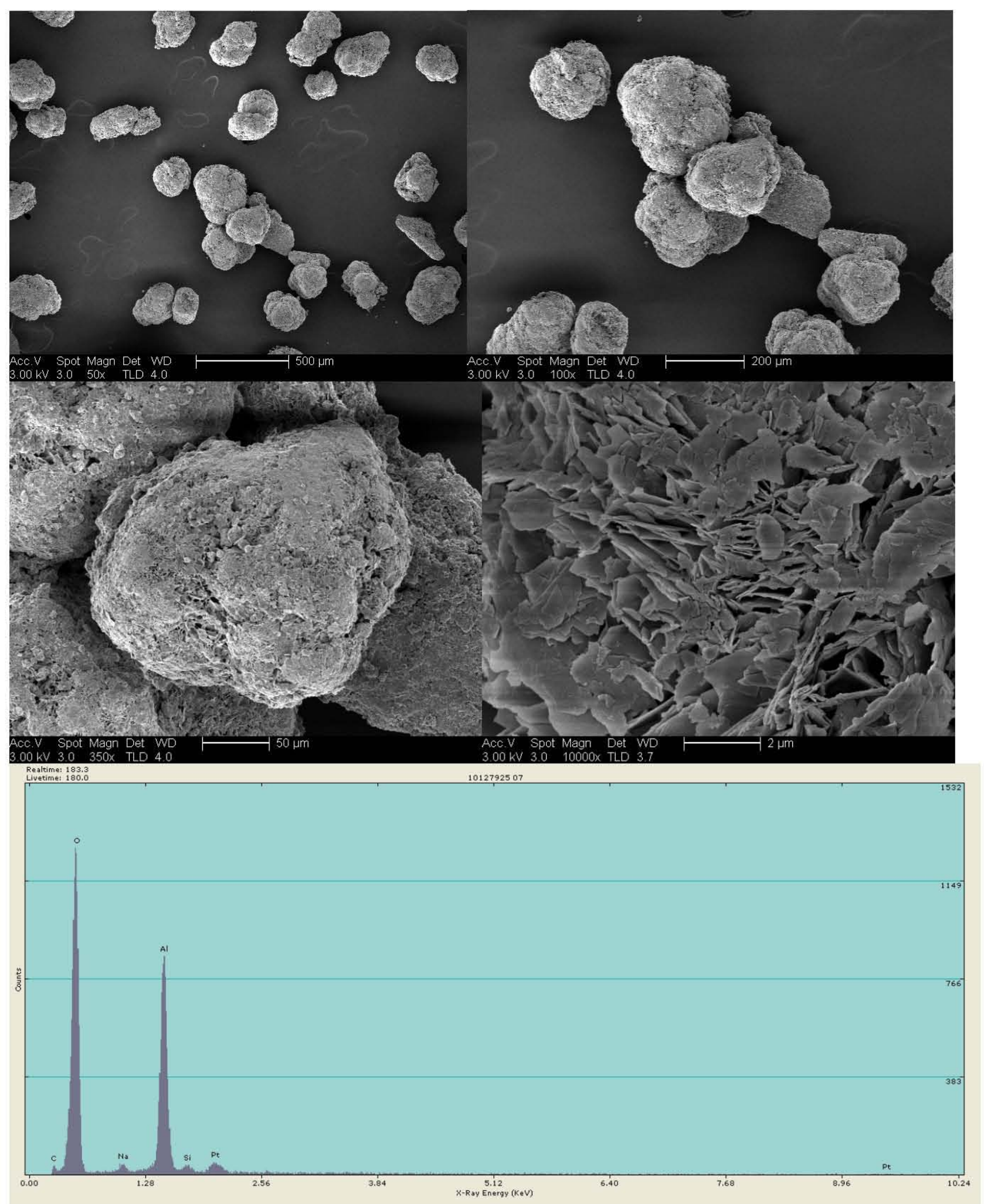

Figure A-7. SEM Images and EDS Analysis of Sample "DST Test \#1 $4^{\text {th }}$ Wash." 


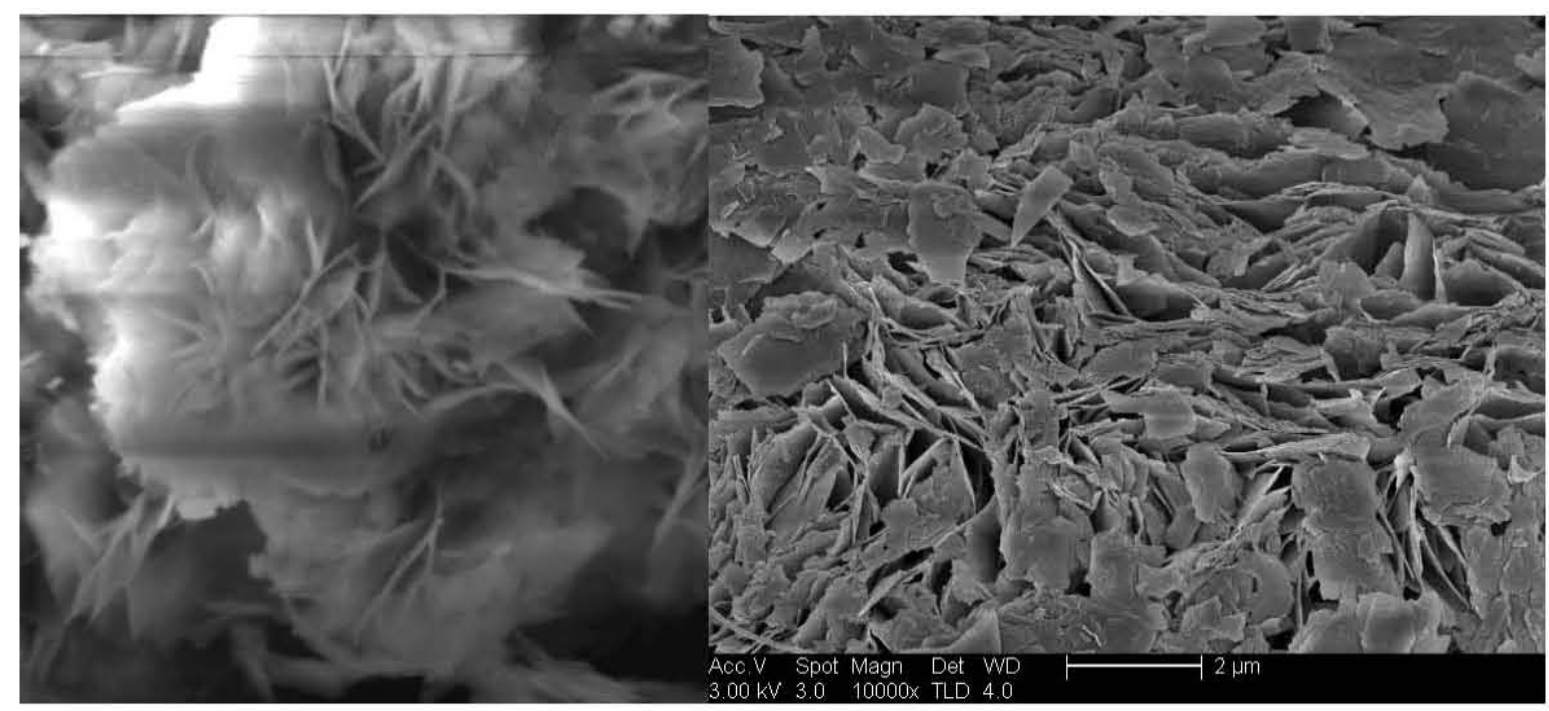

Figure A-8. SEM Images of LiHT Precipitate Before Solids Washing (Left) and After (Right).

\section{A.6 DST TEST \#1 CESIUM DECONTAMINATION}

DF is calculated by the following equation:

$$
\text { Cesium DF }=\frac{\text { Mass Cs in } / \text { Mass } \mathrm{Al} \text { in }}{\text { Mass Cs out } / \text { Mass } \mathrm{Al} \text { out }}
$$

Cesium DFs were calculated for incremental (between washes) and cumulative cases and are presented in Table A-2.

Table A-2. DST \#1 Incremental and Cumulative Filter Cake Cesium DF.

\begin{tabular}{|c|c|c|c|c|}
\hline & Aluminum & Cesium & $\begin{array}{c}\text { Incremental } \\
\text { DF }\end{array}$ & Cumulative DF \\
\hline Simulant (mg) & 23800 & 2.04 & & \\
\hline $\begin{array}{c}\text { Initial Cake } \\
(\mathrm{mg} / \mathrm{kg})\end{array}$ & 59760 & 1.08 & 4.7 & 5 \\
\hline $\begin{array}{c}1^{\text {st }} \text { wash Cake } \\
(\mathrm{mg} / \mathrm{kg})\end{array}$ & 66530 & 0.154 & 7.8 & 37 \\
\hline $\begin{array}{c}2^{\text {nd }} \text { wash Cake } \\
(\mathrm{mg} / \mathrm{kg})\end{array}$ & 38520 & 0.033 & 2.7 & 100 \\
\hline $\begin{array}{c}3^{\text {rd }} \text { wash Cake } \\
(\mathrm{mg} / \mathrm{kg})\end{array}$ & 77000 & 0.024 & 2.7 & 275 \\
\hline $\begin{array}{c}4^{\text {th }} \mathrm{wash} \mathrm{Cake} \\
(\mathrm{mg} / \mathrm{kg})\end{array}$ & 65440 & 0.021 & 1.0 & 267 \\
\hline
\end{tabular}


These results indicate that cesium is readily removed from the LiHT solids. Optimization is needed to determine the methodology best suited to solids washing. Of particular note are the incremental results that indicate a gradual decrease in washing efficiency, which may be due to the breakup and re-agglomeration of crystallites into larger particles that could shield salt ions from the washing process.

\section{A.7 DST TEST \#1 PARTICLE SIZE DISTRIBUTION}

Volume-based and number-based PSD curves and histograms are presented in Figures A-9 and A-10. A bimodal distribution is evident, indicating that there is a fraction of particles that are centered in the $10 \mu \mathrm{m}$ range and a separate population of particles centered around $250 \mu \mathrm{m}$. PSD test results from prior testing of unwashed $\mathrm{LiHT}$ solids indicates that a normal distribution curve centered around $50 \mu \mathrm{m}$ should be expected, which may confirm the effect of the washing steps on particle size.

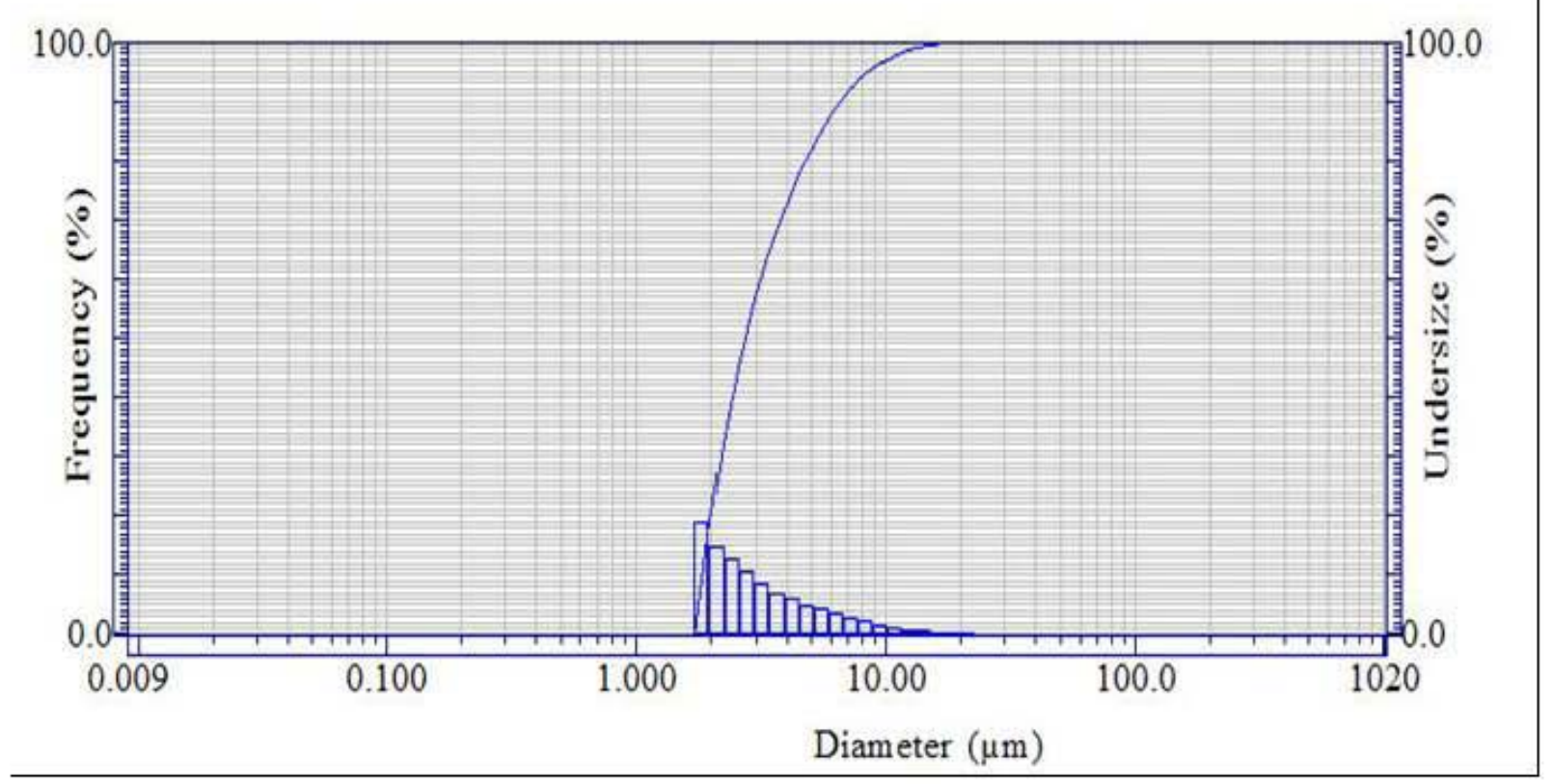

Figure A-9. Sample "DST Test $\# 14^{\text {th }}$ Wash" Represented as a Number-Based Distribution. 


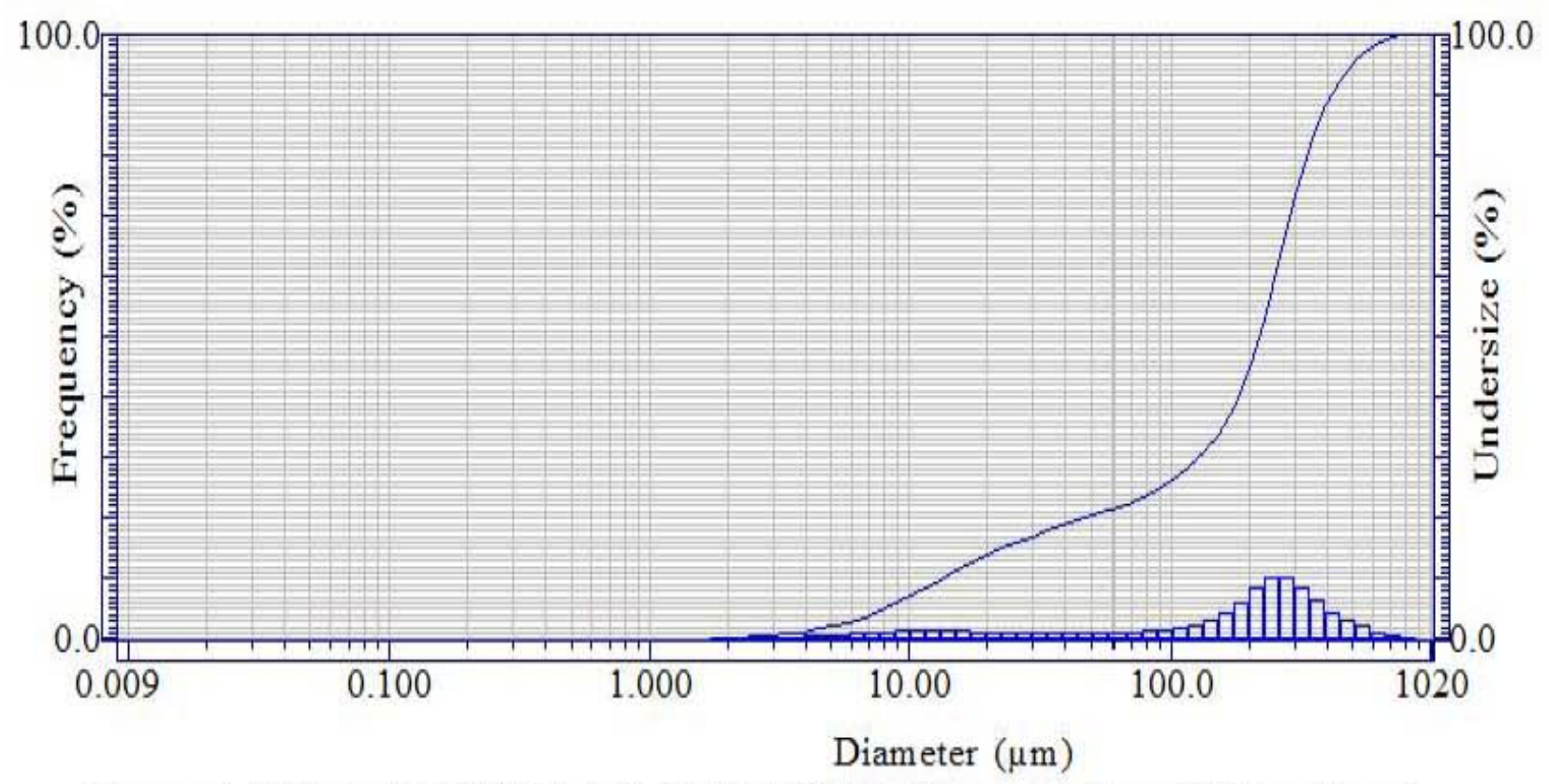

Figure A-10. Sample "DST Test \#1 $4^{\text {th }}$ Wash" PSD Represented as a Volume-Based Distribution.

\section{A.8 DST TEST \#1 THERMO GRAVIMETRIC ANALYSIS}

The TGA analysis (Figure A-11) indicates approximately $38 \% \mathrm{LiHT}$ solids (62\% free water). This compares with oven dried samples $\left(60^{\circ} \mathrm{C}\right)$ that indicate $45.3 \%$ solids. The discrepancy may be that decarboxylation or dehydration of the $\mathrm{LiHT}$ waters of hydration may take place at the TGA analysis conditions.

The analy sis further indicates that $14.7 \%$ solids remains after calcining at $1000{ }^{\circ} \mathrm{C}$. Degradation of the LiHT structure is likety at this temperature and the resulting mineral forms are assumed to be $\mathrm{Li}_{2} \mathrm{O}$ and $\mathrm{Al}_{2} \mathrm{O}_{3}$. In future work, this should be confirmed with $\mathrm{XRD}$ analysis. 
Sample: TGA1133 10127925 D S T 4th Wash

Size: $13.5350 \mathrm{mg}$

DSC-TGA

File: ...ITGA1133 10127925 D S T 4th Wash.001

Method: Ramp

DSC-TGA Operator: $1 \mathrm{jk}$

Run Date: 2010-11-12 03:21

Comment: TGA1133 10127925 D S T 4th Wash .001

Instrument: SDT Q600 V8.0 Build 95

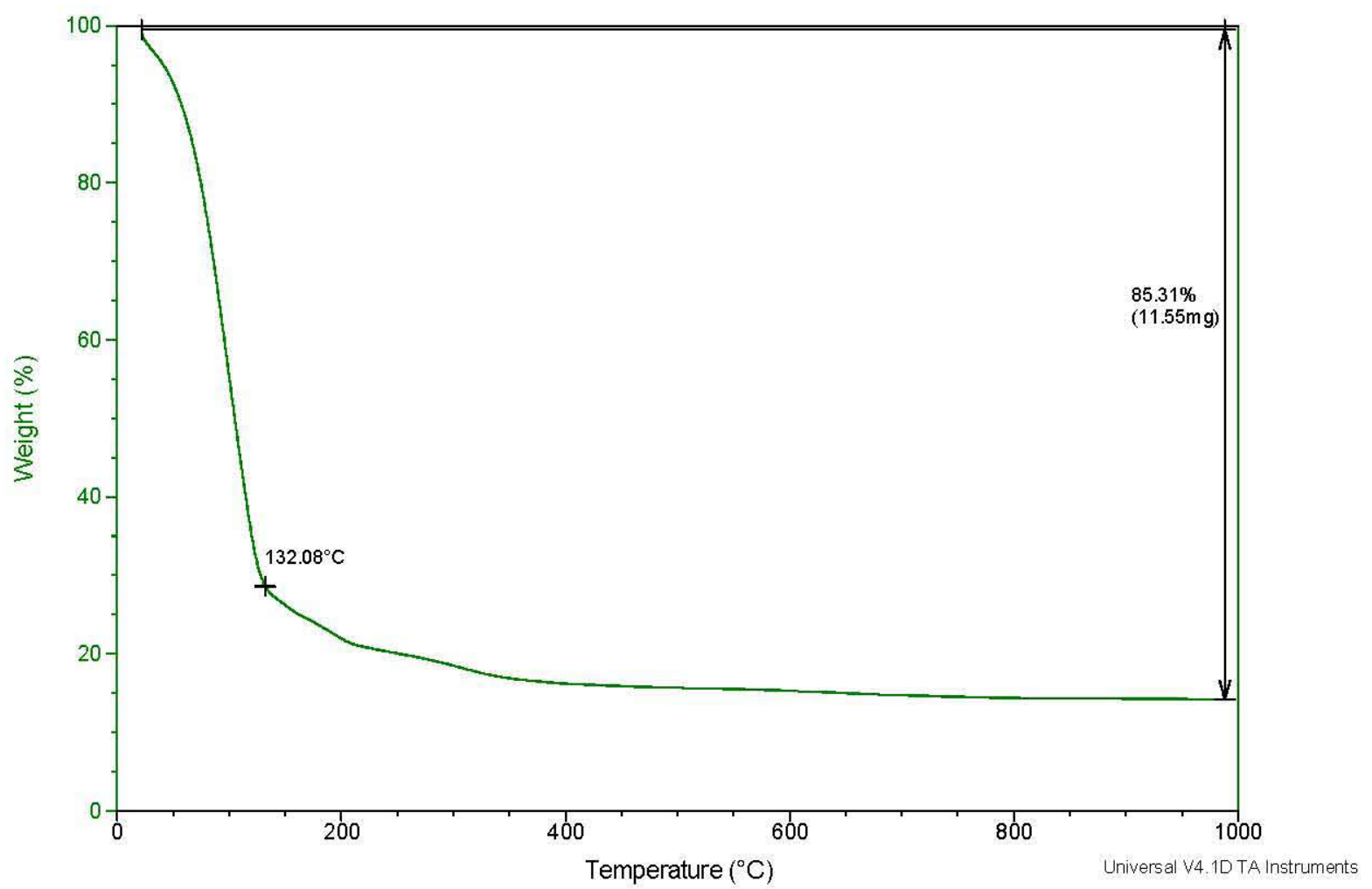

Figure A-11. Sample "DST Test \#1 $4^{\text {th }}$ Wash" TGA Analysis. 


\begin{tabular}{|c|c|c|c|c|c|c|c|c|c|c|c|c|c|c|c|c|c|c|c|c|}
\hline Analyte & Al & $\mathrm{Li}$ & $\mathrm{Na}$ & $F$ & K & $\mathrm{Cs}$ & $\mathrm{Cr}$ & $\mathrm{P}$ & PO4 & PO4 & $S$ & 504 & $\mathrm{Cl}$ & TIC & $\begin{array}{l}\text { Alkalinity } \\
\mathrm{mg} / \mathrm{l} \text { as } \\
\mathrm{CaCO} 3\end{array}$ & Nitrate & Nitrite & $\mathrm{pH}$ & $\begin{array}{c}\text { Conductivity } \\
\text { (uS/cm) }\end{array}$ & \multirow{12}{*}{ 20 } \\
\hline Method & $\begin{array}{l}\text { ICP- } \\
\text { AES }\end{array}$ & $\begin{array}{l}\text { ICP- } \\
\text { AES }\end{array}$ & $\begin{array}{l}\text { ICP- } \\
\text { AES }\end{array}$ & $\begin{array}{l}\text { ICP- } \\
\text { AES }\end{array}$ & $\begin{array}{l}\text { ICP- } \\
\text { AES }\end{array}$ & ICP-MS & $\begin{array}{l}\mathrm{ICP}- \\
\mathrm{MS}\end{array}$ & $\begin{array}{l}\text { ICP- } \\
\text { AES }\end{array}$ & Hach & IC & $\begin{array}{l}\text { ICP- } \\
\text { AES }\end{array}$ & IC & IC & & Titration & IC & IC & & & \\
\hline $\begin{array}{c}\text { Initial Cake } \\
(\mathrm{mg} / \mathrm{kg})\end{array}$ & 71400 & 776.38 & 71420 & 160 & 1330 & 1.08 & 154.1 & 5683 & $<24$ & $<0.242$ & 164 & 440 & 3100 & 1760 & NA & 9500 & 10000 & NA & NA & \\
\hline $\begin{array}{c}1^{\text {st }} \text { wash Cake } \\
(\mathrm{mg} / \mathrm{kg})\end{array}$ & 66530 & 14672 & 11950 & 44 & 822 & 0.154 & 39.71 & 1437 & 170 & $<0.242$ & 75 & 160 & 470 & NA & NA & 1700 & 1800 & NA & NA & \\
\hline $\begin{array}{c}2^{\text {nd }} \text { wash Cake } \\
\text { (mg/kg) }\end{array}$ & 38520 & 2830.3 & 3023 & 16 & 212 & 0.033 & 9.845 & 1509 & 220 & $<0.242$ & 43 & 78 & 75 & NA & NA & 390 & 360 & NA & NA & \\
\hline $\begin{array}{c}3^{\text {rd }} \text { wash Cake } \\
(\mathrm{mg} / \mathrm{kg})\end{array}$ & 77000 & 7521.1 & 2259 & 16 & 162 & 0.024 & 16.13 & 1691 & 230 & $<0.242$ & 48 & 61 & 46 & NA & NA & 290 & 260 & NA & NA & \\
\hline $\begin{array}{c}4^{\text {th }} \text { wash Cake } \\
(\mathrm{mg} / \mathrm{kg})\end{array}$ & 65440 & 8810.3 & 1917 & 13 & 140 & 0.021 & 14.19 & 1456 & 240 & $<0.242$ & 24 & 37000 & 40 & 1560 & NA & 240 & 210 & NA & NA & \\
\hline $\begin{array}{c}\text { Initial Filtrate } \\
\text { (mg/l) }\end{array}$ & 1271 & 8.19 & 73060 & 4000 & 5108 & 1.012 & 55.92 & 12.53 & $<25$ & & $\mathrm{BQL}$ & 33000 & 64000 & 1190 & 134898 & 130000 & 140000 & 13.82 & 200 & \\
\hline $\begin{array}{c}1^{\text {st }} \text { wash Filtrate } \\
(\mathrm{mg} / \mathrm{l})\end{array}$ & 126 & 37.5 & 6729 & $<0.10$ & 507 & 0.1001 & 7.978 & $B Q L$ & 0.9142 & & 12.99 & 34000 & 13000 & NA & 92003 & 14000 & 15000 & 13.58 & 51 & \\
\hline $\begin{array}{c}2^{\text {nd }} \text { wash Filtrate } \\
(\mathrm{mg} / \mathrm{l})\end{array}$ & 33 & 18.84 & 821 & $<0.10$ & 56 & 0.0118 & 2.219 & $B Q L$ & 0.2856 & & 4.065 & 32000 & 8100 & NA & 1200 & 6600 & 5400 & 12.76 & 7.3 & \\
\hline $\begin{array}{c}3^{\text {rd }} \text { wash Filtrate } \\
\text { (mg/l) }\end{array}$ & 8.58 & 8.99 & 89.1 & $<0.10$ & 6.06 & 0.0007 & 0.386 & $\mathrm{BQL}$ & 0.1261 & & $\mathrm{BQL}$ & 32000 & 7400 & NA & 160 & 5000 & $<0.125$ & 11.87 & 780 & \\
\hline $\begin{array}{c}4^{\text {th }} \text { wash Filtrate } \\
(\mathrm{mg} / \mathrm{l})\end{array}$ & 4.49 & 5.2 & 23.09 & $<0.10$ & 1.35 & 0.001 & 0.108 & $B Q L$ & 0.2612 & & $\mathrm{BQL}$ & 36000 & 9000 & $<2$ & 65 & 5600 & $<0.125$ & 10.62 & 170 & \\
\hline
\end{tabular}




\begin{tabular}{|c|c|c|c|c|c|c|c|c|c|c|c|c|c|c|c|c|c|c|c|}
\hline Analyte & Al & $\mathrm{Li}$ & $\mathrm{Na}$ & F & K & Cs & $\mathrm{Cr}$ & P & $\mathrm{PO} 4$ & $\mathrm{PO4}$ & S & $\mathrm{SO4}$ & $\mathrm{Cl}$ & TIC & Alkalinity & | Nitrate & Nitrite & $\mathrm{pH}$ & Conductivity \\
\hline Method & ICP-AES & $\begin{array}{l}\text { ICP- } \\
\text { AES }\end{array}$ & $\begin{array}{l}\text { ICP- } \\
\text { AES }\end{array}$ & $\begin{array}{l}\text { ICP- } \\
\text { AES }\end{array}$ & $\begin{array}{l}\text { ICP- } \\
\text { AES }\end{array}$ & $\begin{array}{l}\text { ICP- } \\
\text { MS }\end{array}$ & $\begin{array}{l}\mathrm{ICP}- \\
\mathrm{MS}\end{array}$ & $\begin{array}{l}\text { ICP- } \\
\text { AES }\end{array}$ & Hach & IC & $\begin{array}{l}\text { ICP- } \\
\text { AES }\end{array}$ & IC & IC & & Titration & IC & IC & & \\
\hline $\begin{array}{c}\text { Initial Cake } \\
(\mathrm{mg} / \mathrm{kg})\end{array}$ & 197200 & 28340 & 114700 & 4.511 & 7669 & 1.64 & 180.5 & 2339 & 1.849 & 180 & 320 & 730 & 2500 & 3910 & NA & 16000 & 17000 & NA & NA \\
\hline $\begin{array}{c}1^{\text {st }} \text { wash Cake } \\
(\mathrm{mg} / \mathrm{kg})\end{array}$ & 200400 & 28197 & 7553 & 16 & 495 & 0.079 & 124.4 & 3036 & 4.434 & 440 & 154 & 310 & 150 & NA & NA & 710 & 610 & NA & NA \\
\hline $\begin{array}{c}2^{\text {nd }} \text { wash Cake } \\
(\mathrm{mg} / \mathrm{kg})\end{array}$ & 126700 & 10528 & 946 & 25 & 40 & 0.003 & 53 & 1659 & 2.425 & 240 & 134 & 190 & 40 & NA & NA & 55 & 46 & NA & $\mathrm{NA}$ \\
\hline $\begin{array}{c}3^{\text {rd }} \text { wash Cake } \\
(\mathrm{mg} / \mathrm{kg})\end{array}$ & 273300 & 28392 & 734 & 15 & 20 & 0.002 & 74.9 & 2732 & 1.817 & 180 & 226 & 170 & 29 & NA & NA & 13 & $<13$ & NA & NA \\
\hline $\begin{array}{c}4^{\text {th }} \text { wash Cake } \\
(\mathrm{mg} / \mathrm{kg})\end{array}$ & 268800 & 23259 & 757 & 24 & 19 & 0.001 & 66.6 & 3099 & 2.882 & 290 & 204 & 130 & 25 & 5030 & NA & $<13$ & $<13$ & NA & NA \\
\hline $\begin{array}{c}\text { Initial Filtrate } \\
(\mathrm{mg} / \mathrm{l})\end{array}$ & 1499 & 315.48 & 83130 & 4300 & 5869 & 1.2470 & 71.77 & 4.677 & 110 & $<0.24$ & 154.5 & 39000 & 44000 & 1010 & 142674 & 150000 & 160000 & 12.84 & 270 \\
\hline $\begin{array}{c}1^{\text {st }} \text { wash Filtrate } \\
(\mathrm{mg} / \mathrm{l})\end{array}$ & 329 & 84.31 & 6932 & $<0.1$ & 480 & 0.1060 & 7.16 & $\mathrm{BQL}$ & $<0.10$ & $<0.24$ & $\mathrm{BQL}$ & 33000 & 9800 & NA & 10000 & 15000 & 15000 & 13.16 & 52 \\
\hline $\begin{array}{c}2^{\text {nd }} \text { wash Filtrate } \\
(\mathrm{mg} / \mathrm{l})\end{array}$ & 79.78 & 23.51 & 369 & $<0.1$ & 25.68 & 0.0057 & 0.412 & $\mathrm{BQL}$ & $<0.10$ & $<0.24$ & $\mathrm{BQL}$ & 33000 & 7500 & $N A$ & 700 & 5400 & 4600 & 12.07 & 3.4 \\
\hline $\begin{array}{c}3^{\text {rd }} \text { wash Filtrate } \\
\text { (mg/l) }\end{array}$ & 34.85 & 16.22 & 23.84 & $<0.1$ & 0 & 0.0002 & 0.283 & $\mathrm{BQL}$ & $<0.10$ & $<0.24$ & $\mathrm{BQL}$ & 34000 & 17000 & NA & 190 & 5600 & $<0.125$ & 11.64 & 540 \\
\hline $\begin{array}{c}4^{\text {th }} \text { wash Filtrate } \\
\text { (mg/l) }\end{array}$ & 29.41 & 13.48 & 4.33 & $<0.1$ & 0 & 0.0000 & 0.649 & $\mathrm{BQL}$ & $<0.10$ & $<0.24$ & 0.7 & 39000 & 7300 & $<2$ & 140 & 5600 & $<0.125$ & 11.69 & 340 \\
\hline
\end{tabular}




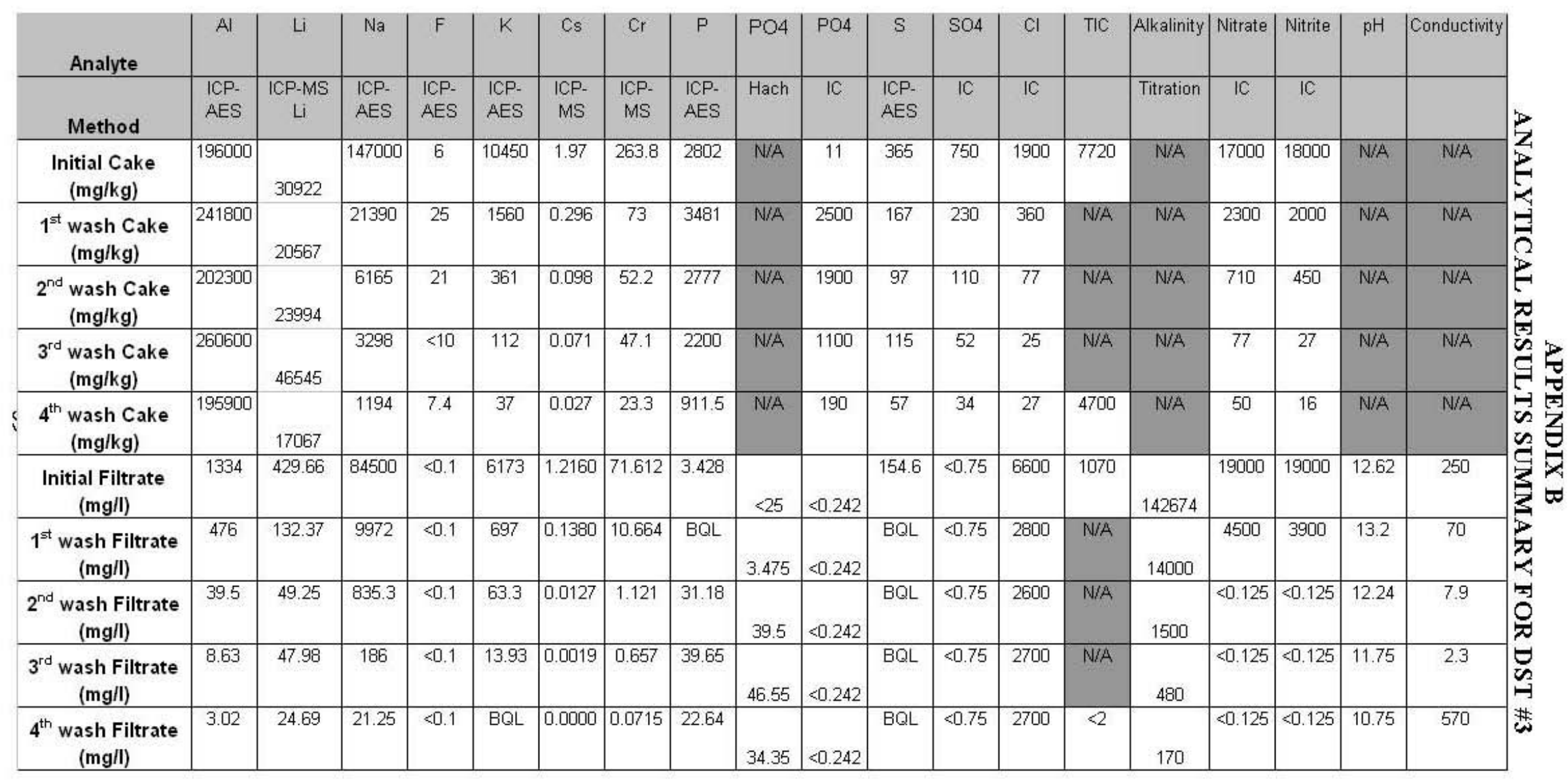




\begin{tabular}{|c|c|c|c|c|c|c|c|c|c|c|c|c|c|c|c|c|c|c|c|}
\hline Analyte & Al & $\mathrm{Li}$ & $\mathrm{Na}$ & F & K & Cs & $\mathrm{Cr}$ & $P$ & PO4 & PO4 & $S$ & 504 & $\mathrm{Cl}$ & TIC & Alkalinity & Nitrate & Nitrite & $\mathrm{pH}$ & Conductivity \\
\hline Method & $\begin{array}{l}\text { ICP- } \\
\text { AES }\end{array}$ & $\begin{array}{l}\text { ICP- } \\
\text { AES }\end{array}$ & $\begin{array}{l}\text { ICP- } \\
\text { AES }\end{array}$ & $\begin{array}{l}\text { ICP- } \\
\text { AES }\end{array}$ & $\begin{array}{l}\text { ICP- } \\
\text { AES }\end{array}$ & ICP-MS & ICP-MS & $\begin{array}{l}\text { ICP- } \\
\text { AES }\end{array}$ & Hach & IC & $\begin{array}{l}\text { ICP- } \\
\text { AES }\end{array}$ & IC & IC & & Titration & IC & IC & & \\
\hline $\begin{array}{c}\text { Initial Cake } \\
(\mathrm{mg} / \mathrm{kg})\end{array}$ & 161400 & 31488 & 123300 & 200 & 971 & 1.76 & 4046 & $25[30$ & 131.6 & 130 & 3552 & $<75$ & 730 & 3910 & N/A & 30000 & 6400 & N/A & N/A \\
\hline $\begin{array}{c}1^{\text {st }} \text { wash Cake } \\
(\mathrm{mg} / \mathrm{kg})\end{array}$ & 221000 & 22716 & 12380 & 330 & 65 & 0.107 & 472 & $39 \Xi 30$ & 118.3 & 12000 & 449 & 710 & 22 & N/A & N/A & 1500 & 190 & N/A & N/A \\
\hline $\begin{array}{c}2^{\text {nd }} \text { wash Cake } \\
(\mathrm{mg} / \mathrm{kg})\end{array}$ & 205700 & 46368 & 6192 & 300 & 33 & 0.04 & 1457 & 42720 & 108.1 & 11000 & 298 & 450 & 11 & N/A & N/A & 960 & 88 & N/A & N/A \\
\hline $\begin{array}{c}3^{\text {rd }} \text { wash Cake } \\
\text { (mg/kg) }\end{array}$ & 206500 & 40865 & 5483 & 280 & 25 & 0.02 & 84.4 & 49830 & 106 & 11000 & 256 & 280 & 1800 & N/A & N/A & 360 & 33 & N/A & N/A \\
\hline $\begin{array}{c}4^{\text {th }} \text { wash Cake } \\
(\mathrm{mg} / \mathrm{kg})\end{array}$ & 217600 & 42273 & 4992 & 280 & 23 & 0.017 & 8222 & $35 E 00$ & 105.4 & 11000 & 219 & 270 & 2100 & 5030 & N/A & 320 & 24 & N/A & N/A \\
\hline $\begin{array}{c}\text { Initial Filtrate } \\
\text { (mgll) }\end{array}$ & 895 & 170.32 & 76210 & 3700 & 484.9 & 1.03500 & 9.77 & 2.277 & $<25$ & $<0.242$ & 1281 & 91000 & 19000 & 2270 & 82474 & 27000 & 60000 & 12.71 & 200 \\
\hline $\begin{array}{c}1^{\text {st }} \text { wash Filtrate } \\
(\mathrm{mgll})\end{array}$ & 330 & 278.15 & 6119 & $<0.10$ & 61.5 & 0.10220 & \# & 97.9 & 79.25 & $<0.242$ & 93.56 & 37000 & 8700 & N/A & 7800 & 28000 & 8900 & 12.92 & 39 \\
\hline $\begin{array}{c}2^{\text {nd }} \text { wash Filtrate } \\
\text { (mgll) }\end{array}$ & 7.52 & 67.26 & 278 & $<0.10$ & 1.86 & 0.00383 & 6.426 & 124 & 110 & $<0.242$ & 7.73 & 33000 & 7600 & N/A & 800 & 5500 & 4500 & 11.82 & 3 \\
\hline $\begin{array}{c}3^{\text {rd }} \text { wash Filtrate } \\
(\mathrm{mgll})\end{array}$ & 2.16 & 103.15 & 48.64 & $<0.10$ & 0.47 & 0.00046 & 0.907 & 89.79 & 110 & $<0.242$ & 0.91 & 34000 & 6600 & N/A & 560 & 6600 & $<0.125$ & 11.37 & 1800 \\
\hline $\begin{array}{c}4^{\text {th }} \text { wash Filtrate } \\
(\mathrm{mgll})\end{array}$ & 1.79 & 74.74 & 20.82 & $<0.10$ & 0 & 0.00014 & 0.507 & 13.1 & 120 & $<0.242$ & 0.75 & 33000 & 8500 & 8 & 540 & $<0.125$ & $<0.125$ & 11.35 & 1700 \\
\hline
\end{tabular}

